University of San Diego

Digital USD

Fall 9-15-2015

\title{
Evaluation of reproductive strategies in captive California yellowtail (Seriola dorsalis) using genetic parentage analyses
}

\author{
Elizabeth K. Smith \\ University of San Diego \\ Mark Drawbridge MS \\ Hubbs-SeaWorld Research Institute \\ John Hyde PhD \\ Southwest Fisheries Science Center \\ Geoffrey Morse PhD \\ University of San Diego
}

Follow this and additional works at: https://digital.sandiego.edu/theses

Part of the Aquaculture and Fisheries Commons, and the Molecular Biology Commons

\section{Digital USD Citation}

Smith, Elizabeth K.; Drawbridge, Mark MS; Hyde, John PhD; and Morse, Geoffrey PhD, "Evaluation of reproductive strategies in captive California yellowtail (Seriola dorsalis) using genetic parentage analyses" (2015). Theses. 6.

https://digital.sandiego.edu/theses/6

This Thesis: Open Access is brought to you for free and open access by the Theses and Dissertations at Digital USD. It has been accepted for inclusion in Theses by an authorized administrator of Digital USD. For more information, please contact digital@sandiego.edu. 


\title{
UNIVERSITY OF SAN DIEGO
}

\section{San Diego}

Evaluation of reproductive strategies in captive California yellowtail

(Seriola dorsalis) using genetic parentage analyses.

The thesis submitted in partial satisfaction of the requirements for the degree of

Master of Science in Marine Science

by

Elizabeth Smith

\author{
Thesis Committee \\ Mark Drawbridge, M.S., Chair \\ John Hyde, Ph.D. \\ Geoffrey Morse, Ph.D.
}


The thesis of Elizabeth Smith is approved by:

Mark Drawbridge, M.S., Chair

John Hyde, Ph.D.

Geoffrey Morse, Ph.D.

University of San Diego

San Diego

2015 
Copyright 2015 Elizabeth Smith 


\section{DEDICATION}

To my parents, who taught me the value of education, and did everything in their power to ensure I had a great one. Mummy and Diddy, this is for you! 


\section{ACKNOWLEDGMENTS}

First and foremost, two people need to be thanked that in all senses of the phrase, really took me under their wings. These two people are Dr. Catherine Purcell and Dr. Kristen Gruenthal. Not only did they teach me the day-to-day of writing and completing research, they patiently listened to my problems, and would calm me down when I felt like I was floundering. Kristen and Catherine both led by example by being strong female scientists and true role models. Over the years working on this project together, my respect and personal opinion has grown for them, as they both did not have to help me as much as they did. I hope that one day I can be half the scientist that they are. I wouldn't have completed this thesis without you two, from the bottom of my heart, thank you.

A HUGE thank you needs to be extended to the Aquaculture Team at Hubbs-SeaWorld Research Institute, who took the samples needed for this study. On top of their daily work load of caring for all the fish in the institute, they set aside genetic samples for me to process while I took classes. Thank you all for showing me what it takes to run an aquaculture facility at the level of efficiency of Hubbs. Kevin Stuart, you handled all questions I had regarding methods thanks for putting up with my constant inquiries. Laboratory work couldn't have been possible without the Southwest Fisheries Research Center various genetic technicians, who provided endless help with machines and supply locations. Thanks for letting me use the reagents and lab space, and a huge shout-out to all the fabulous lab technicians at the SWFSC. Victoria Pease especially never hesitated to show me how to use the machines and made sure I didn't break 
anything. Morgane Lauf not only mentored me through lab work, but also became a great friend -thank you for introducing me to the wonderful local theater scene at the Historic Old Globe!

Analysis of the microsatellites, statistics, and help with R, Excel, and Cervus is owed to Elizabeth Johnston, Dr. Dovi Kacev, Dr. Jennifer Prairie, Dr. Ron Kaufmann, Dr. Eric Archer, and Dr. Jay Barlow. Thank you for the countless hours of helping with code, statistics, and all things genetics related. Dr. Barlow, thank you for letting me sit in on your Computational Statistics course at SIO. I'm infinitely better at $\mathrm{R}$ and understanding statistics because of you.

Funding for this project was made possible by California SeaGrant (Grant ID: NA10OAR4170060 R/AQ-133). The stress reduced by having this funding secured was immeasurable, thank you SeaGrant for everything! Thanks to the Dean's Graduate Merit Scholarship and the Stephen Sullivan Memorial Scholarship for help with my classwork and education in San Diego. The MARS department at USD also directly contributed to a life-changing study abroad in Svalbard, Norway. I could never repay that experience. Consumables for this project were kindly provided by NOAA SWFSC Fisheries Genetics Group.

Mental well-being during this thesis is credited to all my friends, family, and USD grads. You guys rock! A special extension must be made to Nate Schmidt, Anthony Basilio, Em Cullen and Emily Gardner. Thank you for the runs, movies, game nights, puns, beers, constant support, and the privilege of being your friend. 


\section{TABLE OF CONTENTS}

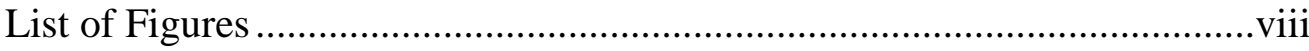

List of Tables .........................................................................................

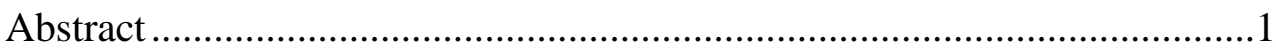

Introduction to Thesis ..............................................................................

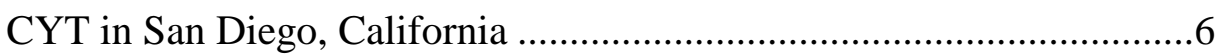

Questions and Hypotheses .....................................................................

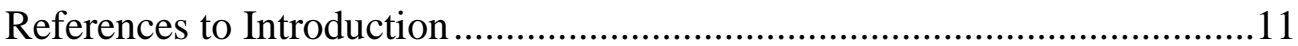

Chapter 1: Methods for genetic parentage assignment of

California yellowtail with an emphasis on sample size

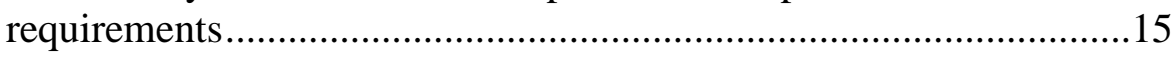

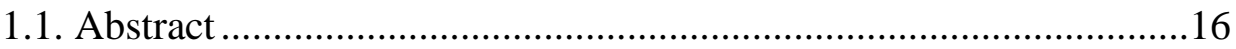

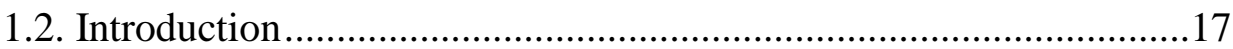

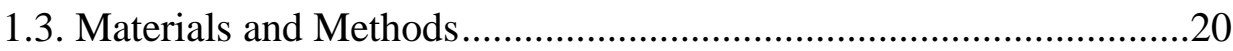

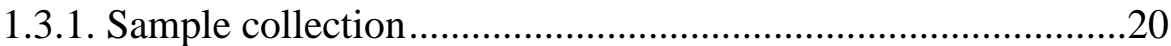

1.3.2. DNA extraction and PCR amplification ...................................21

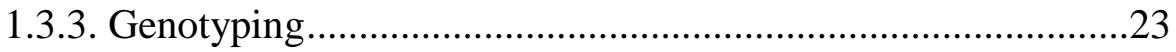

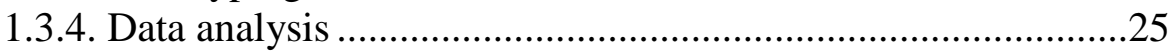

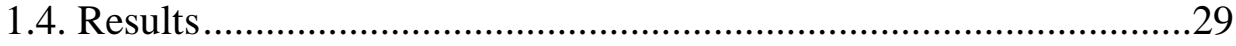

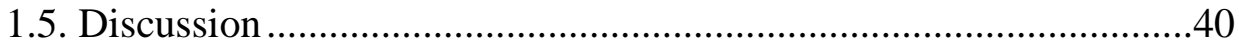

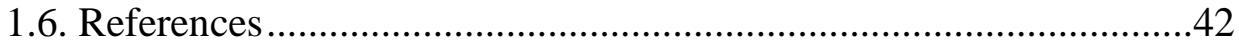

Chapter 2: Reproduction of wild-caught California yellowtail in an aquaculture setting with implications for broodstock

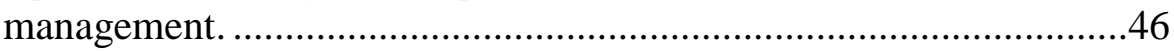

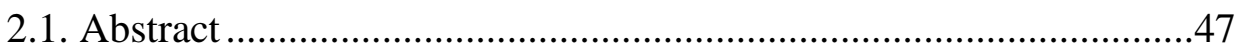

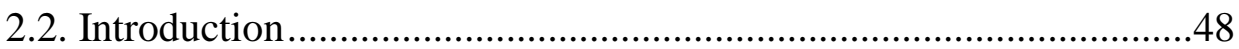

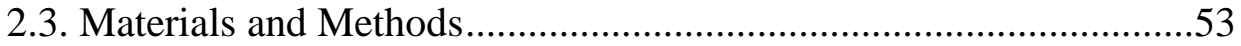

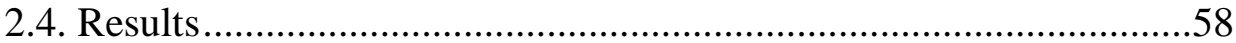

2.4.1. Contribution and possible spawning strategy ..........................58

2.4.2. Female mass and fecundity ....................................................62

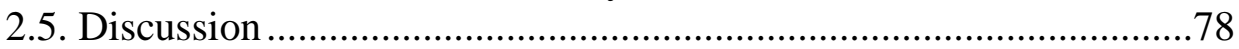

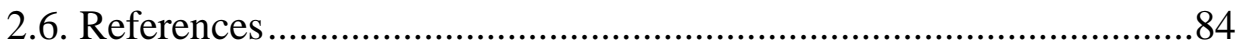

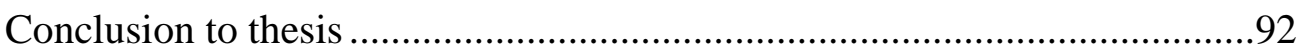

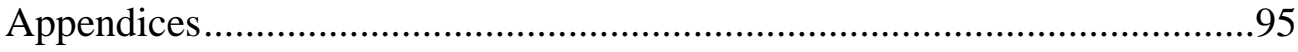




\section{LIST OF FIGURES}

\section{Chapter 1:}

Figure 1. Frequency of all CYT offspring contribution .............................32

Figure 2. Simulated average contribution from April 29...........................33

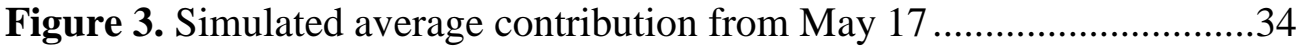

Figure 4. Simulated average contribution from June 21 ...........................35

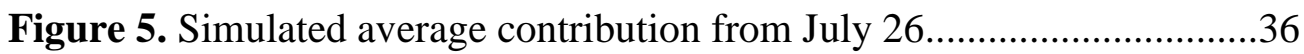

Figure 6. Simulated average contribution from August 26.........................37

\section{Chapter 2:}

Figure 1. Total CYT spawn size with environmental factors .....................64

Figure 2. Total parental assignment for each brood fish...........................65

Figure 3. Proportional contribution from female fish ...............................66

Figure 4. Female spawning interval histogram .....................................67

Figure 5. Female mass vs spawning egg totals ......................................68

Figure 6. 2013 spawning heat map .....................................................69

Figure 7. 2014 spawning heat map (females only) ..................................70

Figure 8. 2014 spawning heat map (males only) .................................... 71 


\section{LIST OF TABLES}

\section{Chapter 1:}

Table 1. CYT Microsatellite primer pairs .............................................28

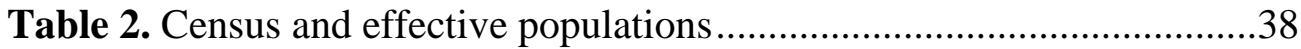

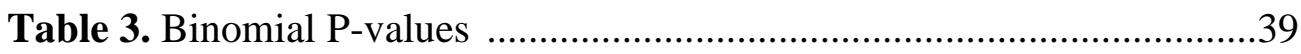

\section{Chapter 2:}

Table 1. CYT Microsatellite primer pairs .............................................57

Table 2. Microsatellite summary statistics ........................................... 72

Table 3. Census and effective populations from 2013 ..............................73

Table 4. Census and effective populations from 2014 ...............................75

Table 5. Spawning events summarized .................................................. 77 


\begin{abstract}
A good understanding of spawning dynamics of species in aquaculture is vital in order to maximize egg production and quality as well as efficient allocation of food and space resources. The breeding program of California yellowtail (CYT; Seriola dorsalis previously Seriola lalandi) at Hubbs-SeaWorld Research Institute (HSWRI) is set up such that up to 30 wild caught brood fish can broadcast spawn in a group setting, just as CYT reproduce in the wild. The population of brood fish were originally caught offshore from Southern California, and are maintained under ambient sea water and natural lighting conditions. The spawning season at HSWRI lasted from March to September during the 2013 and 2014 study period. Reproductive output from this population of cultured CYT was evaluated through microsatellite-based parentage analyses whereby the percent contribution of offspring was determined across all spawning events over two years.
\end{abstract}

Methods were first tested to determine the minimum sample size required to accurately describe the parental contributions in this specific group spawning environment. To do this, five spawns were selected from the 2013 season based on spawn volume, which was presumed to represent a high number of female parents thus representing the most complex spawning dynamic. For these five spawning events, there were 19 brood fish present, representing all possible parents. Actual assignment of samples sizes between 47 and over 300 was assessed for each spawn. Except in one instance, the parental contribution from sample size of 47 CYT offspring analyzed per spawn, was not statistically 
significantly different than a sample size of over 300 offspring per spawn (average P-value $=0.65$ ). Simulated subsampling via computational bootstrapping, and subsequent statistical analysis, indicated that a sample size of 30 offspring per spawn was adequate to accurately describe the parental contributions. Based on this information, a samples size of 47 was used so that samples from two spawns could be run on a single 96 well plate, including one negative control sample per spawn. This constitutes one of the first studies of sample size quality control for genetic parentage contribution for an aquaculture species.

Offspring were then analyzed from every spawning event $(\mathrm{N}=130)$ over two spawning seasons to characterize spawning events of CYT. Analyzing all spawns during multiple spawning seasons allowed for determination of individual contribution levels, spawn pairings, and analysis of female fecundity. The breeding population consisted of 19 brood fish in 2013, and 37 in 2014; both years were roughly 50: 50 male - female. Brood fish added to the population in 2014 were smaller in terms of mass and total lengths. Spawning events tended to have one female contribute (primary female), with relatively equal paternal contribution during both the spawning events and season, for a possible lottery polygyny spawning system (Nunney, 1993). One female in particular contributed $40 \%$ of all offspring during the two years, spawning nearly every 5-6 days during the spawning seasons. The larger females $(\sim 21 \mathrm{~kg})$ had an average batch fecundity of $\sim 490,000$ eggs per spawn, while smaller females $(\sim 8.4 \mathrm{~kg})$ only spawned 35,000 eggs per spawn. Annual and batch spawning totals were 
correlated to female mass $(\mathrm{P}<0.0005)$. All smaller brood fish spawned fewer times in the season than larger brood fish. This work constitutes the first-ever study of reproductive strategy (lottery polygyny) and parental contribution for a carangid species at the individual-level over several spawning events. 


\section{INTRODUCTION TO THESIS}

Applications for aquaculture vary from supplying marine organisms for the aquarium trade to wild stock replenishment. However, aquaculture is most commonly used to produce food for human consumption. Large scale commercial aquaculture has been an effective way to generate protein for human consumption since the 1960s, and has grown to account for $42 \%$ of global seafood harvested in 2012 (FAO, 2014). Since 2008, the aquaculture industry has provided over 50 million tonnes of seafood each year, increasing by an average annual rate of 3.2\%. Of this total, marine finfishes accounted for 5.55 million tonnes in 2012 (FAO, 2014). However, as aquaculture facilities begin to perfect rearing methodologies, new candidate species are being targeted to diversify this growing industry. Candidate species for food aquaculture are usually defined as having fast growth, high quality flesh, high market value, and potential for complete life cycles in culture (Le François et al., 2002).

Much research has been dedicated to achieving optimal growth and production for these species in an aquaculture setting, especially for marine fish. This has led to some aquaculture species being rendered sterile and/or otherwise modified to increase biomass production in culture (Hulata, 2001). Some aquaculture facilities focus on long-term sustainability by utilizing offspring from a pool of brood fish, in contrast to capture-based aquaculture (Ottolenghi, 2008). For all purposes of aquaculture listed above, it is crucial that a scientific understanding of reproduction and life-history is known for each candidate 
species, as this will lead to the most effective management for these species in aquaculture.

A promising species for commercial culture in California is Seriola dorsalis (previously S. lalandi; FAO, USA 2011). This carangid (order: Perciformes) is also known as California yellowtail, yellowtail amberjack, yellowtail kingfish, and hiramasa. Recent publications using genetic data and analysis recommend the old scientific name Seriola dorsalis be resurrected for local Seriola lalandi found from southern Washington to Mexico (Baxter, 1960; Martinez-Takeshita et al., 2015; Purcell et al., 2015). We recognize these recent publications, but as the global species name was previously Seriola lalandi, many of our references and publications about life history refer to Seriola lalandi, and not specifically to the species found in the Northeast Pacific. For this work, we use the local species name Seriola dorsalis, as well as the local common name California yellowtail (CYT). Seriola spp. are high performance pelagic finfishes, defined here as having fast growth and high fecundity, and are found in tropical to sub-tropical globally. Fisheries data from the South Pacific show that in the wild, S. lalandi have roughly linear growth, from about $45 \mathrm{~cm}$ fork length at one year of age and plateauing at $120 \mathrm{~cm}$ fork length at approximately 15 years of age (Stewart et al., 2004). Tag and recapture data of CYT indicate extensive movement in the ocean, from $80 \mathrm{~km}$ to $650 \mathrm{~km}$ (Baxter, 1960) and more than $2000 \mathrm{~km}$ straight line distance from Seriola lalandi from the South Pacific (Gillanders et al., 2001). 
In Southern California, CYT is a major target of the recreational fishing industry, and worldwide species in this genus are becoming increasingly important for aquaculture (Nakada, 2008; Abbink et al., 2011). Due to its popularity, nutritional benefits, and high market value, the production of cultured Seriola has grown recently around the Pacific, including in Japan, Australia and New Zealand, to an industry with a market value worth over one billion USD per year (Poortenaar et al., 2003; Nakada, 2008). Other Seriola spp. are already well represented in aquaculture, with the majority of the culture coming out of Japan and South Korea. At about 160,000 tonnes annually, Seriola quinqueradiata made up 57\% of Japanese farmed finfish in 2003 (Cultured Aquatic Species Information Programme, 2005) and another closely related species, Seriola rivoliana has been in commercial production in Hawaii since 2011. Thus far in the United States, only one experimental CYT facility exists, however, high market value coupled with high performance make CYT a prime species for food aquaculture development in the U.S. as well.

\section{CYT in San Diego, California}

A unique opportunity exists for scientific research at Hubbs-SeaWorld Research Institute (HSWRI) in San Diego, CA, where CYT are currently being studied for commercial aquaculture potential, including an experimental breeding program. The primary brood fish in this program were collected from the wild off the coast of Southern California, and are housed in San Diego, CA, well within their natural range. The wild-caught CYT are kept in a single large tank, allowing reproductively mature males and females to reproduce freely. This practice 
ensures a steady stream of eggs that can be collected during the spawning season and allows for generally "wild-like" or near-natural reproduction conditions. Unfortunately, unlike strip-spawning or hormonal injections, this method of wildlike spawning does not allow for easy parental assignment of offspring. Therefore, the parental contributions to distinct spawning events in this system are not previously known.

Understanding the spawning frequency of each brood fish would be useful for refining aquaculture production by culling non-contributors from the brood fish population or changing sex ratios to potentially improve reproductive output. Individual identification in a population can be done with the use of microsatellite genetic markers, which are inherited sections of genomic DNA that consist of multiple short tandem nucleotide repeats (e.g. CACACACA, GATGATGAT). These repeats can occur anywhere in the genome, but usually occur in non-coding regions for multi-cellular organisms. A region or point on a chromosome is called a locus (plural: loci): and in terms of microsatellites, the different regions where the repeats occur are also called loci (full definitions and explanations in Chistiakov et al., 2006). Loci for microsatellites typically are species- or genusspecific, but due to high mutation rates of these loci, individuals in the population will have unique variations in their nucleotide repeat pattern, called an allele. It is these alleles from multiple microsatellites that allow for individual genetic assessment and relatedness studies, such as parentage analysis.

These alleles are inherited, one each from the male and female parent, and can be used to determine paternity and maternity (Chistiakov et al., 2006; 
Mojekwu and Anumudu, 2013). Parentage analysis can then be accomplished by calculating the probability that the offspring share the same alleles at multiple loci with the potential parental pool (in this case, the brood fish), and excluding parents who do not have these same alleles as the offspring. Several microsatellite loci have been identified and published in Seriola spp. and are known to be polymorphic in local CYT. These loci have successfully been used to determine subspecies, to find genetic correlations between growth rates and condition factors, and help support the splitting of Seriola lalandi into several species based on genetic distance (Miller et al., 2011; Whatmore et al., 2013; MartinezTakeshita et al., 2015; Purcell et al., 2015).

In the case of HSWRI, the microsatellite genetic markers were used here to determine the percent contribution of each brood fish spawning in the experimental breeding program. In this collaborative project with the Southwest Fisheries Science Center (SWFSC), we aimed to present the first-ever record of individual spawning contribution of CYT over multiple spawning events and seasons. The information gathered from this research on spawning dynamics will allow for enhanced management of the brood fish directly at HSWRI, and also provide valuable information for Seriola reproductive dynamics not previously described. Furthermore, with the use of this breeding program and its relatively large output of progeny, it was possible to ground-truth the methods used in this thesis, specifically those related to sub sampling. 


\section{Questions and Hypotheses}

Due to its ability to reproduce in captivity and a high market value, CYT is a great candidate species for aquaculture. Management improvement and efficient culture of CYT will depend in part on the reproductive contribution of the individual brood fish. At HSWRI these brood fish are allowed to freely reproduce in large spawning events, similar to those seen in the wild. This method allows closure of the wild fish harvesting cycle, by producing the next generation in captivity. However, with this method the only practical way to determine parental contribution is with the use of genetic tools to identify individuals as parents of offspring. Using these tools, it is possible to have a higher level of understanding of wild Seriola spp. by examining reproductive strategies that are very difficult to observe directly in the wild. Quantifying contribution will also allow for extrapolated calculations for estimates of fecundity (batch and annual) for each female. This research will also directly affect the management of the fish in this breeding program. Specifically, the goal of my research is to address the following questions by testing the associated hypothesis:

1. How many samples need to be analyzed to accurately understand the patterns of brood fish contribution?

$\mathrm{H}_{0}$ : No clear patterns in sample size will emerge after analyzing all samples available.

2. What is the contribution of production of offspring of each brood fish in the tank on an annual basis? 
$\mathrm{H}_{0}$ : Each brood fish kept in the system will contribute equally to the production of offspring over the course of a season.

3. What is the contribution of production of offspring of each brood fish during each discrete spawning event?

$\mathrm{H}_{0}$ : Each brood fish kept in the system will contribute equally to the production of offspring during each discrete spawning event.

4. Does female fecundity (batch and/or annual egg production) correlate to: female mass; spawning intervals; environmental factors (water temperature, day length, lunar cycles)?

$\mathrm{H}_{0}$ : Egg production will not significantly correlate to female mass, spawning intervals or any environmental parameter tested. 


\section{References to introduction}

Abbink, W., A. Blanco Garcia, J.A.C. Roques, G.J. Partridge, K. Kloet, and O. Schneider, O. 2011. The effect of temperature and $\mathrm{pH}$ on the growth and physiological response of juvenile yellowtail kingfish Seriola lalandi in recirculating aquaculture systems. Aquaculture 330-333: 130-135.

Baxter, J. L. 1960. A study of the yellowtail Seriola dorsalis (Gill). State of California Department of Fish and Game, Marine Resources Operations. Fish Bulletin No. 110.

Chistiakov, D.A., B. Hellemans, and F.A.M. Volckaert. 2006. Microsatellites and their genomic distribution, evolution, function and applications: A review with special references to fish genetics. Aquaculture 255: 1-29.

Cultured Aquatic Species Information Programme. Seriola quinqueradiata. Cultured Aquatic Species Information Programme. Text by Dhirendra P.T.In: FAO Fisheries and Aquaculture Department [online]. Rome. Updated 13 January 2005. [Cited 24 February 2014]. http://www.fao.org/fishery/culturedspecies/Seriola_quinqueradiata/en

Fisheries and Agriculture Organization. Updated February 1, 2011. National Aquaculture Sector Overview (NASO). United States of America. National Aquaculture Sector Overview Fact Sheets. Text by Olin, P.G. Rome, Italy.

Fisheries and Agriculture Organization (FAO) of the United Nations. 2014. The State of the World Fisheries and Aquaculture 2014. FAO, Rome, Italy. 
Gillanders, B.M., D.J. Ferrell, and N.L. Andrews. 2001. Estimates of movement and life-history parameters of yellowtail kingfish (Seriola lalandi): how useful are data from a cooperative tagging progamme? Marine and Freshwater Research 52: 179-192.

Hulata, G. 2001. Genetic manipulations in aquaculture: a review of stock improvement by classical and modern technologies. Genetica 111: 155173.

Le François, N.R., H. Lemieux, and P.U. Blier. 2002. Biological and technical evaluation of the potential of marine and anadromous fish species for cold-water mariculture. Aquaculture Research 33: 95-108.

Martinez-Takeshita, N., C.M. Purcell, C.L. Chabot, M.T. Craig, C.N. Paterson, J.R. Hyde, and L.G. Allen. 2015. A tale of three tails: cryptic speciation in a globally distributed marine fish of the genus Seriola. Copeia 103(2): 357-368.

Miller, P.A., A.J. Fitch, M. Gardner, K.S. Hutson, and G. Mair. 2011. Genetic population structure of yellowtail kingfish (Seriola lalandi) in temperate Australasian waters inferred from microsatellite markers and mitochondrial DNA. Aquaculture 319: 328-336.

Mojekwu, T.O. and C.I. Anumudu. 2013. Microsatellite markers in aquaculture: applications in fish population genetics. Journal of Environmental Science, Toxicology and Food Technology 5(4): 43-48. 
Nakada, M. 2008. Capture-based aquaculture of yellowtail. In A. Lovatelli; P.F. Holthus (eds). Capture-based aquaculture. Global overview. FAO Fisheries Technical Paper. No. 508. Rome, FAO. pp. 199-215.

Nunney, L. 1993. The influence of mating system and overlapping generations on effective population size. Evolution 47(5): 1329-1341.

Ottolenghi, F. 2008. Capture-based aquaculture of bluefin tuna. In A. Lovatelli and P.F. Holthus (eds). Capture-based aquaculture. Global overview. FAO Fisheries Technical Paper. No. 508. Rome, FAO. Pp 169-182.

Poortenaar, C., A. Jeffs, P. Heath, and S. Hooker. 2003. Commercial opportunities for kingfish aquaculture in Northland. Enterprise Northland Trust, National Institute of Water and Atmospheric Research, Auckland. $1-45$.

Purcell, C.M., C.L. Chabot, M.T. Craig, N. Martinez-Takeshita, L.G. Allen, and J.R. Hyde. 2015. Developing a genetic baseline for the yellowtail amberjack species complex, Seriola lalandi senu lato, to assess and preserve variation in wild populations of these globally important aquaculture species. Conservation Genetics DOI 10.1007/s10592-0150755-8.

Stewart, J., D.J. Ferrel and B. van der Walt. 2004. Sizes and ages in commercial landings with estimates of growth, mortality and yield per recruit of yellowtail kingfish (Seriola lalandi) from New South Wales, Australia. Marine and Freshwater Research 55: 489-497. 
Whatmore, P., N.H. Nguyen, A. Miller, R. Lamont, D. Powell, T. D’Antignana, E. Bubner, A. Elizur, and W. Knibb. 2013. Genetic parameters for economically important traits in yellowtail kingfish Seriola lalandi. Aquaculture 400-401: 77-84. 


\section{Chapter 1}

Methods for genetic parentage assignment of California yellowtail with an emphasis on sample size requirements. 


\begin{abstract}
Genetic samples were collected from five spawning events of cultured California yellowtail (CYT; Seriola dorsalis previously lalandi) in 2013. Genetic samples consisted of just-hatched larvae preserved in 100\% EtOH. The spawning tank contained 11 male and 8 female fish. These five spawns occurred roughly one month apart throughout the spawning season, and parental contribution was genetically identified using a panel of nine polymorphic microsatellites for Seriola spp. The first 47 larvae were initially analyzed for proportional contribution from each brood fish. Subsequently an additional 300 larvae were analyzed and assigned parentage depending on the number of larvae available. Increasing sample size had no effect on overall proportions of parental contribution observed (average for all spawns $\mathrm{P}=0.65$ ). For this specific breeding system of CYT a sample size of 47 progeny is adequate to proportion contribution of individual fish to a spawn. Bootstrap resampling of the data using simulated sample sizes $(n=10-300)$ revealed that 30 offspring per spawn achieved proportional parental assignment to $95 \%$ confidence levels.
\end{abstract}




\section{Introduction}

Determining appropriate sample size is an important consideration in scientific planning and sample design. With advancement in mathematics, determining sample sizes needed from an affected populated has become relatively easy for parametric tests. Power analyses were designed to ensure that the proper number of subsampled individuals (n) from a total population $(\mathrm{N})$ are analyzed to have the power (P-value) to detect significant structuring with the population. These types of power analyses can either generate the number of individuals needed to subsample, or if subsampling values are already set, the statistical power of the test (e.g. t-test, ANOVA). For more complicated analyses that require nonparametric testing, statistical programs are available that can capture the complexity for subsampling.

In practical use, it is often desirable to keep sample sizes to a minimum. This may be due to a range of factors, including time limitations in the field or lab, cost of equipment, or rarity of specimens available for study. In molecular genetic studies, cost of reagents and time associated with lab work are often the

primary drivers to optimize sample sizes, though availability of samples may also be a factor. Population genetics studies utilizing microsatellite markers typically conclude that $90-95 \%$ of the genetic diversity of a population is described after analyzing 30 individuals, with little information being gained as sample size increases (Lu-Na and De-Xing, 2004; Miyamoto et al., 2008; Hale et al., 2012). Simulation studies of stable populations have suggested that subsampling at least 480 individuals is needed to correctly assess census populations over 10,000 
(Tallmon et al., 2010). The need to justify the sample size is desirable for studies of parentage in broadcast spawning fishes due to the large number of samples available for analysis (e.g. eggs and larvae) as well as the number of potential parents within the spawning event.

While these studies do focus on genetic markers, the motivation behind them differs from genetic studies of parentage. Rather, the investigators focus on detection of all alleles present in a population. In studies that have focused on microsatellites used to determine parentage, subsampling values have ranged from 60 - 810 with no mention of how sample size was determined (e.g. Estoup et al., 1998; Vandeputte et al., 2004; Hauser et al., 2011; Gruenthal and Drawbridge 2012; Liu et al., 2012), rather, great emphasis has thus far been put into calculating numbers of loci or alleles necessary for correct parental assignment (e.g. Estoup et al., 1998; Bernatchez and Duchesne, 2000; Dakin and Avise, 2004; Liu et al., 2004; Briñez et al., 2011).

The use of animals in an aquaculture setting is an ideal test area for the evaluation of the necessary sampling scheme to quantify patterns of parentage. Using microsatellites as a genetic marker for determining parentage, confidence in subsampling was calculated using the Seriola dorsalis, previously Seriola lalandi, experimental breeding system at Hubbs-SeaWorld Research Institute in San Diego, California (Purcell et al., 2015). Hereafter Seriola dorsalis may be referred to as California yellowtail (CYT). This closed population ensured that $100 \%$ of potential mothers and fathers present and identifiable for the 2013 spawning season. The aim of this study was to take a more in-depth examination 
at how the number of offspring analyzed predicts actual parental contribution to a single spawning event. Determination of optimal sample size for analyzing parentage in a is needed due to the sheer number of available samples per spawn as well as the number of spawns produced per season. These parentage assignments can ultimately be used to fine-tune broodstock selection and husbandry practices for CYT. 


\title{
Materials and Methods
}

\author{
Sample collection
}

All CYT broodstock were housed in a $140 \mathrm{~m}^{3}$ fiberglass tank at HubbsSeaWorld Research Institute (HSWRI), fed by recirculating ambient seawater and exposed to natural light cycles (Stuart and Drawbridge, 2013). Seawater was filtered and recirculated at a rate to allow for 3-6 turnovers per day with feedings 3-5 times a week. Prior to introduction to the tank, broodstock were individually pit-tagged, genetically sampled, and sexed. Eight females and 11 males were present in the breeding population in 2013 at the time of this study. Annually, all brood fish were also measured for mass $(\mathrm{kg})$, total length $(\mathrm{mm})$ and standard length (mm). Prior to this study, fin-clips $(5-10 \mathrm{~mm})$ were taken from each brood fish for future genetic analysis and stored separately in 100\% non-denatured ethyl-alcohol (EtOH) until processing.

During the spawning season (March - September), $500 \mu \mathrm{m}$ mesh eggtraps were placed in a collection basin (sump), through which seawater was pumped before sterilization and drainage. The mesh traps were checked every morning for the presence of eggs. In the event of a spawn, all eggs were collected and enumerated volumetrically in $10 \mathrm{~L}$ graduated cylinders. Volumes were converted to total eggs using average CYT egg density of $\sim 500 \mathrm{eggs} / \mathrm{ml}$. A subsample of approximately $3 \mathrm{ml}$ of fertilized (floating) eggs was grown to hatching from each spawning event. During the 2013 spawning season there were 69 spawns from which at least 50 zero-days-post hatch (dph) yolk-sac larvae 
(YSL) offspring were collected for genetic analysis. YSL were euthanized in an overdose of MS-222 treated seawater and stored in 100\% non-denatured EtOH until processing.

At the end of the spawning season, all specimens were transported to the National Oceanic and Atmospheric Administration Southwest Fisheries Science Center (NOAA SWFSC) in La Jolla, California for genetic analyses. Fin-clips from potential parents and all YSL were genotyped using Seriola-specific microsatellite markers (Table 1). After an initial subset of 47 YSL (one-half 96well plate including a no template control) were analyzed from each spawn (methods below), five of these spawns were identified as having multiple female parents. Several hundred YSL collected from each of these five spawns were used to examine sample size requirements for accurate parental proportional assignments and were used to explore the statistical validity of the genetic methods of parentage in greater detail. These spawns, occurred on April 29, May 17, June 21, July 26, and August 26, 2013.

DNA extraction and PCR amplification

DNA was extracted from an approximately $3 \times 1 \mathrm{~mm}$ clip of fin tissue for broodstock or from entire YSL in $0.2 \mathrm{ml}$ 8-well strip tubes (one individual per well). Only whole YSL were chosen; no DNA was extracted from partial or damaged YSL to ensure that each YSL was genotyped only once. One to two no template negative controls were included per 96 wells (milli-Q water, EMD Millipore, Darmstadt, Germany). All glass-wear and dissection equipment was 
carefully washed before and between handling each fish and nitrile gloves were worn to prevent cross-contamination. Extractions were performed by pipetting $150 \mu 1$ of a $10 \%$ (w/v) Chelex resin solution (Bio Rad Laboratories Inc., Berkeley, CA) into each well, incubating the mixtures at $60{ }^{\circ} \mathrm{C}$ for 20 minutes, and boiling at $103{ }^{\circ} \mathrm{C}$ for 25 minutes. Supernatant was used directly for polymerase chain reaction (PCR) amplification of microsatellite regions. Upon completion of genotyping, all DNA extractions were stored at $-80{ }^{\circ} \mathrm{C}$.

Previously published microsatellite loci (Table 1) were chosen based on ongoing research at the SWFSC, which identified a panel of nine loci that were diverse enough to distinguish parentage in the larvae among brood fish parents at HSWRI (Purcell and Hyde, unpublished data). Loci were pooled for multiplex PCR in the following combinations: 1) Sequ 38; 2) Sequ 77, Sdu gA3D, Sdu 46 and Sdu 4; and 3) Sequ320, Sequ230, Sdu 10 and Sdn 06. DNA amplification were completed in $11 \mu \mathrm{l}$ volumes containing 10X PCR Buffer (Appendix 1), 2 $\mathrm{mM}$ each dNTP (Bioline, Taunton, MA; Appendix 1), bovine serum albumin (BSA, Appendix 1), $10 \mathrm{mM}$ primer pairs, 5-6 units of Taq polymerase (New England Biolabs, Ipswich, MA), and milli-Q water, and $1 \mu 1$ sample DNA. Forward primers for all PCRs were marked with fluorescent labels for genotyping via fragment analysis (Integrated DNA Technologies, Coralville, IA). DNA extraction and PCR set up were all completed in a clean, pre-PCR lab, before being moved to a PCR laboratory for amplification and further processing.

All three PCRs had the following conditions: denaturation at $94{ }^{\circ} \mathrm{C}$ for 4 minutes, followed by 35 cycles of $94{ }^{\circ} \mathrm{C}$ for $30 \mathrm{~s}$, annealing between $53-59{ }^{\circ} \mathrm{C}$ for 
$35 \mathrm{~s}$, and elongation at $72{ }^{\circ} \mathrm{C}$ for $30 \mathrm{~s}$, and a final extension for 5 minutes at 72

${ }^{\circ} \mathrm{C}$, followed by a $4{ }^{\circ} \mathrm{C}$ hold until further analysis. The annealing temperature was

$53{ }^{\circ} \mathrm{C}$ for PCR $1,55{ }^{\circ} \mathrm{C}$ for PCR 2, and $59{ }^{\circ} \mathrm{C}$ for PCR 3 (all information for PCRs in Appendix 2).

Genotyping

The three PCRs were further multiplexed for genotyping, combining PCRs 1 and 2, with product from PCR 3 run separately. PCR product was diluted 1:25 in milli-Q water for use in further laboratory processes. The first dilution plate contained $23 \mu \mathrm{l}$ water with $1 \mu \mathrm{l}$ each from PCR 1 and 2 . The second dilution plate contained $24 \mu \mathrm{l}$ water and $1 \mu \mathrm{l}$ from PCR 3 . In a clean $1.5 \mathrm{ml}$ tube, $12 \mu \mathrm{l}$ of GeneScan 500 ROX size standard was added to $1000 \mu 1$ HiDi Formamide (Applied Biosystems, Waltham, MA). Nine $\mu 1$ of this HiDi/ROX mix, and $1 \mu 1$ of diluted DNA products were added to each well in a clean 96-well semi-skirted plates. Semi-skirted plates were covered with septa silicon sealing mats (Applied Biosystems), vortexed briefly and spun down. DNA was denatured at $95^{\circ} \mathrm{C}$ for 5 minutes followed by $8{ }^{\circ} \mathrm{C}$ for 5 minutes. Immediately after denaturing, semiskirted plates were loaded into plate-holders, and placed into 3730 DNA Analyzer with $50 \mathrm{~cm}$ capillary array filled with Pop-7 polymer for genotyping via fragment analysis (Applied Biosystems).

Post fragment analysis, visualization and sizing of microsatellites was done using GeneMapper v4.0 (Applied Biosystems). Microsatellites were analyzed using the Microsatellite Default Analysis Method, CYT panel of 
microsatellites (Table 1), red size standard dye, and the size calling curve for the ROX 500 size standard modified to incorporate only the following standard peaks (in bp): $75,100,139,150,160,200,300,340,350,400,490,500$. Alleles were scored automatically and visually confirmed; to ensure replication in scoring and minimize errors, all plates were scored by the author, and were viewed multiple times for correction.

Scored peaks were then exported as a text files, and transferred to Microsoft Excel 2010 for rounding and standardization. Microsatellite standardization was conducted by graphing loci individually to linear best-fit lines. The resulting equation was applied to alleles from that locus, and then rounded to the nearest integer to create a size reference bin. This ensured all scored alleles were properly binned when inter-allele distance differed from expected repeat distance (e.g. 2 or 4 bp repeats) due to variation in fragment mobility due to sequence composition.

Converted allele calls were used for parentage assignment, using exclusion (Jones and Arden, 2003) algorithms on Cervus v3.0.6 software (Kalinowski et al., 2007, www.fieldgenetics.com). Allele frequency analysis was completed to assess Hardy-Weinberg Equilibrium (HWE), using a minimum expected frequency of 5, and Bonferonni correction to evaluate significance of HWE. Simulations of parentage were assessed for 10,000 offspring, using three increasing methods of stringency for the simulation. For the first pass, the confidence was calculated using LOD with $80 \%$ relaxed confidence levels, $95 \%$ strict confidence levels, and minimum typed loci set to 5; the second pass only changed the minimum typed 
loci to 6 ; and in the third pass the minimum typed loci was changed to 6 and the relaxed confidence level was changed to $90 \%$. For known parentage assessments, proportions of parents sampled was set to 1.0 . Using these settings, $100 \%$ of offspring were able to be assigned for all simulations at the $95 \%$ confidence level. Parentage assignment was completed using the allele frequency file, and one of the simulations, to assign parents with either broodstock sexes unknown or known, respectively. Parentage files were compared to ensure $100 \%$ agreement between all assignment methods. In events where assignment did not agree, further analysis was completed using the most conservative method of assignment.

Data analysis

Mass $(\mathrm{kg})$ and total length of brood fish were first tested for normality using a Shapiro-Wilks test. This was done in $\mathrm{R}$ version 3.0.2. Both masses and lengths were normally distributed $(\mathrm{P}$-values $=0.19-0.91)$ for the 2013 spawning season.

A theoretical sample size was calculated (e.g. power analysis) to determine how many YSL should be analyzed for statistical significance. This was completed using a sample size calculator aimed at allelic contribution. Using a freely available online sample size calculator from AusVet Animal Health Services (http://epitools.ausvet.com.au/content.php?page=1Proportion), inputs for genetic parameters were conservatively chosen. Estimated proportion was set to 0.5 (e.g. equal allelic contribution from each brood fish), confidence level set to 
$95 \%$, and desired precision of estimate set to 0.05 (e.g. $\mathrm{P}=0.05)$. The sample size calculator also assumed an infinite population (e.g. unlimited YSL samples).

Using these values in the sample-size calculator, the sample size needed to estimate true proportions of allelic contribution was $n=385$.

Effective population for females $\left(N e_{f}\right)$, males $\left(N e_{m}\right)$, and both males and females $\left(N_{e}\right)$ were calculated for each spawning event and season using Microsoft Excel 2010 and the following equations from Gold et al. (2008):

$$
N_{e}=\frac{4 * N e_{f} * N e_{m}}{\left(N e_{f}+N e_{m}\right)}
$$

Where,

$$
N e_{f, m}=\frac{1}{\sum_{k=1}^{n_{f, m}} q_{k}^{2}}
$$

Where,

$$
\begin{aligned}
& n_{f, m, e}=\text { number of spawning females, males, or both } \\
& q=\text { proportion of contribution of each female or male }
\end{aligned}
$$

Values for $q$ were calculated using proportion of offspring genotyped from each spawn. For methods testing, this calculation was done twice, first with the initial 47 YSL analyzed, then with the additional 278 - 330 YSL analyzed.

Binomial tests were conducted between values obtained for proportions of initial parental contribution $(n=47$ YSL) and proportions of final parental contribution ( $\mathrm{n}=325-377$ YSL). For binomial tests, proportions from initial 
YSL were compared to "true" proportions, with "true" (in quotes) being defined as the proportion seen from the grand total of YSL genetic samples examined from each spawn. Each of the spawning events had 100,000s of eggs, analysis of all larvae would be cost and time prohibitive. However, analyzing every genetic sample stored was the closest to getting statistically true results, and thus put into quotes. In order from earliest to latest spawn date, the total numbers of YSL analyzed were: $\mathrm{n}=357,355,366,377$, and 325 . These totals represent the entire amount of genetic samples stored in EtOH, and were the spawns which contained the most preserved YSL from the year.

After parentage assignment, the data were bootstrapped using R software for simulated sample sizes. Each spawn was split into male and female parent data files, and these data files were bootstrapped 10,000 times, with final n-values set to: $10,20,30,40,47,60,100,150,200,250$, and 300. From the bootstrapped data, averages and $95 \%$ confidence intervals were calculated for both males and females. Binomial tests were conducted to determine whether parental contribution levels of resampled pools were different from "true" proportions. 
Table 1: Microsatellite primer pairs, GenBank accession numbers, relevant publications, proper annealing temperatures, and fragment lengths for multiplexed PCR of CYT at HSWRI. 
Table 1 -- Seriola spp. microsatellite primer pairs used

\begin{tabular}{|c|c|c|c|c|c|c|}
\hline Locus & Forward $(F)$ & Reverse (R) & $\begin{array}{c}\text { Accession } \\
\text { number }\end{array}$ & $\begin{array}{c}\text { Annealing } \\
\text { temperature }\end{array}$ & Publication & $\begin{array}{c}\text { Approx. } \\
\text { fragment } \\
\text { length (bp) }\end{array}$ \\
\hline Sequ38 & CCATTACAATTTGTCTCTC & CTTATCAACACACGAGCG & AB098518 & $53^{\circ} \mathrm{C}$ & Ohara et al., 2003 & $100-145$ \\
\hline Sequ77 & CCTACACATGCACATGAA & CAAGGCTGATACGTCATG & AB098519 & $55^{\circ} \mathrm{C}$ & Ohara et al., 2003 & $135-190$ \\
\hline Sdu gA3D & CTCAACATGAGAGGCAACG & GCATGGCTTCATGGGAAGG & DQ435602 & $55^{\circ} \mathrm{C}$ & Porta et al., 2009 & $140-180$ \\
\hline Sdu 46 & GCAGTGTGAGCCATACATTAC & CTACAGGACAAAAGCCATT & DQ883580 & $55^{\circ} \mathrm{C}$ & Renshaw et al., 2007 & $220-260$ \\
\hline Sdu 4 & GGAAATAGTTTGGATCACGCTGG & GGATGCTCAGTGAAGTTGTGC & DQ468084 & $55^{\circ} \mathrm{C}$ & Renshaw et al., 2006 & $270-310$ \\
\hline Sequ320 & GACAGGGTAAGAAACGAAAC & GACAATGACCAAAGCTGCC & AB508215 & $59^{\circ} \mathrm{C}$ & Ohara et al., 2005 & $90-140$ \\
\hline Sequ230 & CTCCAGAAACGCCACATAAC & AAGCAAACCGCACAAGTAGG & AB508202 & $59^{\circ} \mathrm{C}$ & Ohara et al., 2005 & $150-165$ \\
\hline Sdu 10 & CCAAGTCCTCCGCTACTACCAT & CCTTGTGGATGACCTGTTTG & DQ468090 & $59^{\circ} \mathrm{C}$ & Renshaw et al., 2006 & $250-310$ \\
\hline Sdn 06 & GGGTTTGTGCTGTGAGTG & TCCGTCTGTCTTTTCCTGT & N/A & $59^{\circ} \mathrm{C}$ & Nugroho \& Taniguchi, 1999 & $300-330$ \\
\hline
\end{tabular}




\section{Results}

Spawns for sample size validation were chosen based on the number of archived samples, as well as the requirement that more than one female contributed to the spawning event based on preliminary analysis of 47 YSL. These spawns occurred on April 29, May 17, June 21, July 26, and August 26. All microsatellite loci were in HWE. Using a freely available sample size calculator, sub sampling of all five spawns should have been $n=385$ offspring, to obtain a $\mathrm{P}$ value $=0.05$.

The proportional contribution from each brood fish is consistent among all five spawns whether sample sizes of 47 or 300 analyzed (Figure 1). Indeed, the proportions between the first 47 YSL (first one-half of a 96-well plate processed; half-plate) were not significantly different from the maximum total sample size, except for one instance, indicated by the "**" in Figure 1, which corresponds to the bolded value in Table 3. In this instance, one male brood fish with pit tag number 083-070-054, contributed $17 \%$ to the first 47 YSL, but only $7.3 \%$ out of the total, resulting in $\mathrm{P}=0.019$. Overall, proportions from females were closer to "true" values, than from males, with primary and secondary females clearly identified among the first 47 samples. This is also seen with P-values from contributing females at or near 1.000, and females with no contribution in both the first 47 YSL and the "true" value indicated as N/A (Table 3).

For the spawn that occurred on April 29th, the primary female contributor was 061-363-804 at 60.3\% YSL, followed by female 083-103-352 at 39.2\% YSL. 
Two other females contributed less than $1 \%$ (Figure 2). This is consistent with the calculated effective population of females $\left(N e_{f}\right)$ of 1.82 from the first 47 YSL, and 1.93 from the total sample (Table 2). These percentages of female contribution were observed at all levels of simulated sample size, via bootstrapping, however at lower levels of simulated sample size $95 \%$ confidence intervals (CI) were much larger than at higher levels. For example, for the primary female in this spawn, the $95 \% \mathrm{CI}$ at the lowest level of simulated sample size, $\mathrm{n}=10 \mathrm{YSL}$, was $\pm \sim 0.3$, but decreases to $\pm \sim 0.02$ at the highest simulated sample size, $n=300$ (Table 4). As the simulated sample size increase for each spawn, the $95 \%$ CI bars become closer to the mean, showing a truer representation of the "true" proportions (Figures 2-6, all listed in Appendices 3 and 4).

From the spawn on May 17, female 083-026-876 and 083-103-352 each contributed $49.8 \%$ of the YSL to the spawning event (Figure 3), agreeing with $N e_{f}$ $=2.0$ (Table 2). Female 061-375-363 contributed almost every YSL from the June 21 spawning event, at 94.7\% (Figure 4), and similarly female 061-363-804 was prominent for the July 26 spawning event at $99.4 \%$ (Figure 5). These two spawns also had an $\mathrm{Ne}_{f}$ of $\sim 1$ (Table 2). Female 083-027-609 is the primary female spawning $76.3 \%$ of the YSL, and female 061-363-804 contributing a secondary amount with $23.4 \%$ of the YSL from August 26 (Figure 6). All other females shown in figures did contribute to the spawning event but at much lower levels, in some cases, less than $1 \%$ of the spawning event. All male or female brood fish not individually graphed had zero contribution to the spawn. 
From each spawn analyzed, no male brood fish contributed more than $25 \%$ of the YSL to a spawn, and the mean contribution from each male to a spawning event was $\sim 10 \%$ (Figure 2-6), or roughly equal contribution from the participating male brood fish. This results in a calculated male contribution for each spawn being $3.65-8.28$ (Table 2). All spawning events appear to have a primary female, or in one case, two females that contributed nearly equal proportions (May 17, 2013, Figure 3). The remaining analyzed spawns all had one female that contributed $>70 \%$ of the YSL (Figure 4-6), with two spawns having one female contribute $\sim 100 \%$ of the YSL from that spawning event (Figure 4-5). While each spawn seemed to have a primary female contributor, at each spawning event it was a different female who took on this role.

All simulated sample sizes quickly found the "true" mean, and had decreasing $95 \% \mathrm{CI}$ as the simulated sample size becomes closer to the total number of YSL analyzed. Calculated census and effective population numbers also quickly find "true" values, with the first 47 YSL effective populations nearly matching "true" effective populations (Table 2). A complete list of means and 95\% CI from all brood fish, at each spawn and each simulated sample size, are available in Appendix 3. 
Figure 1: Frequency of contribution from first 47 yolk-sac larvae (YSL) assigned parentage (black), and then total processed (gray) from each spawn processed. Pit tag numbers before the vertical line indicate female brood fish, those after indicate male brood fish. The X-axis represents brood fish pit-tag number. Each graph represents different spawn date, and all light gray values were calculated from different totals (N). A) Spawn date from April 29 with $N=357$, B) spawn date from May 17 with $\mathrm{N}=355, \mathrm{C}$ ) spawn date from June 21 with $\mathrm{N}=366$, D) spawn date from July 26 with $\mathrm{N}=377$, E) spawn date from August 26 where $\mathrm{N}=$ 325. 

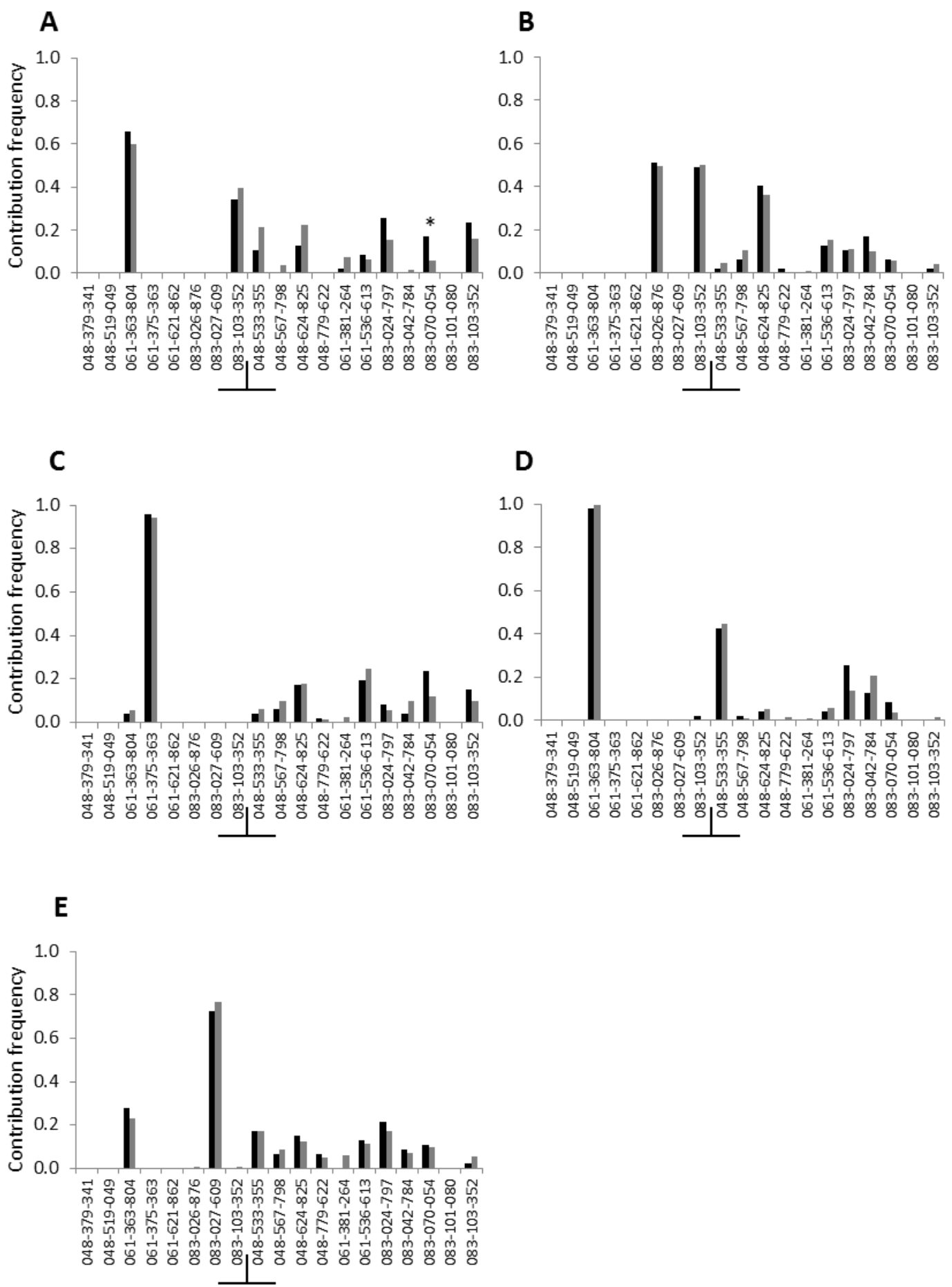
Figure 2: Mean frequency of contribution to spawn, from 10,000 bootstrap replicates at various simulated sample sizes, for CYT spawn occurring on April 29. Error bars represent plus/minus $95 \%$ confidence intervals of the mean. Simulated sample sizes were $\mathrm{n}=10,20,30,40,47,60,100,150,200$, and 300 . All broodstock that contributed were represented, with empty squares representing females (A-D) and filled black squares representing males (E-N). Graphs each represent one brood fish by pit-tag number, with A) 061-363-804, B) 061-621-862, C) 083-027-609, D) 083-103-352, E) 048-533-355, F) 048-567-798, G) 048-624-825, H) 061-381-264, I) 061-536-613, J) 083-024-797, K) 083-042784, L) 083-070-054, M) 083-101-080, and N) 083-103-352. 

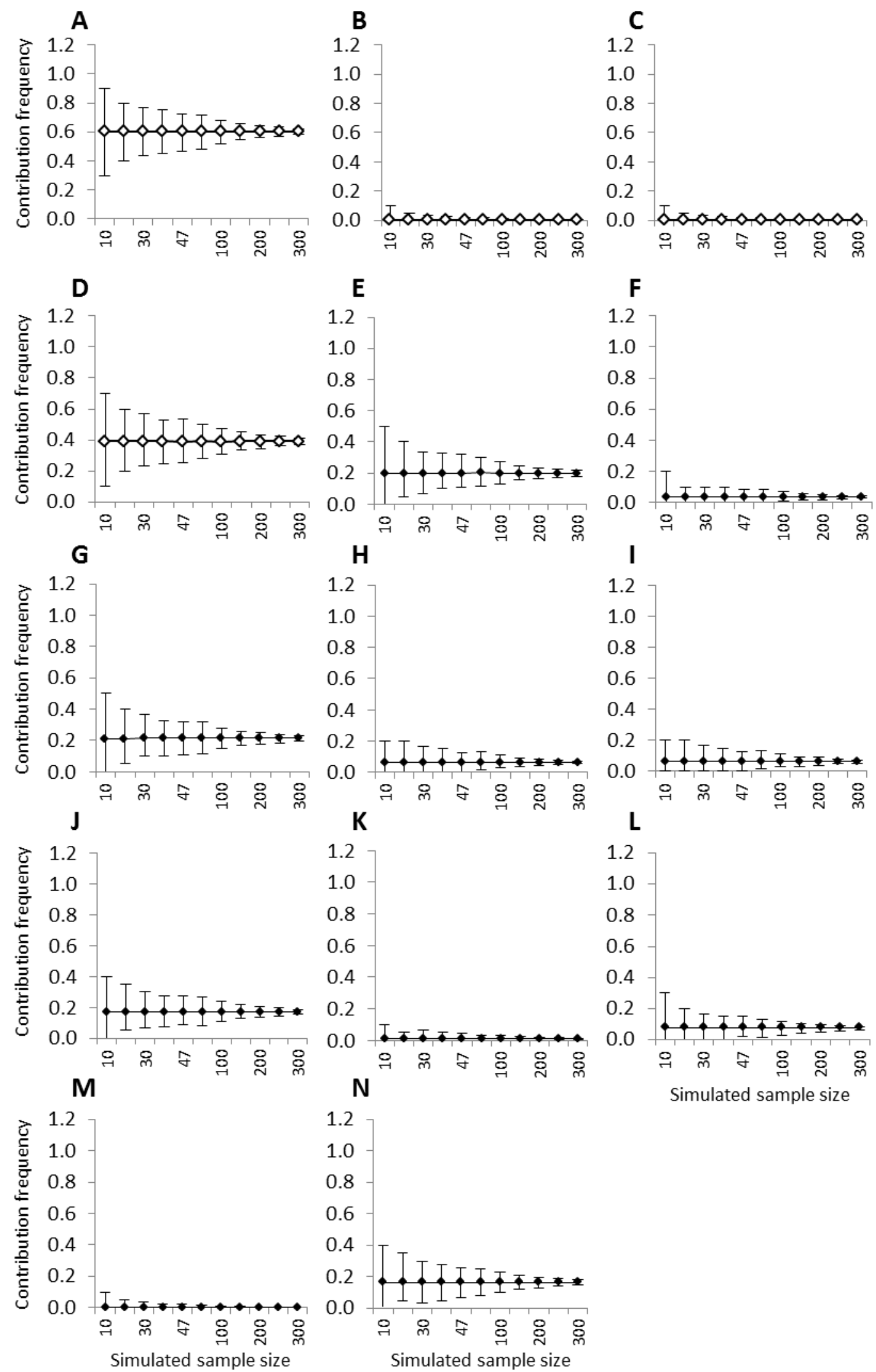
Figure 3: Mean frequency of contribution to spawn, from 10,000 bootstrap replicates at various simulated sample sizes, for CYT spawn occurring on May 17. Error bars represent plus/minus $95 \%$ confidence intervals of the mean. Simulated sample sizes were $\mathrm{n}=10,20,30,40,47,60,100,150,200$, and 300 . All broodstock that contributed were represented, with empty squares representing females (A-C) and filled black squares representing males (D-M). Graphs each represent one brood fish by pit-tag number, with A) 083-026-876, B) 083-027-609, C) 083-103-352, D) 048-533-355, E) 048-567-798, F) 048-624-825, G) 048-779-622, H) 061-381-264, I) 061-536-613, J) 083-024-797, K) 083-042784, L) 083-070-054, and M) 083-103-352. 

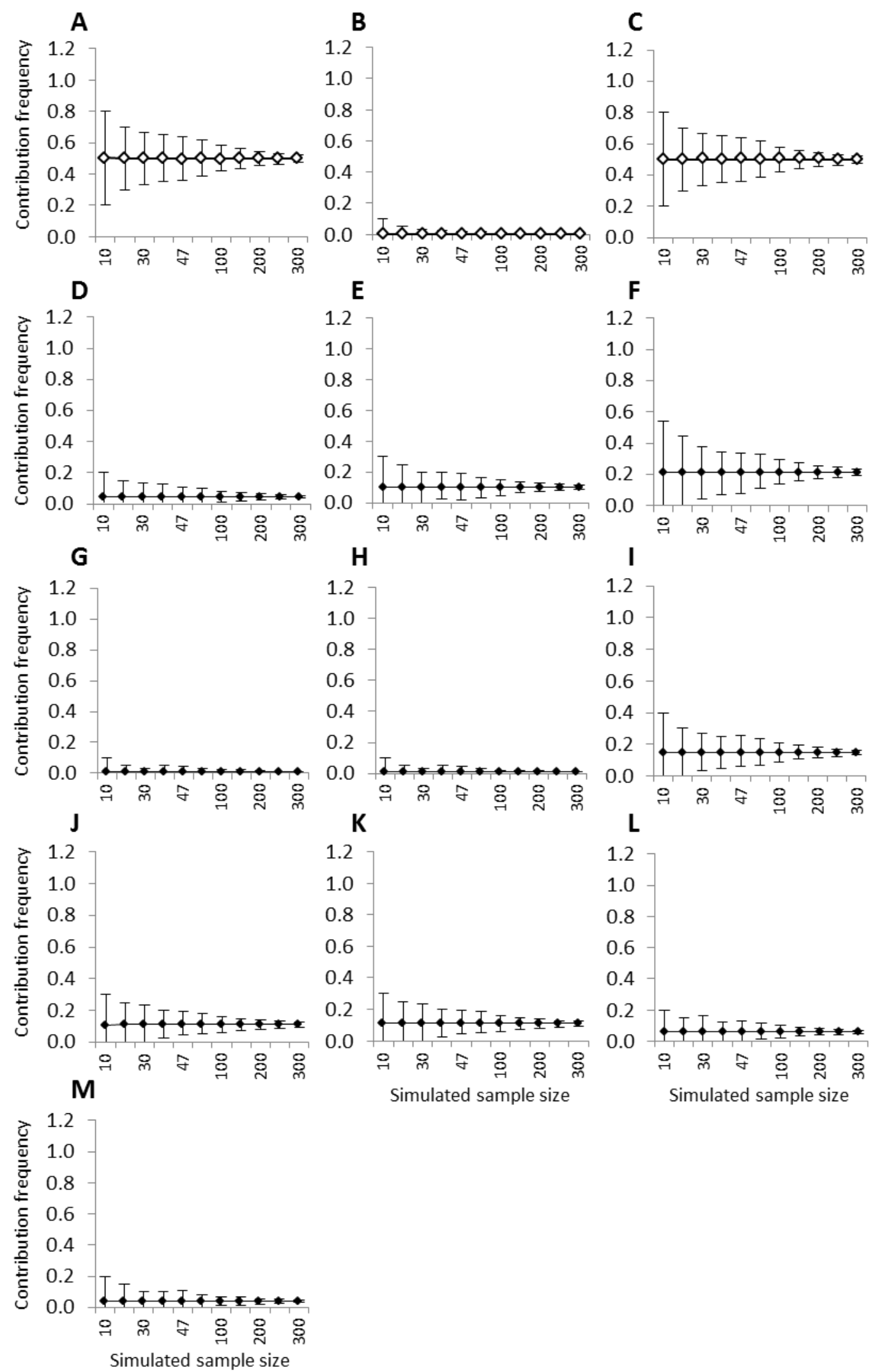
Figure 4: Mean frequency of contribution to spawn, from 10,000 bootstrap replicates at various simulated sample sizes, for CYT spawn occurring on June 21. Error bars represent plus/minus $95 \%$ confidence intervals of the mean.

Simulated sample sizes were $\mathrm{n}=10,20,30,40,47,60,100,150,200$, and 300 . All broodstock that contributed were represented, with empty squares representing females (A-B) and filled black squares representing males (C-L). Graphs each represent one brood fish by pit-tag number, with A) 061-363-804, B) 061-375-363, C) 048-533-355, D) 048-567-789, E) 048-624-825, F) 048-779-622, G) 061-381-264, H) 061-536-613, I) 083-024-797, J) 083-042-784, K) 083-070054, and L) 083-103-352. 

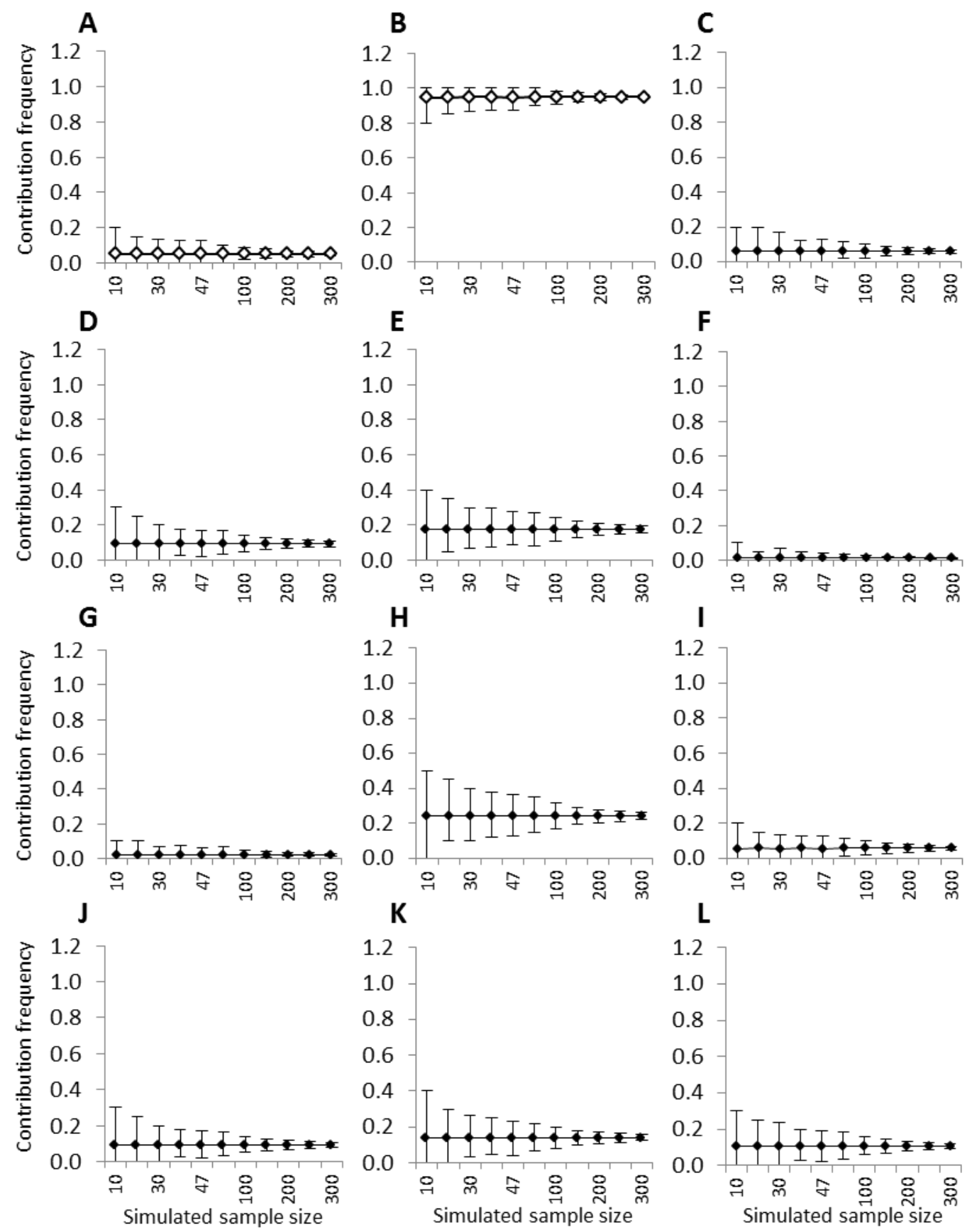
Figure 5: Mean frequency of contribution to spawn, from 10,000 bootstrap replicates at various simulated sample sizes, for CYT spawn occurring on July 26. Error bars represent plus/minus 95\% confidence intervals of the mean. Simulated sample sizes were $\mathrm{n}=10,20,30,40,47,60,100,150,200$, and 300. All broodstock that contributed were represented, with empty squares representing females (A-C) and filled black squares representing males (D-M). Graphs each represent one brood fish by pit-tag number, with A) 048-379-341, B) 061-363804, C) 083-103-352, D) 048-533-355, E) 048-567-798, F) 048-624-825, G) 048779-622 H) 061-381-264, I) 061-536-613, J) 083-024-797, K) 083-042-784, L) 083-070-054, and M) 083-101-080. 

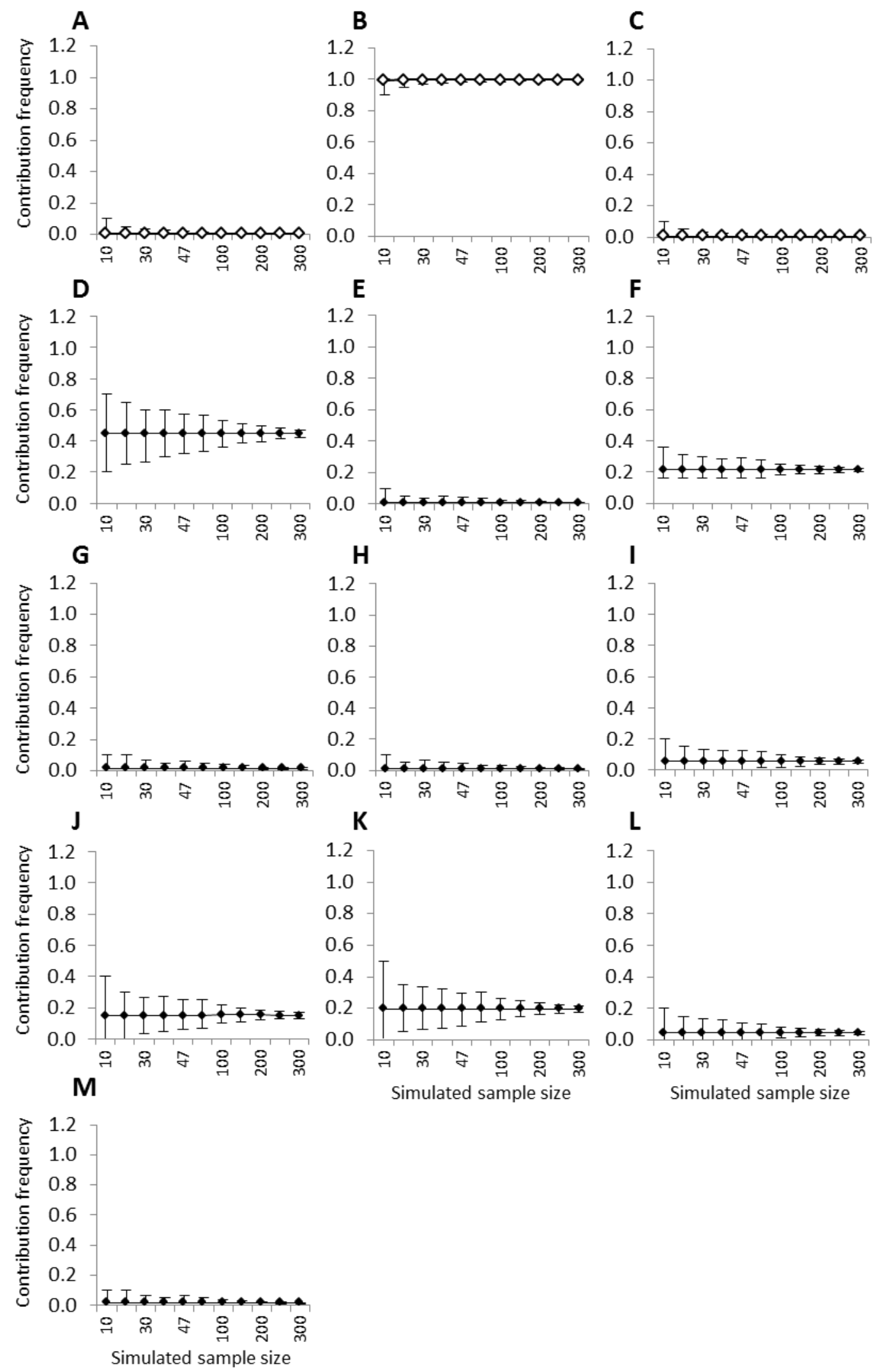
Figure 6: Mean frequency of contribution to spawn, from 10,000 bootstrap replicates at various simulated sample sizes, for CYT spawn occurring on August 26. Error bars represent plus/minus 95\% confidence intervals of the mean. Simulated sample sizes were $\mathrm{n}=10,20,30,40,47,60,100,150,200$, and 300 . All broodstock that contributed are represented, with empty squares representing females (A-C) and filled black squares representing males (D-M). Graphs each represent one brood fish by pit-tag number, with A) 061-363-804, B) 083-026876, C) 083-027-609, D) 048-533-355, E) 048-567-798, F) 048-624-825, G) 048779-622, H) 061-381-264, I) 061-536-613, J) 083-024-797, K) 083-042-784, L) 083-070-054, and M) 083-103-352. 

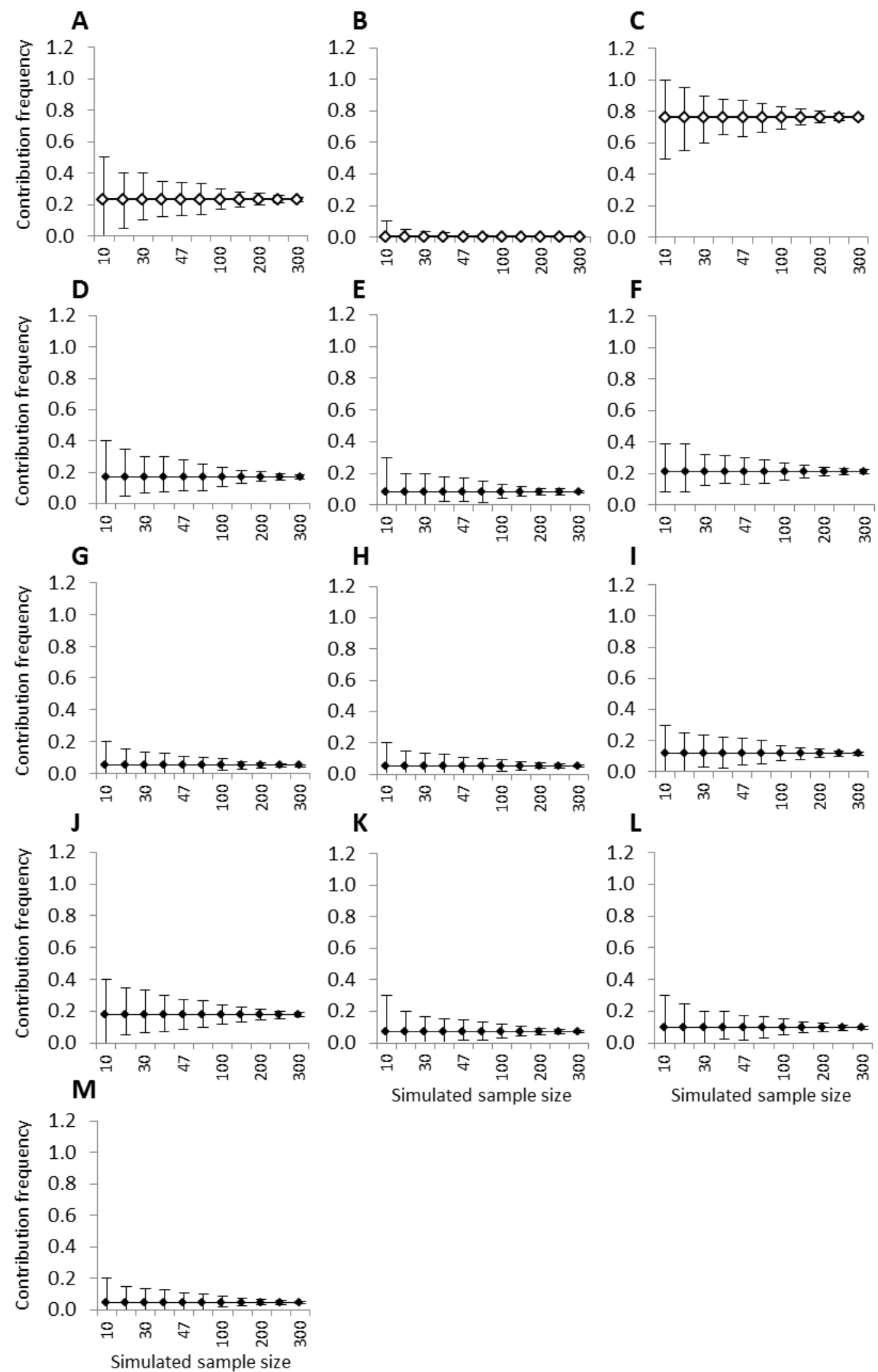
Table 2: Calculated census $(n)$ and effective $(\mathrm{Ne})$ population from each spawn during the 2013 spawning season, for female brood fish $(f)$, male brood fish $(m)$, and both $\left(N_{e}\right)$. Calculations were made from the first 47 YSL analyzed, and with grand totals of YSL from each spawn ( $\geq 325 \mathrm{YSL})$. 
Table 2: Censes and effective population of five spawns from 2013

\begin{tabular}{|c|c|c|c|c|c|c|c|c|c|c|c|c|}
\hline $\begin{array}{l}\text { Date } \\
\mathrm{mm} / \\
\mathrm{dd}\end{array}$ & $\begin{array}{l}n_{f} \\
47\end{array}$ & $\begin{array}{c}n_{f} \\
\text { Total }\end{array}$ & $\begin{array}{c}N e_{f} \\
47\end{array}$ & $\begin{array}{l}\mathrm{Ne}_{f} \\
\text { Total }\end{array}$ & $\begin{array}{c}n_{m} \\
47\end{array}$ & $\begin{array}{c}n_{m} \\
\text { Total }\end{array}$ & $\begin{array}{c}N e_{m} \\
47\end{array}$ & $\begin{array}{l}\mathrm{Ne}_{m} \\
\text { Total }\end{array}$ & $\begin{array}{l}n_{e} \\
47\end{array}$ & $\begin{array}{c}n_{e} \\
\text { Total }\end{array}$ & $\begin{array}{l}N_{e} \\
47\end{array}$ & $\begin{array}{c}N_{e} \\
\text { Total }\end{array}$ \\
\hline $04 / 29$ & 2.00 & 4.00 & 1.82 & 1.93 & 7.00 & 10.00 & 5.43 & 6.38 & 9.00 & 14.00 & 5.44 & 5.93 \\
\hline $05 / 17$ & 2.00 & 3.00 & 2.00 & 2.01 & 9.00 & 10.00 & 4.36 & 5.00 & 11.00 & 13.00 & 5.48 & 5.74 \\
\hline $06 / 21$ & 2.00 & 2.00 & 1.09 & 1.11 & 9.00 & 10.00 & 6.33 & 6.89 & 11.00 & 12.00 & 3.72 & 3.82 \\
\hline $07 / 26$ & 2.00 & 3.00 & 1.04 & 1.01 & 7.00 & 10.00 & 3.65 & 3.71 & 9.00 & 13.00 & 3.25 & 3.18 \\
\hline $08 / 26$ & 2.00 & 3.00 & 1.67 & 1.57 & 9.00 & 10.00 & 7.15 & 8.28 & 11.00 & 13.00 & 5.41 & 5.28 \\
\hline
\end{tabular}


Table 3: P-values from all binomial tests between frequencies of first 47 YSL assigned, and total frequencies. Frequencies calculated from totals $(\mathrm{N})$ were used as "true frequencies" from the spawn, and values from first 47 were measured against this value to discern how correct this sample-size predicted parentage from spawn. Solid bars beside pit tag numbers indicates female brood fish, dashed bar indicates male brood fish. Frequency from totals for each spawn were calculated from different total YSL, in order left-to-right, $\mathrm{N}=357 ; 355 ; 366 ; 377$; and 325. Cells containing "N/A" indicate a frequency of zero from first 47 , and zero from totals. Bolded values indicate statistically significance differences $(\mathrm{P}<$ $0.05)$. 
Table 3: P-values from each spawn date and brood fish

Spawn date (mmdd20yy)

\begin{tabular}{|lccccc} 
Pit-tag number & $04 / 29 / 13$ & $05 / 17 / 13$ & $06 / 21 / 13$ & $07 / 26 / 13$ & $08 / 26 / 13$ \\
\hline $048-379-341$ & N/A & N/A & N/A & 1.000 & N/A \\
$048-519-049$ & N/A & N/A & N/A & N/A & N/A \\
$061-363-804$ & 0.551 & N/A & 1.000 & 0.221 & 0.492 \\
$061-375-363$ & N/A & N/A & 1.000 & N/A & N/A \\
$061-621-862$ & 1.000 & N/A & N/A & N/A & N/A \\
$083-026-876$ & N/A & 0.885 & N/A & N/A & 1.000 \\
$083-027-609$ & 1.000 & 1.000 & N/A & N/A & 0.496 \\
$083-103-352$ & 0.552 & 1.000 & N/A & 1.000 & N/A \\
$048-533-355$ & 0.142 & 0.724 & 1.000 & 0.884 & 1.000 \\
$048-567-798$ & 0.410 & 0.626 & 0.799 & 0.313 & 1.000 \\
$048-624-825$ & 0.210 & 0.651 & 1.000 & 1.000 & 0.658 \\
$048-779-622$ & N/A & 0.329 & 0.403 & 1.000 & 0.503 \\
$061-381-264$ & 0.374 & 1.000 & 0.628 & 1.000 & 0.178 \\
$061-536-613$ & 0.124 & 0.640 & 0.498 & 1.000 & 0.819 \\
$083-024-797$ & 0.123 & 1.000 & 0.345 & 0.065 & 0.566 \\
$083-042-784$ & 1.000 & 0.237 & 0.318 & 0.275 & 0.775 \\
$083-070-054$ & 0.019 & 0.757 & 0.087 & 0.161 & 0.806 \\
$083-101-080$ & 1.000 & N/A & N/A & N/A & N/A \\
$083-103-352$ & 0.235 & 1.000 & 0.341 & 1.000 & 0.730
\end{tabular}




\section{Discussion}

For this CYT spawning system consisting of 11 male and 8 female brood fish, 47 YSL samples was enough to understand patterns of parental contribution and a convenient number to analyze in a 96 well format. When analyzing simulated sample sizes, 30 YSL was sufficient to get the mean $\pm 95 \%$ CI to not differ significantly differ from "true" proportions as determined by sampling more than 300 YSL. These sample numbers are in the same range as other studies that focus on sample collection for population genetics (Hale et al., 2012). It is important to note that while computer simulation suggests that a sample size of 30 is adequate, one initial value at $n=47$ YSL was significantly different than "true" values (Table 3). However, with a Bonferonni correction, this $\mathrm{P}$-value is no longer significant, as it is $\mathrm{P}>0.01$.

For practical use, and for more conservative statistical analysis, $n=47$ YSL offspring was chosen for this study. This is a convenient number for genetic work since, with the addition of a negative control, two groups (e.g. spawns) fit into a standard 96-well plate. Initial proportional contribution was not statistically significantly different between $n=47$ and $N>300$ YSL, in all cases but one (Table 3). These subsample numbers of $n=30-47$ YSL, are an order of magnitude smaller than a predicted power analysis, which was $n=385$ YSL. With the addition of 300 samples assigned, little information is gained in terms of proportional contribution of parentage, at the cost of time and laboratory expenses. 
Additionally, if resources are limiting, or for pilot studies, reasonably accurate average parental contribution proportions were seen in as few as 10 offspring (Figures 2-6). However, broader conclusions would be limited, since 95\% CI when $\mathrm{n}=10$ YSL were extreme, and outside the "true" proportion. The fact that average proportions of parental contribution in as few as $n=10 \mathrm{YSL}$ being reasonably accurate could be due to the low number of potential parents $(\mathrm{N}$ =19). As relatively few females contribute per spawning event (lottery polygyny, Nunney, 1993), 10 YSL was enough sub sampling to quickly predict the primary female, but not to understand how males were contributing. However, for any statistical power in parental proportional contribution, $\mathrm{n} \geq 30$ offspring is necessary.

As this system is closed to the wild, even rare alleles will be detected, which is extremely important for population genetic studies (Crandall et al., 2000) or for studies regarding evolutionary migration (Slatkin, 1985). This is not an issue for parentage presented here, as all potential parents were first genotyped at loci for this study and rare alleles actually ensure offspring to be assigned parentage. This study did not address potential parents not genetically identified, or a more fluid movement of parental pairs, and inferences from this study become difficult to apply to different breeding systems or where more potential pairs are present. 


\section{References}

Bernatchez, L. and P. Duchesne. 2000. Indivdiual-based genotype analysis in studies of parentage and population assignment: how many loci, how many alleles? Canadian Journal of Fisheries and Aquatic Science 57: 1-12.

Briñez, B.R., X.O. Caraballo, and M.V. Salazar. 2011. Genetic diversity of six populations of red hybrid tilapia, using microsatellites genetic markers. Revista MVZ Córdoba 16(2): 2491-2498.

Crandall, K.A., O.R.P. Bininda-Emonds, G.M. Mace, and R.K. Wayne. 2000. Considering evolutionary processes in conservation biology. Trends in Ecology and Evolution 15(7): 290-295.

Dakin, E.E. and J.C. Avise. 2004. Microsatellite null alleles in parental analysis. Heredity 93: 504-509.

Estoup, A., K. Gharbi, M. SanCristobal, C. Chevalet, P. Haffray, and R. Guyomard. 1998. Parentage assignment using microsatellites in turbot (Scophtalmus maximus) and rainbow trout (Oncorhynchus mykiss) hatchery populations. Canadian Journal of Fisheries and Aquatic Science 55: $715-725$.

Gold, J.R., L. Ma, E. Saillant, P.S. Silva, and R.R. Vega. 2008. Genetic effective size in populations of hatchery-raised red-drum released for stock enhancement. Transactions of the American Fisheries Society 137: 13271344. 
Gruenthal, K.M. and M.A. Drawbridge. 2012. Toward responsible stock enhancement: broadcast spawning dynamics and adaptive genetic management in white seabass aquaculture. Evolutionary Applications 5(4): 405-417.

Hale, M.L., Burg, T.M., Steeves, T.E. 2012. Sampling for microsatellite-based population genetics studies: $25-30$ individuals per population is enough to accurately estimate allele frequencies. PLOS One 7(9): e45170.

Hauser, L., M. Baird, R. Hilborn, L.W. Seeb, and J.E. Seeb. 2011. An empirical comparison of SNPs and microsatellites for parentage and kinship assignment in wild sockeye salmon (Oncorhynchus nerka) population. Molecular Ecology Resources 11: 150-161.

Jones, A.G. and W.R. Arden. 2013. Methods of parentage analysis in natural populations. Molecular Ecology 12:2511-2523.

Kalinowski, S.T., M.L. Taper, and T.C. Marshall. 2007. Revising how the computer program CERVUS accommodates genotyping error increases success in paternity assignment. Molecular Ecology 16: 1099-1006. doi: 10.1111/j.1365-294x.2007.03089.x

Liu, Z.J. and J.F. Cordes. 2004. DNA marker technologies and their application in aquaculture. Aquaculture 238: 1-37.

Liu, P., J.H. Xia, G. Lin, F. Sun, F. Liu, H.S. Lim, H.Y. Pang, and G. H. Yue. 2012. Molecular parentage analysis is essential in breeding Asian seabass. PLoS ONE 7(12): e51142. 
Lu-Na, Y., and Z. De-Xing. 2004. Effects of sampling size on various genetic diversity measures in population genetic study with microsatellite DNA markers. Acta Zoologica Sinica 50(2): 279-290.

Miyamoto, N., J.F. Fernandez-Manjarres, M-E. Morand-Prieur, P. Bertolino, and N. Frascaria-Lacoste. 2008. What sampling is needed for reliable estimations of genetic diversity in Fraxinus excelsior L. (Oleaceae)? Annals of Forest Science 65 (4), pp.1

Nugroho E., and N. Taniguchi. 1999. Isolation of greater amberjack microsatellite DNA and their application as genetic marker to species of genus Seriola from Japan. Fisheries Science 65: 353-357.

Nunney, L. 1993. The influence of mating system and overlapping generations on effective population size. Evolution 47(5): 1329-1341.

Ohara, E., T. Nishimura, T. Sakamoto, Y. Nagakura, K. Mushiake, and N. Okamoto. 2003. Isolation and characterization of microsatellite loci from yellowtail Seriola quinqueradiata and cross-species amplification within the genus Seriola. Molecular Ecology Notes 3: 390-391.

Ohara, E., T. Nishimura, Y. Nagakura, T. Sakamoto, K. Mushiake, and N. Okamoto. 2005. Genetic linkage maps of two yellowtails (Seriola quinqueradiata and Seriola lalandi). Aquaculture 244: 41-48.

Porta, J.M., P. Novel, G. Martinez-Rodrigues, M.C Alverez, and J. Porta. 2009. Isolation and characterization of microsatellites from Seriola dumerili (Risso 1810). Aquaculture Research 40(2): 249-251. 
Purcell, C.M., C.L. Chabot, M.T. Craig, N. Martinez-Takeshita, L.G. Allen, and J.R. Hyde. 2015. Developing a genetic baseline for the yellowtail amberjack species complex, Seriola lalandi senu lato, to assess and preserve variation in wild populations of these globally important aquaculture species. Conservation Genetics DOI 10.1007/s10592-0150755-8.

Renshaw, M.A., J.C. Patton, C.E. Rexroad III, and J.R. Gold. 2006. PCR primers for trinucleotide and tetranucleotide microsatellites in greater amberjack, Seriola dumerili. Molecular Ecology Notes 6(4): 1162-1164.

Renshaw, M.A., J.C. Patton, C.E. Rexroad III, and J.R. Gold. 2007. Isolation and characterization of dinucleotide microsatellites in greater amberjack, Seriola dumerili. Conservation Genetics 8(4): 1009-1011.

Slatkin, M. 1985. Rare alleles as indicators of gene flow. Evolution 39(1): 53-65.

Tallmon, D., D. Gregovich, R.S. Waples, S. Baker, J. Jackson, B.L. Taylor, E. Archer, K.K. Martien, F.W. Allendorf, and M.K. Schwartz. 2010. When are genetic methods useful for estimating contemporary abundance and detecting population trends? Molecular Ecology Resources 10: 684-692.

Vandeputte, M., M. Kocour, S. Mauger, M. Dupont-Nivet, D. De Guerry, M. Rodina, D. Gela, D. Vallod, B. Chevassus, and O. Linhart. 2004. Heritability estimates for growth-related traits using microsatellite parentage assignment in juvenile common carp (Cyprinus carpio L.). Aquaculture 235: 223-236. 


\section{Chapter 2}

Reproduction of wild-caught California yellowtail (Seriola dorsalis) in an aquaculture setting with implications for broodstock management. 


\begin{abstract}
Microsatellite markers were used to determine parental contribution from a captive population of California yellowtail (CYT, Seriola dorsalis previously lalandi) over two spawning seasons. Parental contribution from these brood fish would have otherwise been unknown without genetic tools. Forty-seven yolk-sac larvae offspring were assigned to parents for all spawning events in 2013 and 2014. In 2013 there were 11 males and 8 females in the population weighing 20 $\mathrm{kg}$ on average. In 201418 smaller fish of $7.5 \mathrm{~kg}$ average were added to the pool bringing the population up to 19 males and 18 females. In most spawning events, one of the larger females produced most of the eggs, at or near $100 \%$. After a female spawned, she did not reproduce again for another $\sim 11-19$ days. The average, batch fecundity of larger females was approximately 500,000 eggs per spawn while for smaller females it was approximately 35,000 eggs per spawn. Female mass and egg production, both batch and annual fecundity, were positively correlated $(\rho>0.739)$ in the 2014 spawning season only. In 2014 , smaller female brood fish only contributed $\sim 10 \%$ to the annual egg production. For both years, approximately six males would participate in each spawning event, with no clear primary contributing male fish in this breeding system.
\end{abstract}




\section{Introduction}

Understanding reproduction is a vital component of sustainable aquaculture management. Fish make for good model organisms for studying reproduction, as they utilize a wide variety of reproductive strategies (reviewed in Gonçalves-de-Freitas et al., 2009). In spawning systems where parental contribution is unclear, genetic tools such as microsatellites can be used to determine who is breeding with whom. Microsatellites have previously been used to determine contribution of brood fish in captivity, notably in turbot (Scophtalmus maximus), trout (Oncorhynchus mykiss), flounder (Paralichthys olivaceus), common carp (Cyprinus carpio), red drum (Scaiaenops ocellatus), tilapia (Oreochromis spp.) and white seabass (Atractoscion nobilis) (Estoup et al., 1998; Hara and Sekino, 2003; Vandeputte et al., 2004; Gold et al., 2010; Briñez et al., 2011; Gruenthal and Drawbridge, 2012). For studies of red drum and white seabass, genetic analysis was used to determine which brood fish were contributing over multiple spawning events, while the flounder were only assessed at one point during the spawning season. In the case of common carp, brood fish were selected for fast weight gain in a breeding program (Vandeputte et al., 2004). For aquaculture, parentage analysis (SNPs or microsatellites) help ensure a controlled breeding program while limiting conflicts from inbreeding (Vandeputte and Haffray, 2014). These methods can also aide in the selection of

$F_{1}$ populations that can become the next generation of aquaculture brood fish and thereby reducing wild capture to supplement aquaculture production. 
Reproductive studies of pelagic fishes, including mackerels, jacks and tuna species, show that many are iteroparous asynchronous batch-spawners (Murua and Saborido-Rey, 2003). An up and coming candidate species for aquaculture is the pelagic finfish California yellowtail (FAO, USA 2011). Until very recently, this species was globally known as Seriola lalandi, but recent genetic data suggest the original name of Seriola dorsalis be resurrected for the species found in the Northeast Pacific (Baxter, 1960; Martinez-Takeshita et al., 2015; Purcell et al., 2015) and will refer to the species studied in this paper as the local common name, California yellowtail (CYT). Much like other pelagic finfishes, Seriola dorsalis are aggregate, broadcast spawning fish; releasing gametes multiple times in synchronized events during warmer summer months (Baxter, 1960; Sumida et al., 1985; Poortenaar et al., 2001; Sala et al., 2003).

From laboratory research, Seriola spp. spawned only when water temperature was above $17^{\circ} \mathrm{C}$, and courtship behavior has been described as males "nipping" or "nudging" ripe females (Moran et al., 2007; Stuart and Drawbridge, 2013). Assessment of wild Seriola lalandi from the Southwest Pacific confirm median size at reproductive maturity of between 834 and $944 \mathrm{~mm}$ fork length for females and 450-750 mm fork length for males (Gillanders et al., 1999;

Poortenaar et al., 2001). Average standard lengths of the Seriola dorsalis ranged from 350 - $970 \mathrm{~mm}$ (Baxter, 1960). However, little is known about individual spawning dynamics of CYT. Due to large aggregation sizes and the broadcast of gametes at times of breeding, details of reproductive parental contribution in the wild is very difficult to ascertain. 
Reproductive strategies in CYT have not been characterized in detail, and much information about reproduction is still unknown. Reproductive strategy here refers to the basic reproductive systems that a fish species exhibits, including monogamous breeding pairs (one male and one female), polygyny (one male with multiple female sexual partners), or lottery polygyny (males competing equally for a single female, Nunney, 1993) systems. This term can also refer to the period or cyclicality of reproduction. Fecundity is a measurement of a species' ability to reproduce, typically used in regard to female egg production. Fecundity is measured by quantifying egg production, and it has been well described in fish species that older, larger females tend to be more fecund and produce higher quality gametes due to the more mature development of the ovaries (Hixon et al., 2013). In species that can reproduce multiple times over a spawning season, distinction is made between batch and annual fecundity. The former is a measurement of eggs per female produced during one spawning event, and the latter is a measurement of total eggs per female produced during one year.

As detailed above, wild Seriola spp. broadcast spawn freely during the warmer months (Baxter, 1960; Sumida et al., 1985; Poortenaar et al., 2001; Sala et al., 2003). This same breeding system is set up for a captive group of CYT brood fish at the Hubbs-SeaWorld Research Institute (HSWRI) experimental breeding program, in San Diego, CA. At HSWRI, the CYT are bred to investigate the feasibility of culturing this species for food, so larval and juvenile stages are studied extensively (Stuart and Drawbridge, 2013). Wild-caught CYT brood fish are kept in a single large tank, allowing reproductively mature males and females 
to reproduce freely. This practice ensures a steady stream of eggs that can be collected throughout the spawning season and allows for the most "wild-like" or near-natural reproduction conditions available. Unfortunately, unlike stripspawning or hormonal injections, this method of wild-like spawning does not allow for easy parental assignment to offspring. Therefore, it is typically unknown which brood fish are contributing to distinct spawning events in this system. Knowing this information would be valuable in order to help maximize the egg production from the system, as well as to potentially link quality metrics of the offspring to the parents.

For the breeding system at HSWRI, previously published Seriola microsatellite markers were used to determine parentage of offspring. These microsatellite loci have been used to investigate population connectivity of Seriola spp. in the wild, refine the taxonomy of the Seriola lalandi species complex, and to find genetic correlations between growth rates and condition factors (Miller et al., 2011; Whatmore et al., 2013; Martinez-Takeshita et al., 2015; Purcell et al., 2015). Knowing the egg production output of individual brood fish is useful for refining aquaculture production because non-contributors can be culled from the brood fish population or sex ratios can be changed to fit reproductive strategy. Additionally, linking correlates of egg quality to individual parents can increase the efficiency of the culture system.

By tracking parental contribution over two spawning seasons, the first detailed description of CYT reproductive strategy was described here. This study enhances our understanding of the spawning dynamics of a species that is 
otherwise not well understood. It is known that CYT are aggregate breeders with large spawning events, but this study provides an individual-level analysis of spawning frequency of male and female brood fish in a captive population. The genetic data generated from this study provides information on female fecundity and spawning intervals, information that has yet been characterized in this species. This characterization of each spawning event will directly impact management of these fish in a culture setting, and may represent a proxy of spawning capacities of CYT in the wild. 


\section{Materials and Methods}

Brood fish were collected from the wild between 2001 and 2004, and have since been maintained in a $140 \mathrm{~m}^{3}$ breeding tank, under natural day length and water temperature (Stuart and Drawbridge, 2013). Genetic samples (fin clips) were collected from all individuals within the brood fish population. Water temperatures were collected directly from brood fish tank, and lunar cycles and day length data were gathered online from www.timeanddate.com.

In 2013, the broodstock population was composed of 11 males and 8 females. The population yielded 69 spawning events between March $29^{\text {th }}$ and September $30^{\text {th }}$. From this spawning year, at least 47 zero-day post-hatch (dph) yolk-sac larvae (YSL) were collected from 66 spawns, 9-13 YSL were collected from two spawns, and one spawn had zero larvae collected due to eggs not hatching. In total, 3170 YSL from 2013 were assigned to parental pair brood fish. In 2014, 18 younger animals originally collected in 2012 were added to the broodstock population, resulting in 18 females and 19 males. One male and one female were also culled from the system for health reasons, for a final total of 17 females and 18 males in the tank for the 2014 season. The 2014 spawning season resulted in 62 unique spawning events with at least 47 YSL being collected from 58 of these spawning events. In two spawning events 32-38 YSL were collected, and no larvae were collected from two other spawning events because the eggs did not hatch. A total of 2789 YSL were assigned to brood fish from the 2014 spawning season. 
It should be noted that previous simulation and statistical calculations suggested an optimal subsample of $n \geq 30$ YSL per spawn were necessary to make accurate proportional assignment of CYT parents in the HSWRI breeding system (Smith et al., in prep). For this project, 47 YSL were targeted for analysis from every spawning event during 2013 and 2014. In the event a spawn had less than 47 YSL samples preserved, all available YSL were analyzed. The YSL were obtained by hatching a subsample of eggs and storing them in $100 \%$ nondenatured ethanol for genetic analysis.

All primer pairs, PCR conditions, genotyping protocols, and analysis of published microsatellites are discussed in detail in Chapter 1 and Purcell et al., 2015. Briefly, DNA was extracted using a 10\% (w/v) Chelex resin solution (Bio Rad Laboratories Inc., Berkeley, CA), and amplification of 9 microsatellite loci (Table 1) were multiplexed into three PCRs (Appendix 2): 1) Sequ 38; 2) Sequ 77, Sdu gA3D, Sdu 46 and Sdu 4; and 3) Sequ320, Sequ230, Sdu 10 and Sdn 06. Forward primers for all PCRs were fluorescently labeled for genotyping via fragment analysis. All three PCRs had the following conditions: denaturation at $94{ }^{\circ} \mathrm{C}$ for 4 minutes, followed by 35 cycles of $94{ }^{\circ} \mathrm{C}$ for $30 \mathrm{~s}$, annealing between $53-59^{\circ} \mathrm{C}$ for $35 \mathrm{~s}$, and elongation at $72{ }^{\circ} \mathrm{C}$ for $30 \mathrm{~s}$, and a final extension for 5 minutes at $72{ }^{\circ} \mathrm{C}$, followed by a $4{ }^{\circ} \mathrm{C}$ hold until further analysis (complete information for PCRs in Chapter 1 and Appendix 2).

For fragment analysis and genotyping, PCRs 1 and 2 were combined with PCR 3 run separately. PCR product was diluted 1:25 in milli-Q water (EMD Millipore, Darmstadt, Germany) for fragment analysis. Fragment analysis was 
completed using a 1:84 dilution of GeneScan 500 ROX size standard in HiDi Formamide (Applied Biosystems, Waltham, MA). Nine $\mu 1$ of this HiDi/ROX mix, and $1 \mu \mathrm{l}$ of diluted DNA products were added to each well in a clean 96-well semi-skirted plate, denatured, and placed into 3730 DNA Analyzer for genotyping via fragment analysis (Applied Biosystems). Microsatellites were scored using GeneMapper v4.0 (Applied Biosystems). Scored allele peaks were exported to Microsoft Excel 2010 for rounding and standardization. Converted allele calls were used for parentage assignment using Cervus v3.0.6 (Kalinowski et al., 2007, www.fieldgenetics.com). Both years yielded 100\% assignment of known parental pairs.

Female fecundity, female spawning intervals, effective and census populations (From Gold et al., 2008, presented in Chapter 1), and proportional contribution of each spawn were calculated using Microsoft Excel 2010. Heterozygotes observed and expected, as well as Hardy-Weinberg Equilibrium were calculated in Cervus 3.0.6. Statistical analyses were completed using $R$ v3.0.2 software. Proportional contribution from each individual from each spawn was compared to theoretical equal proportions using a non-parametric binomial test. This tested to see if each brood fish contributed equally or disproportionately. For example, for all eight female brood fish available in 2013, actual proportions of offspring contribution were compared to the theoretical value of each female contributing equally, or each female contributing $1 / 8$ of offspring. This was completed for both years for number of males and females. Shapiro-Wilks tests were performed to evaluate the normality of fish masses. Statistical differences 
among fish masses were tested using a two-tailed t-test. Correlations regarding egg totals and environmental factors, and female masses and batch/annual fecundity were tested using Spearman's rank correlation coefficient tests. 
Table 1: Microsatellite primer pairs, GenBank accession numbers, relevant publications, proper annealing temperatures, and fragment lengths for multiplexed PCR of CYT at HSWRI. 
Table 1 -- Seriola spp. microsatellite primer pairs used

\begin{tabular}{|c|c|c|c|c|c|c|}
\hline Locus & Forward (F) & Reverse (R) & $\begin{array}{c}\text { Accession } \\
\text { number }\end{array}$ & $\begin{array}{c}\text { Annealing } \\
\text { temperature }\end{array}$ & Publication & $\begin{array}{c}\text { Approx. } \\
\text { fragment } \\
\text { length (bp) }\end{array}$ \\
\hline Sequ38 & CCATTACAATTTGTCTCTC & CTTATCAACACACGAGCG & AB098518 & $53{ }^{\circ} \mathrm{C}$ & Ohara et al., 2003 & $100-145$ \\
\hline Sequ77 & ССТАCACATGCACATGAA & CAAGGCTGATACGTCATG & AB098519 & $55^{\circ} \mathrm{C}$ & Ohara et al., 2003 & $135-190$ \\
\hline Sdu gA3D & CTCAACATGAGAGGCAACG & GCATGGCTTCATGGGAAGG & DQ435602 & $55^{\circ} \mathrm{C}$ & Porta et al., 2009 & $140-180$ \\
\hline Sdu 46 & GCAGTGTGAGCCATACATTAC & CTACAGGACAAAAGCCATT & DQ883580 & $55^{\circ} \mathrm{C}$ & Renshaw et al., 2007 & $220-260$ \\
\hline Sdu 4 & GGAAATAGTTTGGATCACGCTGG & GGATGCTCAGTGAAGTTGTGC & DQ468084 & $55^{\circ} \mathrm{C}$ & Renshaw et al., 2006 & $270-310$ \\
\hline Sequ320 & GACAGGGTAAGAAACGAAAC & GACAATGACCAAAGCTGCC & AB508215 & $59^{\circ} \mathrm{C}$ & Ohara et al., 2005 & $90-140$ \\
\hline Sequ 230 & CTCCAGAAACGCCACATAAC & AAGCAAACCGCACAAGTAGG & AB508202 & $59^{\circ} \mathrm{C}$ & Ohara et al., 2005 & $150-165$ \\
\hline Sdu 10 & ССААGTССТССGСТАСТАССАТ & CCTTGTGGATGACCTGTTTG & DQ468090 & $59^{\circ} \mathrm{C}$ & Renshaw et al., 2006 & $250-310$ \\
\hline Sdn 06 & GGGTTTGTGCTGTGAGTG & TCCGTCTGTCTTTTCCTGT & N/A & $59^{\circ} \mathrm{C}$ & Nugroho \& Taniguchi, 1999 & $300-330$ \\
\hline
\end{tabular}




\section{Results}

A total of 3170 YSL were assigned to parental pairs during the 2013 spawning season, and 2789 YSL were assigned from the 2014 spawning season, with $100 \%$ assignment. All microsatellite loci were in Hardy-Weinberg Equilibrium for 2013 and 2014, with allelic variation of $7-22$ alleles per locus (Table 2). Fish masses from 2013 and 2014 were normally distributed $(\mathrm{P}=0.11-$ 0.91). Spawns occurred approximately every 6 days, and were usually average 900,000 - 1.6 million total eggs (standard deviation: 700,000 - 1 million eggs; Figure 1). In 2013, the largest spawn was on April 22 with 3.65 million spawned eggs from three females. For the 2014 spawning season, the largest spawn was from May 12, with 3 million total eggs being spawned by three females. No significant correlation was found between spawning occurrence and environmental parameters (water temperature, lunar cycle, or day length) for the $2013(\mathrm{P}=0.5539-0.9276)$ or the $2014(\mathrm{P}=0.1457-0.8794)$ spawning season. During these two spawning seasons, female 083-026-609 had the highest contribution of offspring, with $>1000$ YSL assignment, or $\sim 40 \%$ of the total fertilized eggs during these years (Figure 2), an estimated 23 - 27 million eggs in total from this one female.

\section{Brood fish contributions during 2013 and 2014}

During both spawning seasons multiple males contributed to each spawn in roughly equal proportions to each other; typically $2-15$ (average: 9, standard deviation: 1.9) males contributed to a spawn. Of the larger males, male 083-101080, consistently contributed far less than the other males. The older brood fish 
demonstrated proportional contribution of paternity in visually similar patterns across both spawning seasons (Figure 2). Overall, the younger brood fish that were added at the end of 2013 (i.e. wild-caught fish from 2012) did not participate at similar levels of the older broodstock. During 2014, only 9.6\% of the offspring were produced by younger females, and $14.6 \%$ of offspring from younger males. The effective population for males $\left(\mathrm{Ne}_{m}\right)$ during the 2013 spawning season was 8.63, and the effective population for males and females $\left(N_{e}\right)$ for 2013 was 12.46 (Table 3). During 2014, $N e_{m}$ was 9.79 and $N_{e}$ was 13.24 (Table 4). With the exception of female 057-815-612 and male 057-790-030, all other newly added fish had $<100$ YSL assigned over the entire spawning season.

The male contribution to offspring was more equal than female contribution in 2013 when analyzed by individual spawning event (Figure 6). This was supported statistically $(\mathrm{P}>0.05)$, as the male distribution did not differ significantly from equal contribution. This is visualized by heat map colors being various shades of lighter grays indicating that males contributed on average $9.03 \%$ of offspring per spawn (Figure 6). On average 5.87 males (range $=1.67$ 12.37), contributed during each spawn in 2013 (Table 3). Spawning patterns for older brood fish males were similar in both the 2013 and 2014 spawning seasons, however, the younger males that were added to the 2014 brood fish population showed lower overall participation per spawn (Figure 8). In 2014 on average 6.24 males (range 2.77-9.73) participated in spawn events in 2014 (Table 4), with newly added males not participating in 30-93\% of the spawning events as illustrated by the white colored cells ( $0 \%$ contribution) in Figure 8. During the 
2014 spawning season, male number 083-042-784 was culled from the system on August 1 so it was no longer a possible sire after this date (Figure 8). For both males and females, during the 2014 season only, values of $0 \%$ contribution did not differ significantly from equal contribution $(\mathrm{P}>0.05$; blank cells in Figures 7 $-8)$. The numbers of contributing females and males, and the weighted value as a calculated effective population, are presented for each spawn, and entire spawning season, in Tables 3 and 4.

Overall contribution from female 083-027-609 was highest in terms of proportion of YSL assigned, and when standardized to total number of eggs during the spawning year for both 2013 and 2014, at 40\% (Figure 3). This female was also the most consistent in spawn interval timing, with her mean and median spawning interval being 5.2 and 5 days, respectively, in 2013. Female 061-621-862 had a mean and median spawning interval of 11.4 and 11 days, and female 083-103-352 was 6.8 and 7 days. This agrees with the most common female frequency of spawning interval and median spawning interval being $5-10$ days, during 2013 (Figure 4, Table 5). All other female spawning mean and median intervals differed by $>4$ days. These three females also participated in the most spawning events - 32 for female 083-027-609, 16 for female 061-621-862, and 20 for female $083-103-352$. The effective population for females $\left(N e_{f}\right)$ for the entire 2013 spawning season was 4.87 (Table 2), which is $\sim 3$ less than the total number of female fish in the system.

During the 2014 spawning season, female 083-027-609 spawned 28 times at an average spawning interval of 6.3 days. Female $083-026-876$ was the second 
highest contributing female with $14.8 \%$ of YSL assigned, with 13 spawns at an average interval of 6 days. However, spawning intervals for most females during the 2014 season were closer together than observed in 2013 , typically $1-5$ days (Figure 4). The mean and median spawning intervals for females during 2014 were the same at $\sim 19$ days (Table 5). The differences between mean and median female spawning interval timing from 2014 were more varied than the 2013 year. For the 2014 spawning season, three females did not contribute to any of the spawns, all being from the younger brood fish added that year. These were females 057-816-535, 057-798-784, and 008-362-851 (Figure 3). Despite 10 new females being added to the system, the observed effective female population size $\left(N e_{f}\right)$ from 2014 ( 5.0) was similar to that of 2013 (Tables 3 and 4). During this year, female 061-621-862 only had 10.6\% of the total YSL assigned, but in terms of total number of eggs was the second highest contributing female, at $20.1 \%$ total eggs. Out of the newly added fish, the female that contributed the most in terms of proportion of YSL and total eggs was female $057-815-612$, at $8.2 \%$ and $2.7 \%$ respectively. Three of the newly added females did not contribute any offspring throughout the entire season.

Analysis of individual spawning events, as opposed to annual contribution, indicated a primary female per spawn for the 2013 and 2014 spawning season (Figures 6 and 7). This is shown with colors for the female brood fish being mostly either $100 \%$ contribution (black) or $0 \%$ contribution (white). This agrees with the calculated $N e_{f}$ for a spawning event, being on average 1.37 females per spawn in 2013 (Tables 3 and 5) and 1.21 in 2014 
(Tables 4 and 5). Values at or near 100\% (Figures 6 and 7) were also significantly different than equal contribution $(* * * ; \mathrm{P}<0.0001)$ for both spawning seasons. During 2014, female 061-363-804 was culled from the system on July 18 (Figure 7).

Female mass and fecundity

Mean mass of the older females was $20.75 \mathrm{~kg}$ (range $14.6-27.2 \mathrm{~kg}$ ). The mean mass of the newly added females from the 2014 spawning was $8.44 \mathrm{~kg}$ (range 4.28 - $13.54 \mathrm{~kg}$; Figure 5). The older females did not significantly increase their mass over the two years $(\mathrm{P}=0.45-0.66)$. The smaller females added in 2014 all increased significantly in mass $(\mathrm{P}<0.0001)$. Annual and batch fecundity was not significantly correlated to female mass for the 2013 spawning year $(\mathrm{P}=$ 0.50 - 0.62). Each female from 2013 spawned on average 420,000 eggs/female $\mathrm{kg} /$ year during the season, for an annual total of approximately 8.2 million eggs per female. Female masses and both annual and batch fecundity were significantly, and positively correlated during the 2014 spawning year (respectively, $\rho=0.753-0.739 ; \mathrm{P}=0.0003-0.00045$ ). Annual fecundity of the older brood fish from 2014 was 330,000 eggs/female kg/year, but only 23,000 eggs/female kg/year for the newly added females. This resulted in each older female contributing a total of 6.8 million eggs in 2014 and only a total of 200,000 eggs per female from the smaller females. Female batch fecundity from 2013 and 2014 did not correlate with days between spawning events (spawning intervals; $\mathrm{P}$ $>0.251)$. 
When analyzed by spawning event, proportional contribution can be extrapolated into batch fecundity. Batch fecundity per female from 2013 is on average 460,000 eggs/spawn, and from 2014 on average 250,000 eggs/spawn (Table 4). However, when the 2014 year was broken down into older females $(\sim 20 \mathrm{~kg})$ vs. newly added females $(\sim 8 \mathrm{~kg})$, batch fecundity is on average 520,000 and 35,000 eggs, respectively. These values were calculated using only data available from when females spawned (e.g. ignoring days when individual females did not participate). 
Figure 1: Total number of eggs volumetrically calculated from each spawn throughout the 2013 (A) and 2014 (B) spawning season. Dates of spawning season are along the $\mathrm{X}$-axis. Overlaid on top of spawn volume, are day length (dashed line) and water temperature (solid line), both values are represented on the secondary Y-axis. Circles represent lunar cycles, both new moon (white/empty) and full moon (black). 

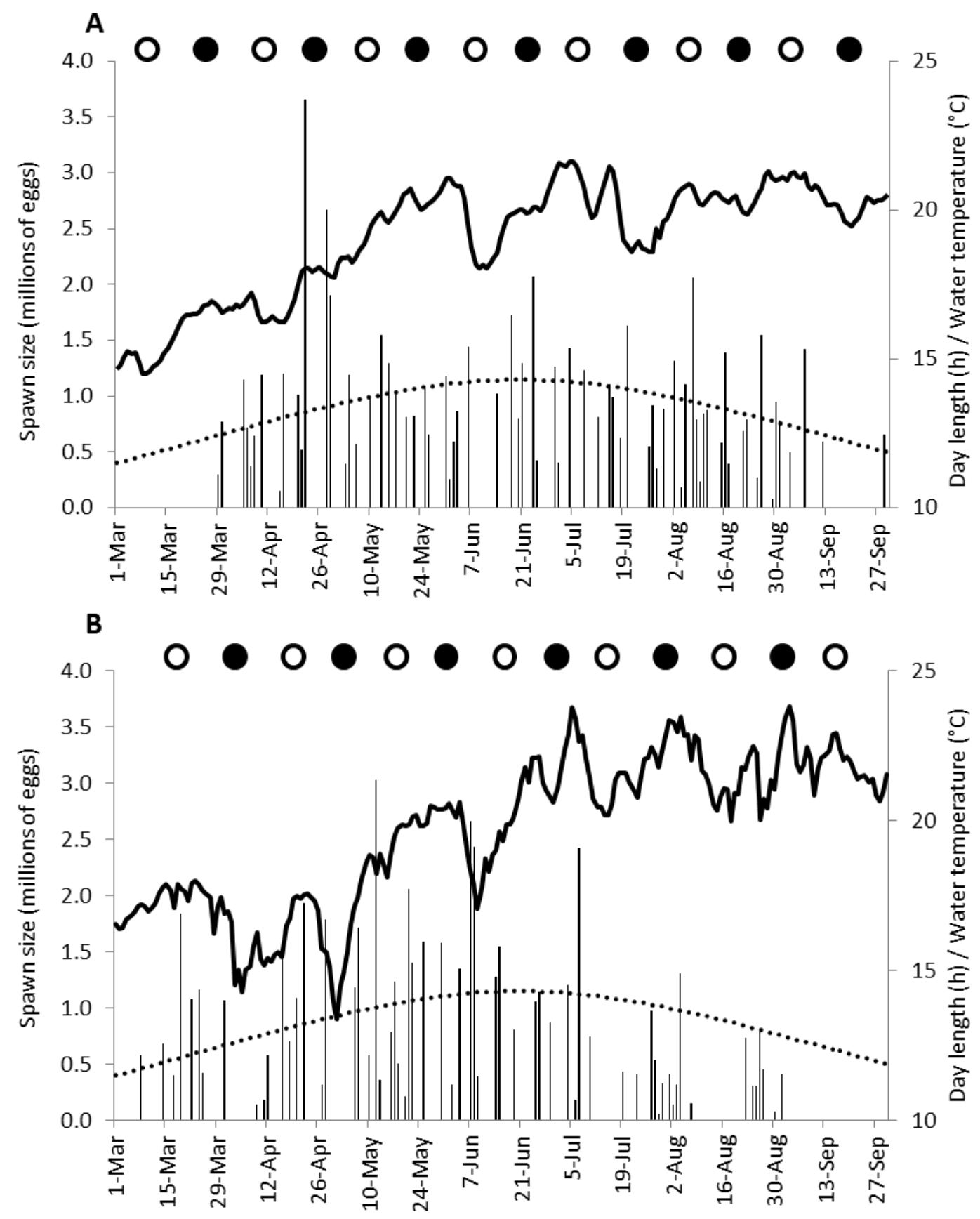
Figure 2: Total number of YSL assigned to each broodstock CYT, from the 2013 (A), and the 2014 (B) spawning season. All brood fish are listed by pit-tag number, with females in black and males in gray. For the 2014 spawning season, additional brood fish were added to the tank. In 2013, there was a total 3170 YSL assigned, and 2789 YSL from 2014. 

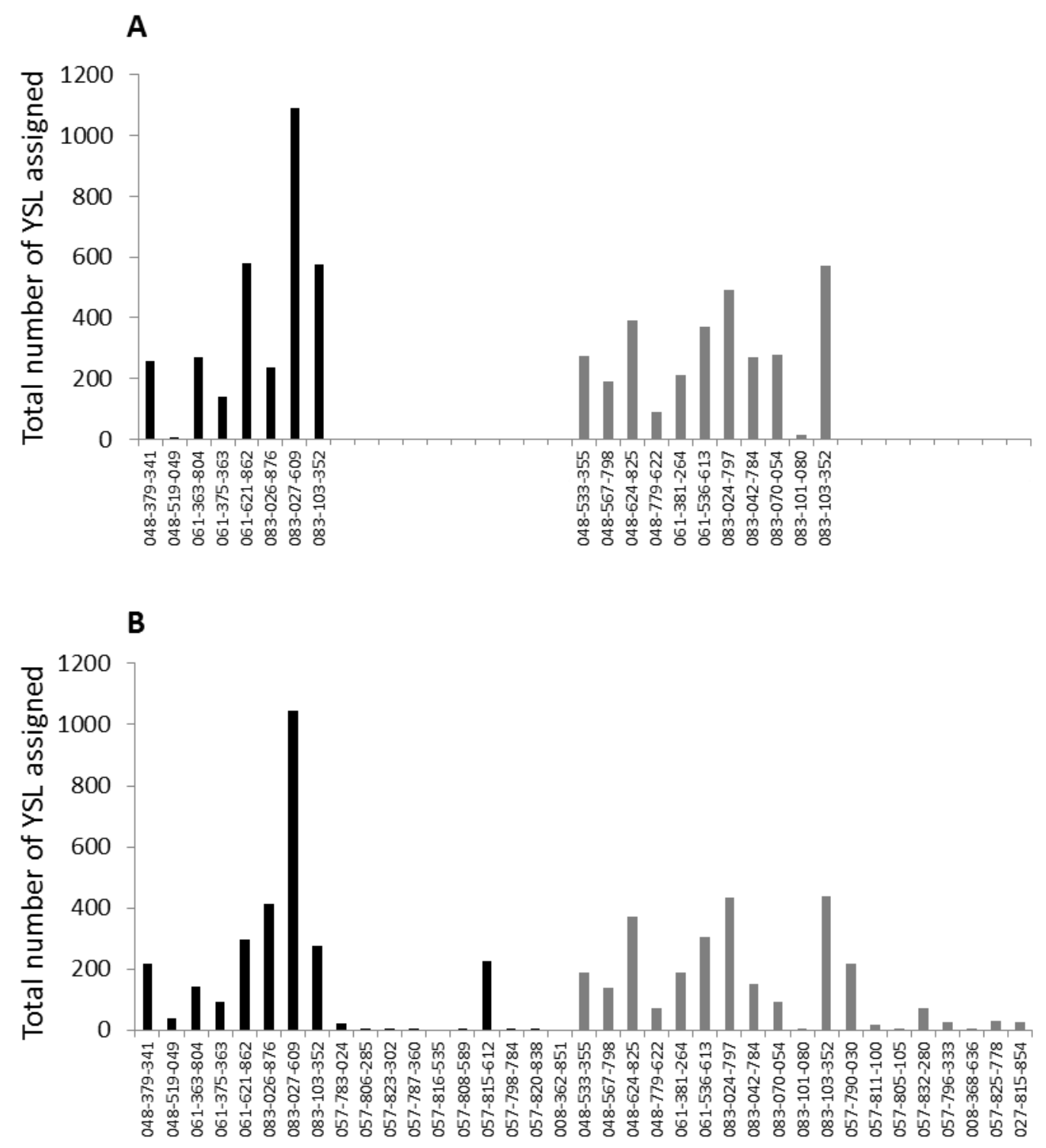
Figure 3: Proportions of $n=47$ YSL (gray) and percentage from total eggs (black) assigned to each potential broodstock female, from the 2013 (A) and the 2014 (B) spawning season. Differences between proportions attributed to uneven egg totals from each spawning event. All fish are listed by pit-tag number. 

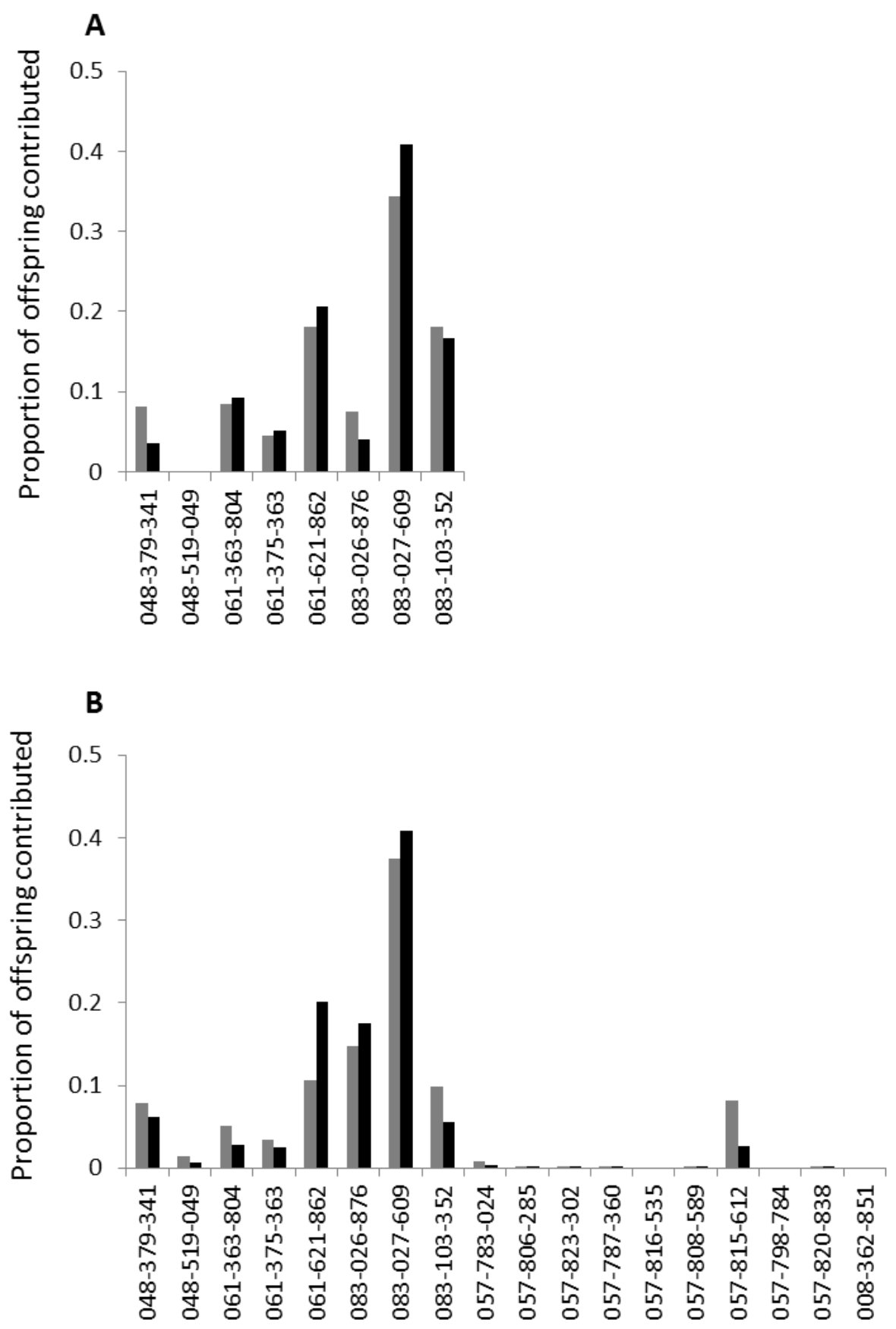
Figure 4: Frequency of female spawning intervals during the entire 2013 (black) and 2014 (gray) season, as explained by the intervals in individual female spawning. For both seasons, female intervals are binned by 5 days until day 20 , then by 10 days. 


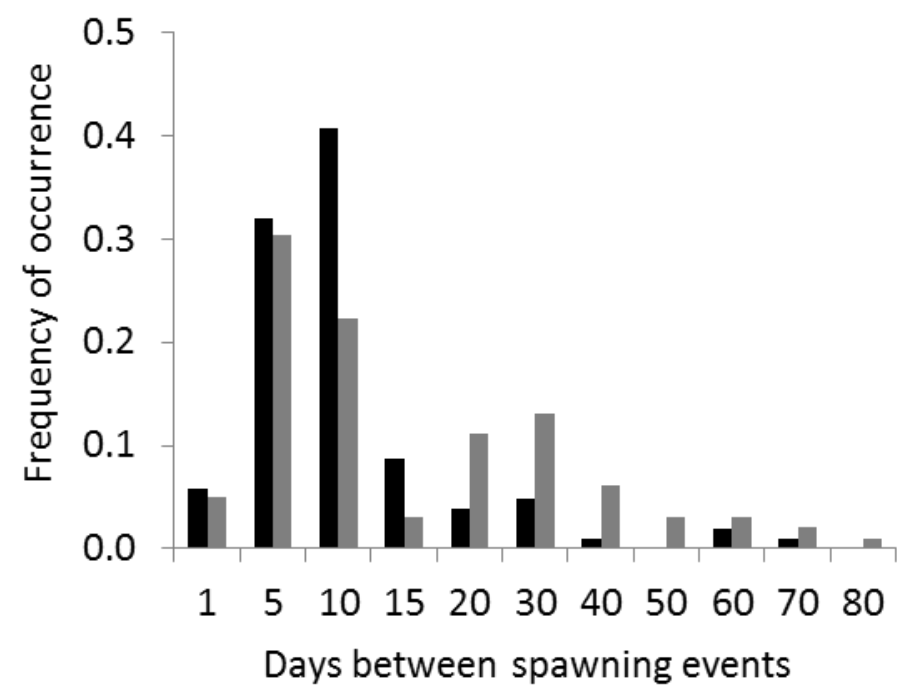


Figure 5: Proportional contribution of total eggs from each female from the 2013 (A) and 2014 (B) spawning seasons, as a function of average mass (kg). Original female brood fish (from both 2013 and 2014) are represented in black, with the added females from the 2014 spawning season in gray. 

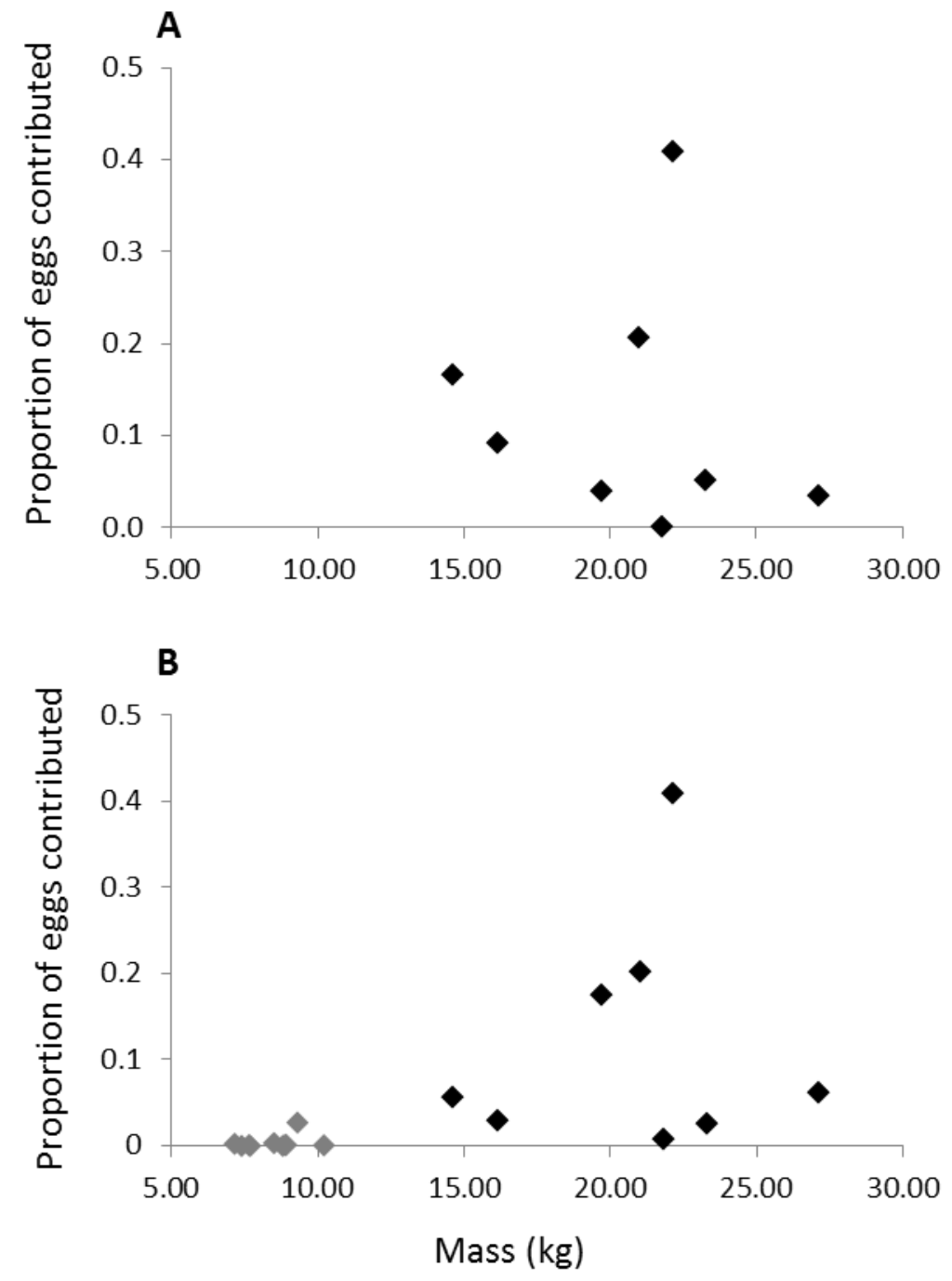
Figure 6: Proportion contribution to individual spawn for each fish from the 2013 spawning season, where black indicates $100 \%$ spawn contribution, and white indicating $0 \%$ contribution. Dates of spawn are given as yyyymmdd (first column), and all fish are represented by pit-tag number. Symbols within each cell indicate significance from binomial tests for females (red) and males (blue), evaluating whether observed parental contribution differs significantly from equal contribution, where blank cells are not significance, $* *=0.05>\mathrm{P}>0.0001$, and $* * *=\mathrm{P}<0.0001$. 


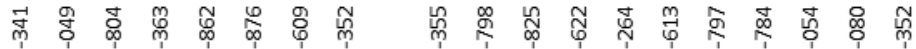

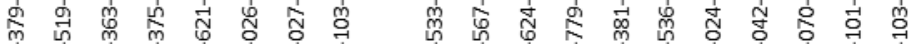

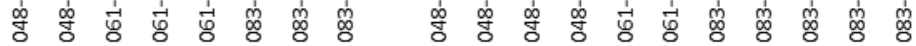

20130329

20130330

20130405

20130406

20130407

20130408

20130410

20130415

20130416

20130420

20130421

20130422

20130428

20130429

20130503

20130504

20130506

20130510

20130513

20130515

20130517

20130520

20130522

20130525

20130526

20130531

20130601

20130602

20130603

20130606

20130614

20130618

20130620

20130621

20130624

20130701

20130704

20130708

20130712

20130715

20130716

20130718

20130720

20130723

20130726

20130727

20130728

20130802

20130804

20130805

20130807

20130808

20130809

20130810

20130811

20130815

20130816

20130817

20130821

20130822

20130825

20130826

20130830

20130831

20130903

20130907

20130912

20130929

Total

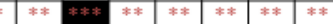

\begin{tabular}{lllllllll} 
& $* * *$ & $* *$ & $* *$ & $* *$ & $* *$ & $* *$ & $* * *$ & $* *$ \\
\hline$*$ & $*$ & $* *$ & $* *$ & $* * *$ & $* *$ & $* *$ & $* *$ \\
\hline
\end{tabular}

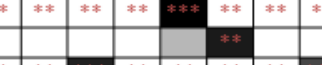

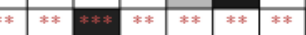

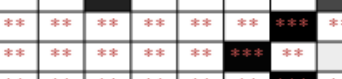

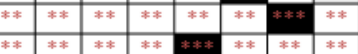

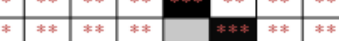

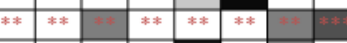

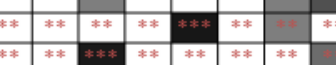

\begin{tabular}{|l|l|l|l|l|l|l|l|}
\hline$* *$ & $* *$ & $* * *$ & $* *$ & $* *$ & $* *$ & $* *$ & \\
\hline$* *$ & $* *$ & $* *$ & $* *$ & $* *$ & $* * *$ & $* *$ & $* *$ \\
\hline
\end{tabular}

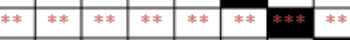

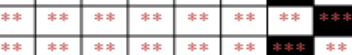
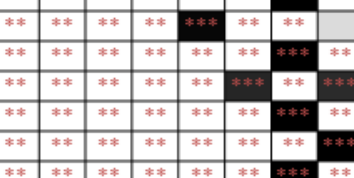

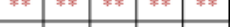
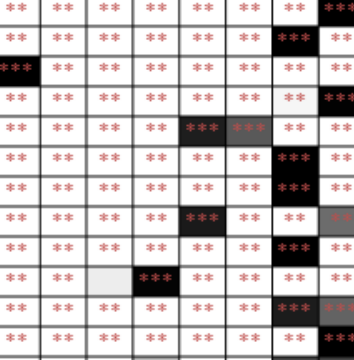

\begin{tabular}{l|l|l|l|l|l|}
$* * *$ & $* *$ & $* *$ & & $* *$ & $* *$ \\
\hline & $* *$ & $* *$ & $* *$ & $* *$ & $* *$
\end{tabular}

\begin{tabular}{l|l|l|l|l|l|}
$* * *$ & $* *$ & $* *$ & $* *$ & $* *$ & $* *$ \\
\hline$* *$ & $* * *$ & $* *$ & $* *$ & $* *$ & $* *$ \\
\hline
\end{tabular}

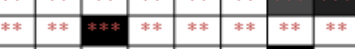

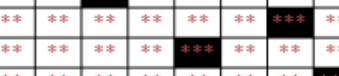
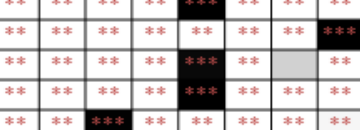

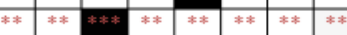
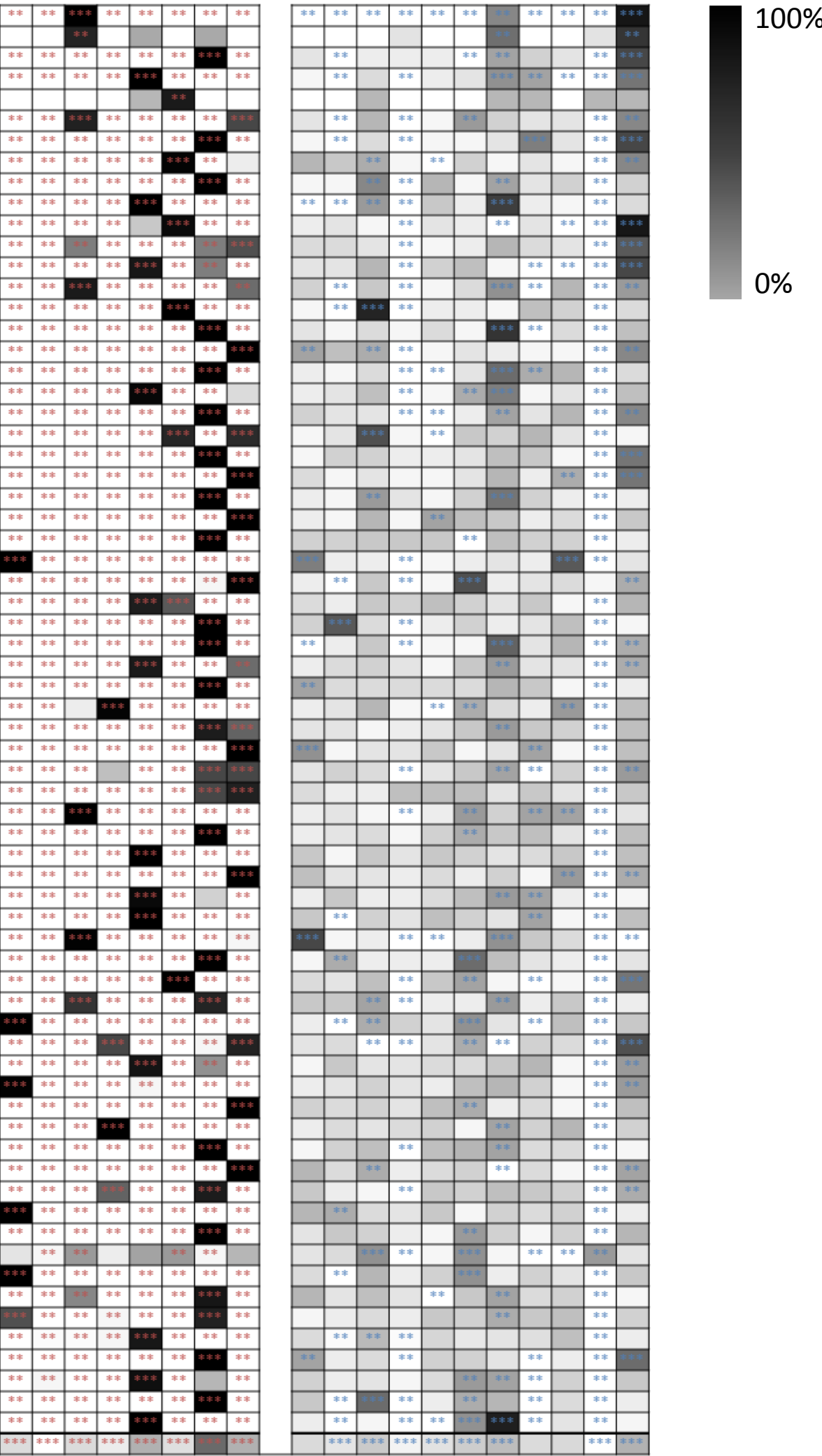
Figure 7: Proportion contribution to individual spawn for female fish from the 2014 spawning season, where black indicates $100 \%$ spawn contribution, and white indicating $0 \%$ contribution. Dates of spawn are given as yyyymmdd (first column), and all fish are represented by pit-tag number. Symbols within each cell indicate significance from binomial tests, evaluating whether observed parental contribution differs significantly from equal contribution, where blank cells are not significance, $* *=0.05>\mathrm{P}>0.0001$, and $* * *=\mathrm{P}<0.0001$. 


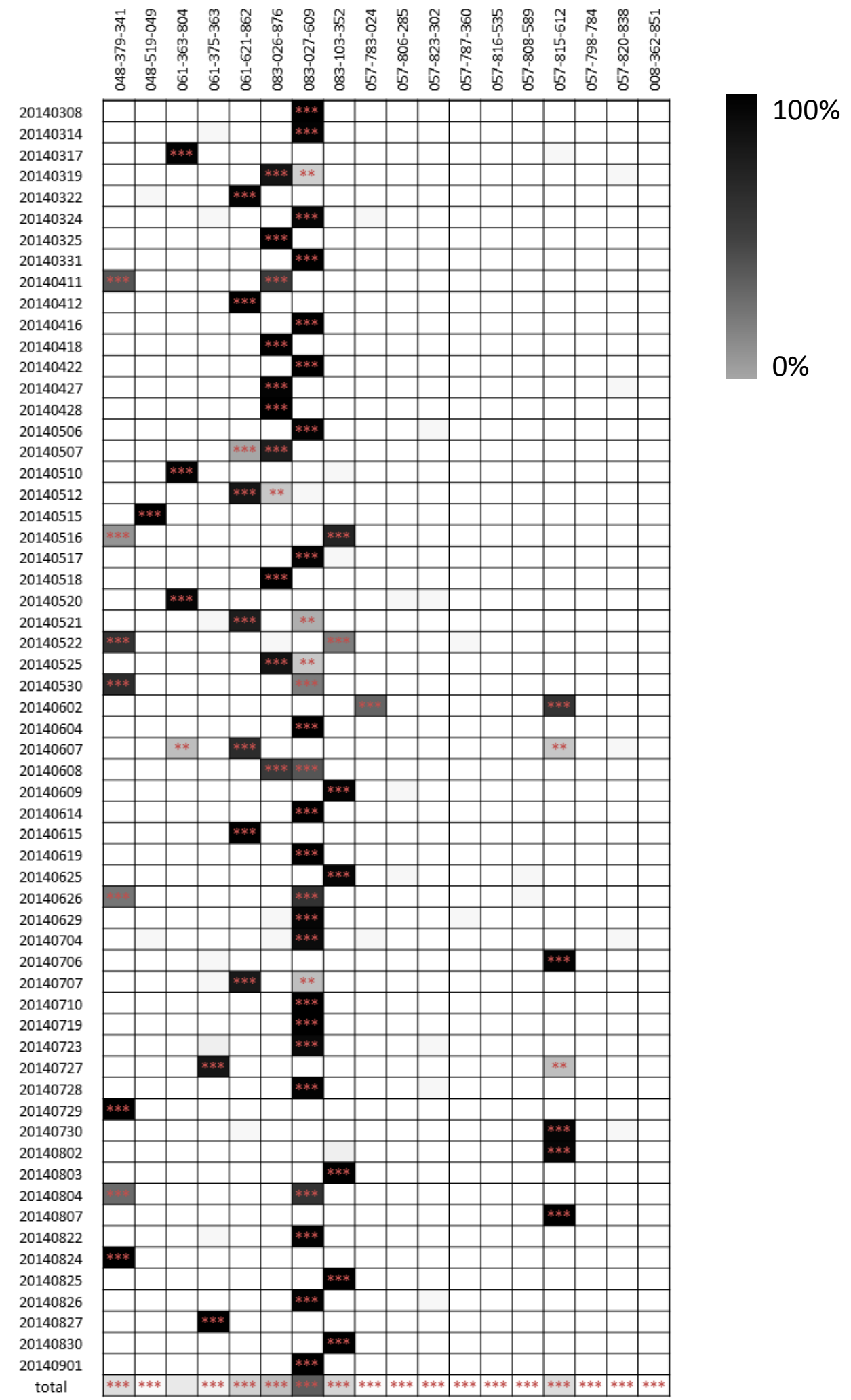


Figure 8: Proportion contribution to individual spawn for male fish from the 2014 spawning season, where black indicates $100 \%$ spawn contribution, and white indicating $0 \%$ contribution. Dates of spawn are given as yyyymmdd (first column), and all fish are represented by pit-tag number. Symbols within each cell indicate significance from binomial tests, evaluating whether observed parental contribution differs significantly from equal contribution, where blank cells are not significance, $* *=0.05>\mathrm{P}>0.0001$, and $* * *=\mathrm{P}<0.0001$. 


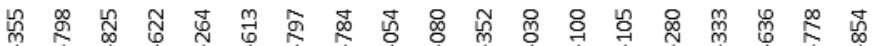

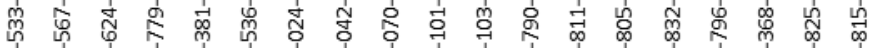

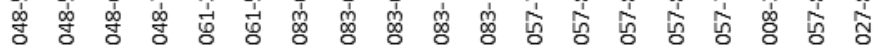

20140308

20140314

20140317

20140319

20140322

20140324

20140325

20140331

20140411

20140412

20140416

20140418

20140422

20140427

20140428

20140506

20140507

20140510

20140512

20140515

20140516

20140517

20140518

20140520

20140521

20140522

20140525

20140530

20140602

20140604

20140607

20140608

20140609

20140614

20140615

20140619

20140625

20140626

20140629

20140704

20140706

20140707

20140710

20140719

20140723

20140727

20140728

20140729

20140730

20140802

20140803

20140804

20140807

20140822

20140824

20140825

20140826

20140827

20140830

20140901

total
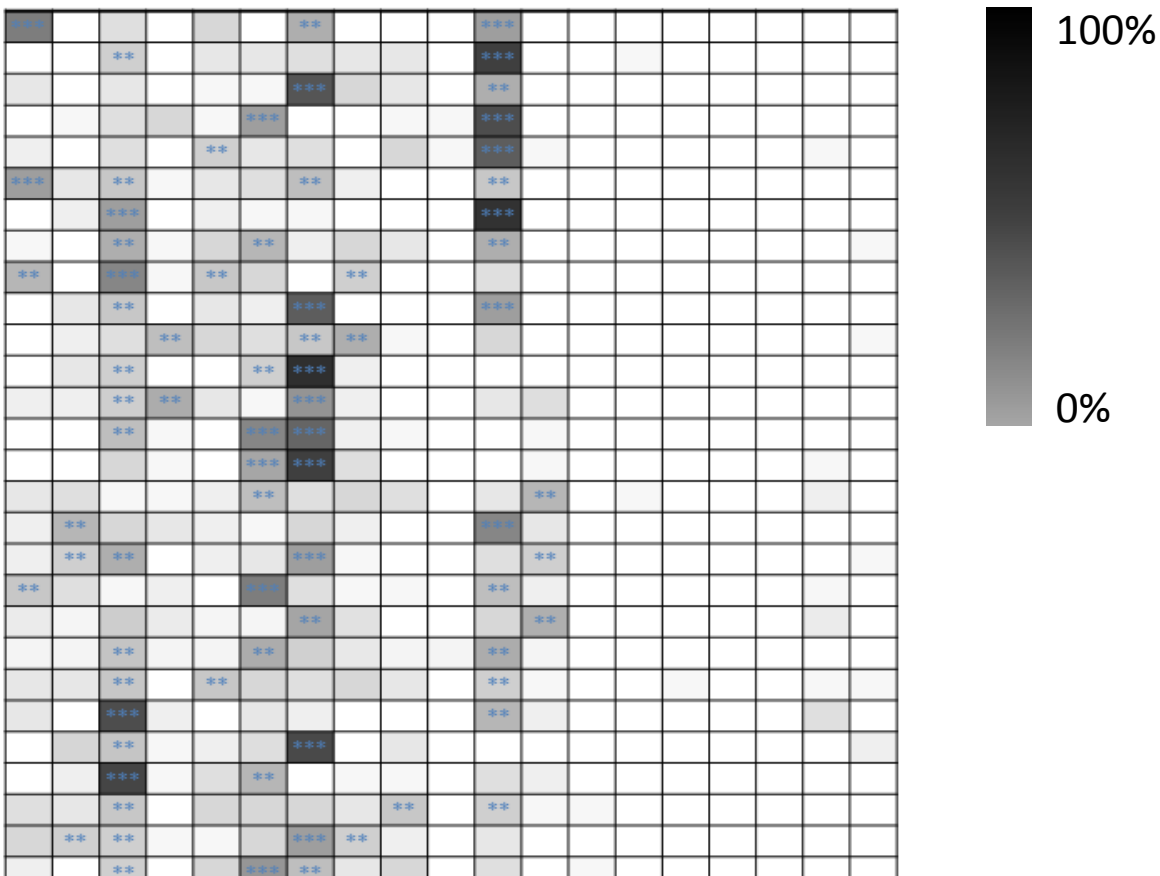

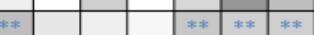
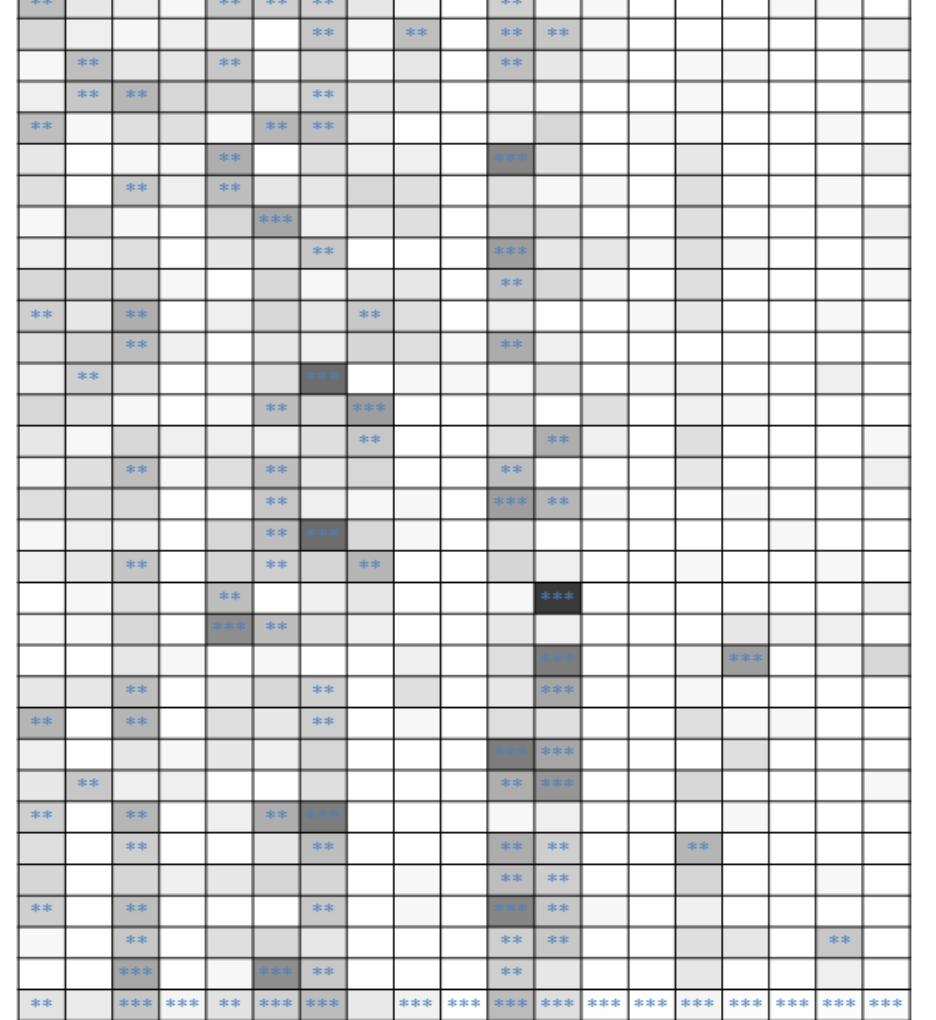
Table 2: Summary statistics for microsatellite loci including repeat motif, allele

number allele number $(\mathrm{k})$, total number of fish genotyped $(\mathrm{N})$, observed (HObs) and expected (HExp) heterozygosity, and conformance to Hardy-Weinberg equilibrium (HWE). 
Table 2: Genetic statistics from each spawning season (2013 / 2014)

\begin{tabular}{ccccccc}
\hline Locus & Repeat & $\mathrm{k}$ & $\mathrm{N}$ & HObs & HExp & HWE \\
\hline Sequ 38 & GT & $20 / 21$ & $3190 / 2725$ & $0.858 / 0.868$ & $0.892 / 0.892$ & NS / NS \\
Sequ 77 & CA & $17 / 23$ & $3181 / 2793$ & $0.814 / 0.821$ & $0.892 / 0.887$ & NS / NS \\
Sdu gA3D & GT & $12 / 19$ & $3183 / 2818$ & $0.891 / 0.888$ & $0.859 / 0.871$ & NS / NS \\
Sdu 46 & GA & $13 / 14$ & $3101 / 2795$ & $0.646 / 0.668$ & $0.636 / 0.659$ & NS / NS \\
Sdu 4 & $\wedge$ & $7 / 10$ & $3119 / 2821$ & $0.568 / 0.544$ & $0.566 / 0.534$ & NS / NS \\
Sequ 320 & CA & $19 / 21$ & $3182 / 2816$ & $0.918 / 0.908$ & $0.889 / 0.890$ & NS / NS \\
Sequ 230 & CA & $8 / 8$ & $3192 / 2828$ & $0.709 / 0.689$ & $0.664 / 0.648$ & NS / NS \\
Sdu 10 & GAA & $13 / 15$ & $3153 / 2820$ & $0.738 / 0.747$ & $0.758 / 0.747$ & NS / NS \\
Sdn 06 & GATA & $17 / 22$ & $3085 / 2819$ & $0.850 / 0.853$ & $0.830 / 0.853$ & NS / NS \\
All loci & & $\mathbf{1 4 / 1 7}$ & $\mathbf{3 1 9 6 / 2 9 0 2}$ & $\mathbf{0 . 7 7 6 7 / 0 . 7 7 5 7}$ & $\mathbf{0 . 7 7 6 1 / 0 . 7 5 2 6}$ &
\end{tabular}

^ Repeat motif for Sdu 4: GACA,GGCA,GACA 
Table 3: Spawn date, census and effective broodstock populations for females $\left(n_{f} /\right.$ $\left.N e_{f}\right)$, males $\left(n_{m} / N e_{m}\right)$ and both sexes $\left(n_{e} / N e\right)$ for the 2013 spawning season. 
Table 3: 2013 census $(n)$ and effective $(\mathrm{Ne})$ breeding size per spawn.

\begin{tabular}{|c|c|c|c|c|c|c|}
\hline idd & $n_{f}$ & $N e_{f}$ & $n_{m}$ & $N e_{m}$ & $n_{e}$ & $N_{0}$ \\
\hline 20130329 & 1.00 & 1.00 & 2.00 & 1.67 & 3.00 & 2.50 \\
\hline 20130330 & 3.00 & 2.74 & 4.00 & 2.96 & 7.00 & 5.70 \\
\hline 20130405 & 1.00 & 1.00 & 8.00 & 3.98 & 9.00 & 3.20 \\
\hline 20130406 & 1.00 & 1.00 & 7.00 & 4.43 & 8.00 & 3.26 \\
\hline 20130407 & 2.00 & 2.12 & 5.00 & 7.20 & 7.00 & 6.55 \\
\hline 20130408 & 2.00 & 1.96 & 8.00 & 5.43 & 10.00 & 5.75 \\
\hline 20130410 & 1.00 & 1.00 & 8.00 & 3.49 & 9.00 & 3.11 \\
\hline 20130415 & 2.00 & 1.09 & 9.00 & 5.71 & 11.00 & 3.66 \\
\hline 20130416 & 1.00 & 1.00 & 9.00 & 5.59 & 10.00 & 3.39 \\
\hline 20130420 & 1.00 & 1.00 & 7.00 & 3.55 & 8.00 & 3.12 \\
\hline 20130421 & 2.00 & 1.29 & 7.00 & 1.96 & 9.00 & 3.11 \\
\hline 20130422 & 3.00 & 2.93 & 9.00 & 4.81 & 12.00 & 7.29 \\
\hline 20130428 & 2.00 & 1.72 & 7.00 & 3.97 & 9.00 & 4.80 \\
\hline 20130429 & 2.00 & 1.82 & 7.00 & 5.43 & 9.00 & 5.44 \\
\hline 20130503 & 1.00 & 1.00 & 8.00 & 3.05 & 9.00 & 3.01 \\
\hline 20130504 & 1.00 & 1.00 & 9.00 & 3.73 & 10.00 & 3.15 \\
\hline 20130506 & 1.00 & 1.00 & 9.00 & 5.32 & 10.00 & 3.37 \\
\hline 20130510 & 1.00 & 1.00 & 8.00 & 4.94 & 9.00 & 3.33 \\
\hline 20130513 & 2.00 & 1.18 & 9.00 & 5.54 & 11.00 & 3.90 \\
\hline 20130515 & 1.00 & 1.00 & 8.00 & 5.68 & 9.00 & 3.40 \\
\hline 20130517 & 2.00 & 2.00 & 9.00 & 4.36 & 11.00 & 5.48 \\
\hline 20130520 & 1.00 & 1.00 & 10.00 & 5.83 & 11.00 & 3.41 \\
\hline 20130522 & 1.00 & 1.00 & 10.00 & 5.37 & 11.00 & 3.37 \\
\hline 20130525 & 1.00 & 1.00 & 10.00 & 5.27 & 11.00 & 3.36 \\
\hline 20130526 & 1.00 & 1.00 & 10.00 & 7.10 & 11.00 & 3.51 \\
\hline 20130531 & 1.00 & 1.00 & 9.00 & 8.46 & 10.00 & 3.58 \\
\hline 20130601 & 1.00 & 1.00 & 9.00 & 3.98 & 10.00 & 3.20 \\
\hline 20130602 & 2.00 & 1.04 & 9.00 & 4.31 & 11.00 & 3.36 \\
\hline 20130603 & 2.00 & 1.90 & 10.00 & 8.34 & 12.00 & 6.18 \\
\hline 20130606 & 1.00 & 1.00 & 9.00 & 4.83 & 10.00 & 3.31 \\
\hline 20130614 & 1.00 & 1.00 & 8.00 & 4.55 & 9.00 & 3.28 \\
\hline 20130618 & 2.00 & 1.82 & 10.00 & 7.10 & 12.00 & 5.78 \\
\hline 20130620 & 1.00 & 1.00 & 10.00 & 7.75 & 11.00 & 3.54 \\
\hline 20130621 & 2.00 & 1.09 & 9.00 & 6.33 & 11.00 & 3.72 \\
\hline 20130624 & 2.00 & 1.86 & 10.00 & 7.39 & 12.00 & 5.94 \\
\hline 20130701 & 1.00 & 1.00 & 10.00 & 6.15 & 11.00 & 3.44 \\
\hline 20130704 & 3.00 & 2.60 & 8.00 & 6.48 & 11.00 & 7.43 \\
\hline 20130708 & 2.00 & 1.96 & 10.00 & 8.46 & 12.00 & 6.36 \\
\hline 20130712 & 1.00 & 1.00 & 9.00 & 5.92 & 10.00 & 3.42 \\
\hline 20130715 & 1.00 & 1.00 & 10.00 & 7.92 & 11.00 & 3.55 \\
\hline 20130716 & 1.00 & 1.00 & 10.00 & 8.73 & 11.00 & 3.59 \\
\hline 20130718 & 1.00 & 1.00 & 10.00 & 6.92 & 11.00 & 3.50 \\
\hline 20130720 & 2.00 & 1.23 & 10.00 & 6.52 & 12.00 & 4.15 \\
\hline 20130723 & 1.00 & 1.00 & 9.00 & 7.29 & 10.00 & 3.52 \\
\hline 20130726 & 2.00 & 1.04 & 7.00 & 3.65 & 9.00 & 3.25 \\
\hline 20130727 & 1.00 & 1.00 & 10.00 & 5.25 & 11.00 & 3.36 \\
\hline 20130728 & 1.00 & 1.00 & 8.00 & 5.05 & 9.00 & 3.34 \\
\hline
\end{tabular}


Table 3: Continued

\begin{tabular}{ccccccc} 
yyyymmdd & $n_{f}$ & $N e_{f}$ & $n_{m}$ & $N e_{m}$ & $n_{e}$ & $N_{e}$ \\
\hline 20130802 & 2.00 & 1.99 & 9.00 & 6.40 & 11.00 & 6.08 \\
20130804 & 1.00 & 1.00 & 8.00 & 6.19 & 9.00 & 3.44 \\
20130805 & 3.00 & 2.05 & 7.00 & 4.27 & 10.00 & 5.54 \\
20130807 & 2.00 & 1.61 & 10.00 & 7.15 & 12.00 & 5.27 \\
20130808 & 2.00 & 1.04 & 10.00 & 7.10 & 12.00 & 3.64 \\
20130809 & 1.00 & 1.00 & 10.00 & 8.03 & 11.00 & 3.56 \\
20130810 & 1.00 & 1.00 & 10.00 & 7.75 & 11.00 & 3.54 \\
20130811 & 1.00 & 1.00 & 9.00 & 6.88 & 10.00 & 3.49 \\
20130815 & 1.00 & 1.00 & 9.00 & 6.84 & 10.00 & 3.49 \\
20130816 & 2.00 & 1.86 & 9.00 & 7.54 & 11.00 & 5.96 \\
20130817 & 1.00 & 1.00 & 10.00 & 7.97 & 11.00 & 3.55 \\
20130821 & 1.00 & 1.00 & 10.00 & 7.10 & 11.00 & 3.51 \\
20130822 & 8.00 & 5.25 & 8.00 & 4.96 & 16.00 & 10.20 \\
20130825 & 1.00 & 1.00 & 9.00 & 6.76 & 10.00 & 3.48 \\
20130826 & 2.00 & 1.67 & 9.00 & 7.15 & 11.00 & 5.41 \\
20130830 & 3.00 & 2.02 & 10.00 & 7.97 & 13.00 & 6.46 \\
20130831 & 4.00 & 2.03 & 10.00 & 12.73 & 14.00 & 6.99 \\
20130903 & 1.00 & 1.00 & 8.00 & 5.03 & 9.00 & 3.34 \\
20130907 & 3.00 & 1.46 & 9.00 & 6.55 & 12.00 & 4.79 \\
20130912 & 1.00 & 1.00 & 7.00 & 4.79 & 8.00 & 3.31 \\
20130929 & 1.00 & 1.00 & 6.00 & 2.34 & 7.00 & 2.80 \\
\hline Total & 8.00 & 4.87 & 11.00 & 8.63 & 19.00 & 12.46 \\
\hline & & & & & & \\
Average & 1.63 & 1.37 & 8.65 & 5.87 & 10.28 & 4.25 \\
Std. dev. & 1.06 & 0.69 & 1.53 & 1.88 & 1.79 & 1.45 \\
Min & 1.00 & 1.00 & 2.00 & 1.67 & 3.00 & 2.50 \\
Max & 8.00 & 5.25 & 10.00 & 12.73 & 16.00 & 10.20 \\
Median & 1.00 & 1.00 & 9.00 & 5.77 & 11.00 & 3.51
\end{tabular}


Table 4: Spawn date, census and effective broodstock populations for females $\left(n_{f} /\right.$ $\left.N e_{f}\right)$, males $\left(n_{m} / N e_{m}\right)$ and both sexes $\left(n_{e} / N_{e}\right)$ for the 2014 spawning season. 
Table 4: 2014 census $(n)$ and effective $(\mathrm{Ne})$ breeding size per spawn.

\begin{tabular}{ccccccc} 
yyyymmdd & $n_{f}$ & $N e_{f}$ & $n_{m}$ & $N e_{m}$ & $n_{e}$ & $N_{e}$ \\
\hline 20140308 & 1.00 & 1.00 & 5.00 & 4.08 & 6.00 & 3.21 \\
20140314 & 2.00 & 1.04 & 8.00 & 3.32 & 10.00 & 3.18 \\
20140317 & 2.00 & 1.04 & 8.00 & 3.71 & 10.00 & 3.26 \\
20140319 & 3.00 & 1.35 & 8.00 & 3.28 & 11.00 & 3.83 \\
20140322 & 2.00 & 1.04 & 10.00 & 4.34 & 12.00 & 3.36 \\
20140324 & 3.00 & 1.09 & 9.00 & 6.40 & 12.00 & 3.73 \\
20140325 & 1.00 & 1.00 & 6.00 & 2.22 & 7.00 & 2.76 \\
20140331 & 1.00 & 1.00 & 10.00 & 6.37 & 11.00 & 3.46 \\
20140411 & 2.00 & 1.98 & 7.00 & 5.10 & 9.00 & 5.70 \\
20140412 & 1.00 & 1.00 & 6.00 & 3.59 & 7.00 & 3.13 \\
20140416 & 1.00 & 1.00 & 10.00 & 7.34 & 11.00 & 3.52 \\
20140418 & 1.00 & 1.00 & 5.00 & 2.24 & 6.00 & 2.77 \\
20140422 & 1.00 & 1.00 & 10.00 & 6.01 & 11.00 & 3.43 \\
20140427 & 2.00 & 1.04 & 7.00 & 3.36 & 9.00 & 3.19 \\
20140428 & 1.00 & 1.00 & 7.00 & 2.98 & 8.00 & 3.00 \\
20140506 & 2.00 & 1.04 & 13.00 & 8.94 & 15.00 & 3.74 \\
20140507 & 2.00 & 1.56 & 10.00 & 5.71 & 12.00 & 4.90 \\
20140510 & 2.00 & 1.04 & 10.00 & 6.29 & 12.00 & 3.58 \\
20140512 & 3.00 & 1.41 & 11.00 & 5.35 & 14.00 & 4.45 \\
20140515 & 1.00 & 1.00 & 11.00 & 6.88 & 12.00 & 3.49 \\
20140516 & 2.00 & 1.68 & 12.00 & 6.83 & 14.00 & 5.39 \\
20140517 & 2.00 & 1.04 & 13.00 & 9.56 & 15.00 & 3.76 \\
20140518 & 1.00 & 1.00 & 8.00 & 3.62 & 9.00 & 3.13 \\
20140520 & 3.00 & 1.09 & 8.00 & 3.57 & 11.00 & 3.35 \\
20140521 & 3.00 & 1.58 & 9.00 & 3.38 & 12.00 & 4.31 \\
20140522 & 4.00 & 2.01 & 11.00 & 9.02 & 15.00 & 6.57 \\
20140525 & 2.00 & 1.34 & 10.00 & 6.97 & 12.00 & 4.49 \\
20140530 & 2.00 & 1.82 & 9.00 & 6.33 & 11.00 & 5.64 \\
20140602 & 2.00 & 1.93 & 14.00 & 8.87 & 16.00 & 6.34 \\
20140604 & 1.00 & 1.00 & 12.00 & 8.03 & 13.00 & 3.56 \\
20140607 & 4.00 & 2.05 & 15.00 & 9.02 & 19.00 & 6.69 \\
20140608 & 2.00 & 1.98 & 13.00 & 8.87 & 15.00 & 6.47 \\
20140609 & 2.00 & 1.04 & 13.00 & 7.92 & 15.00 & 3.69 \\
20140614 & 1.00 & 1.00 & 11.00 & 5.68 & 12.00 & 3.40 \\
20140615 & 1.00 & 1.00 & 13.00 & 9.73 & 14.00 & 3.63 \\
20140619 & 1.00 & 1.00 & 12.00 & 8.40 & 13.00 & 3.57 \\
20140625 & 3.00 & 1.09 & 13.00 & 7.92 & 16.00 & 3.83 \\
20140626 & 3.00 & 1.95 & 13.00 & 9.73 & 16.00 & 6.51 \\
20140629 & 3.00 & 1.09 & 12.00 & 8.40 & 15.00 & 3.86 \\
\hline & & & & & &
\end{tabular}


Table 4: Continued

\begin{tabular}{ccccccc} 
yyyymmdd & $n_{f}$ & $N e_{f}$ & $n_{m}$ & $N e_{m}$ & $n_{e}$ & $N_{e}$ \\
\hline 20140704 & 5.00 & 1.20 & 11.00 & 7.90 & 16.00 & 4.16 \\
20140706 & 2.00 & 1.04 & 13.00 & 5.20 & 15.00 & 3.48 \\
20140707 & 3.00 & 1.46 & 11.00 & 7.06 & 14.00 & 4.85 \\
20140710 & 1.00 & 1.00 & 13.00 & 8.87 & 14.00 & 3.59 \\
20140719 & 1.00 & 1.00 & 11.00 & 8.09 & 12.00 & 3.56 \\
20140723 & 3.00 & 1.14 & 11.00 & 6.52 & 14.00 & 3.88 \\
20140727 & 2.00 & 1.39 & 10.00 & 4.75 & 12.00 & 4.31 \\
20140728 & 2.00 & 1.04 & 11.00 & 8.14 & 13.00 & 3.70 \\
20140729 & 1.00 & 1.00 & 8.00 & 2.85 & 9.00 & 2.96 \\
20140730 & 3.00 & 1.09 & 12.00 & 6.55 & 15.00 & 3.74 \\
20140802 & 2.00 & 1.09 & 10.00 & 4.79 & 12.00 & 3.55 \\
20140803 & 1.00 & 1.00 & 10.00 & 7.39 & 11.00 & 3.52 \\
20140804 & 2.00 & 1.91 & 11.00 & 7.72 & 13.00 & 6.12 \\
20140807 & 1.00 & 1.00 & 9.00 & 4.96 & 10.00 & 3.33 \\
20140822 & 2.00 & 1.04 & 9.00 & 5.86 & 11.00 & 3.54 \\
20140824 & 1.00 & 1.00 & 8.00 & 4.57 & 9.00 & 3.28 \\
20140825 & 1.00 & 1.00 & 7.00 & 6.19 & 8.00 & 3.44 \\
20140826 & 2.00 & 1.04 & 11.00 & 8.82 & 13.00 & 3.74 \\
20140827 & 1.00 & 1.00 & 8.00 & 5.15 & 9.00 & 3.35 \\
20140830 & 1.00 & 1.00 & 10.00 & 8.53 & 11.00 & 3.58 \\
20140901 & 1.00 & 1.00 & 8.00 & 5.20 & 9.00 & 3.35 \\
\hline Total & 15.00 & 5.00 & 19.00 & 9.79 & 34.00 & 13.24 \\
\hline & & & & & & \\
Average & 1.90 & 1.21 & 10.07 & 6.24 & 11.97 & 3.98 \\
Std. dev. & 0.93 & 0.33 & 2.30 & 2.12 & 2.77 & 1.03 \\
Min & 1.00 & 1.00 & 5.00 & 2.22 & 6.00 & 2.76 \\
Max & 5.00 & 2.05 & 15.00 & 9.73 & 19.00 & 6.69 \\
Median & 2.00 & 1.04 & 10.00 & 6.35 & 12.00 & 3.58
\end{tabular}


Table 5: Summary statistics of effective population sizes for females $\left(\mathrm{Ne}_{f}\right)$, males $\left(N e_{m}\right)$ and both sexes $\left(N_{e}\right)$, as well as estimates of fecundity, and spawning intervals for females across both the 2013 and 2014 spawning seasons. 
Table 5: General genetic statistics from 2013 and 2014 spawning seasons

\begin{tabular}{|ccccccc|}
\hline 2013 & $N e_{f}$ & $N e_{m}$ & $N_{e}$ & $\begin{array}{c}\text { Annual } \\
\text { fecundity } \\
\text { (total eggs) }\end{array}$ & $\begin{array}{c}\text { Batch } \\
\text { fecundity } \\
\text { (eggspawn) }\end{array}$ & $\begin{array}{c}\text { Female } \\
\text { interval } \\
\text { (days) }\end{array}$ \\
\hline Minimum & 1.00 & 1.66 & 2.50 & 55,000 & 18,000 & 1.00 \\
Mean & 1.38 & 5.89 & 4.26 & $8,200,000$ & 460,000 & 11.16 \\
Median & 1.00 & 5.77 & 3.53 & $4,700,000$ & 460,000 & 7.50 \\
Maximum & 5.25 & 12.73 & 10.20 & $27,000,000$ & 790,000 & 64.00 \\
Std. dev. & 0.69 & 1.89 & 1.46 & $8,800,000$ & 250,000 & 4.77 \\
$\mathbf{2 0 1 4}$ & & & & & & \\
Minimum & 1.00 & 2.22 & 2.75 & 0 & 0 & 1.00 \\
Mean & 1.21 & 6.23 & 3.98 & $3,100,000$ & 250,000 & 19.57 \\
Median & 1.04 & 6.31 & 3.58 & 290,000 & 98,000 & 18.64 \\
Maximum & 2.05 & 9.78 & 6.69 & $23,000,000$ & $1,200,000$ & 77.00 \\
Std. dev. & 0.33 & 2.11 & 1.03 & $6,000,000$ & 350,000 & 10.01 \\
\hline
\end{tabular}




\section{Discussion}

All microsatellites loci were in HWE, and $100 \%$ of offspring were assigned to parental pairs using Cervus software. No clear spawning patterns from this system were reasonably attributed to environmental factors, as correlations were not significant. Effective population was lower than census population of brood fish, which was also reported in a similar study where cultured Asian seabass (Lates calcarifer) contributed unequally to offspring (Liu et al., 2012). When looking at annual totals, however, this effective population number more closely represented the number of brood fish in the tank (Table 2-3). While each male contributed nearly equally, usually one female contributed to each spawn, however, the primary spawning female changed daily (Figure 6-8). This primary female lottery polygyny system was also observed in a similar study on white seabass (Gruenthal and Drawbridge, 2012).

Wild CYT, along with the majority of pelagic finfish, reproduce with eager males following ripe females, synchronizing sperm release at the time of her egg release (Gonçalves and Oliveira, 2010). This appears to be the same breeding system in these captive CYT, but has now been linked to one female clearly out-performing others by contributing $\sim 40 \%$ of the offspring during both spawning seasons. It is important to note that only fertilized eggs were studied for this parentage analysis, and that many of the unfertilized eggs could have easily been from a different female. If our primary female had a genetic compatibility with the other males, or otherwise produced eggs more likely to be fertilized than the other females, then our results are biased towards her. However, we could not 
assess unfertilized eggs for parentage analysis, for obvious reasons. This female was not the largest female in the tank, but was in the larger and older subset of brood fish, at $22.6 \mathrm{~kg}$. This disproportionate offspring contribution linked to female size class has also been observed in many other fish parentage studies (Beldade et al., 2012). Interestingly, the largest female, number 048-379-341, was $5 \mathrm{~kg}$ heavier than this primary female, but contributed only $6.2 \%$ to the annual production of offspring (Figure 3). This could be due to the largest female perhaps having added metabolic costs which reduced energy for egg production, a factor that plagues very old fish (Hixon et al., 2013). For 2013, there was a slight negative correlation between fish mass and annual female fecundity; however, this correlation had a strong positive trend in 2014. The lack of wider variety in fish masses from 2013 is thought to contribute to this observation, as this correlation was not found to be significant.

Rearing at $26.5^{\circ} \mathrm{C}$ has been found to lead to optimal growth rates in Seriola lalandi (Abbink et al., 2011), and it is possible future studies could assess whether there may be similar optimal temperatures regimes for reproductive output. Aside from temperature, it is possible that these fish have some kind of hormonal or behavioral hierarchy, which was not tested for in this work. As courtship has been previously observed in CYT, it is possible that females respond to visual cues, as seen Nile tilapia (Oreochromis niloticus) (Castro et al., 2009). In coral and pelagic fish, elevated levels of testosterone and cortisol were linked to aggressive and bold behaviors in confrontation (Chang et al., 2012). These two behavioral attributes had been previously linked to successful increases 
in reproduction at the cost of survival (Smith and Blumstein, 2008). In a closed system, like those used in aquaculture, these aggressive fish would be able to reproduce at increased rates with no negative effects from confrontation, unless survival was based on intraspecific interactions. However, as no fish were removed from this system without dependence on humans, this is likely not the case for our breeding system. Female $083-027-609$, who provided $40 \%$ of all offspring, could have elevated hormones, or another behavioral or genetic factor involved making her the primary female in our system, which would provide interesting analysis in future studies. However, other cues for female mating choice or social hierarchy, such as male-male competition or other chemical/visual cues (Gonçalves-de-Freitas et al., 2009), must not be ruled out, as these were not directly assessed in this study.

The average spawning time for 2013 and 2014 was every 5 - 19 days per female (Figure 4). The primary female of both years, female 083-027-609, spawned consistently every $5-6$ days throughout both spawning seasons. This time was surely spent reforming eggs internally, as up to $3 \%$ loss in weight has been reported from spawning carangid species (Clarke and Privitera, 1995). However, averages for female spawning intervals presented here are much higher than other studies reported. Yellowfin (Thunnus albacares) and bluefin tuna ( $T$. thynnus) share a similar life history of CYT in terms of being large pelagic migratory fish that broadcast spawn. These tuna spawn every $1.5-4.5$ days, with larger females spawning more frequently (McPherson, 1991; Chen et al., 2006), as was seen in our study. Other carangid fish, such as bigeye scad (Selar 
crumenophthalmus) and round scad (Decapturus macarellus), spawn every 3 days (Clarke and Privitera, 1995). It is important to note, that these values are averages based upon oocyte development from histology, rather than with genetic markers for parentage as our study was done. Therefore results from previous studies based on histology may complicate comparisons of results.

Comparisons of fecundity estimate also become complicated. In carangid females, eggs are produced in high quantity $>100,000$ per female per spawning event) but with little per-egg energetic investment. Batch fecundity for two species of scad was reported at 92,000 and 136,000 eggs (Clarke and Privitera, 1995), 344,700 eggs for horse mackerel (Trachurus trachurs) (Macer, 1974), and an estimated 95,000 eggs from CYT (Stuart and Drawbridge, 2013). These values represent calculations based on oocyte development, ovarian weight and/or number of females present. Other studies of the local Seriola dorsalis estimate batch fecundity around 450,000 - 940,000 eggs (Baxter, 1960). These measurements of fecundity do not track individual reproduction, or fecundity of individual females. Our results were within the same orders of magnitude, with larger females producing $~ 500,000$ eggs per spawn, and smaller females producing 35,000 eggs per spawn. Also like the mackerel and scad species above, batch fecundity increased with mass of the female in CYT. Annual fecundity and female mass (Figure 5) were positively correlated in CYT $(\rho=0.753)$, as seen in many other fish species, including estimates from wild Seriola dorsalis (Baxter, 1960; Beldade et al., 2012; Hixon et al., 2013). 
This study provides the first detailed evaluation on mating system, measurements of fecundity, and spawning intervals for CYT, based on genetic assignment of parentage. These data are on the same order of magnitude as those previously reported for wild carangid species, using histologic evaluation of ovarian development only. By understanding this lottery polygyny spawning system behavior, brood fish management could be implemented to potentially enhance egg production. While we did not directly test mating strategies, a similar study in minnows (Hybognathus amarus) had more successful offspring when allowed to mate in naturalized settings (e.g. environmental or hormonal cues) compared to forced monogamy (Osborne et al., 2013). In terms of our study, for example, lesser contributing females may produce more in the absence of the primary female in this tank (female 083-027-609). By removing these females to a new brood tank without the presence of female 083-027-609, they might begin to produce more offspring. Sex ratios could also be skewed in favor of females, as was done for white seabass after the conclusions from Gruenthal and Drawbridge (2012).

In conclusion, CYT spawning was dynamic, but predictable in our system, with males spawning equally during each spawning event, and females spawning at fairly consistent intervals. Female 083-027-609 is clearly the primary female of both spawning seasons, as she spawned more frequently and produced more eggs than any other female for 2013 and 2014. Females that were $\sim 20 \mathrm{~kg}$ produced more than double the amount of eggs as females in lower weight classes, with some smaller females not producing at all. Measurements of batch and annual 
fecundity were consistent with wild estimates, despite these data coming from cultured fish. These data can be used to better understand how wild fish interact during the spawning season, and will also benefit the direct management of this breeding program in San Diego. 


\section{References}

Abbink, W., A. Blanco Garcia, J.A.C. Roques, G.J. Partridge, K. Kloet, and O. Schneider, O. 2011. The effect of temperature and $\mathrm{pH}$ on the growth and physiological response of juvenile yellowtail kingfish Seriola lalandi in recirculating aquaculture systems. Aquaculture 330-333: 130-135.

Baxter, J. L. 1960. A study of the yellowtail Seriola dorsalis (Gill). State of California Department of Fish and Game, Marine Resources Operations. Fish Bulletin No. 110.

Beldade, R. S.J. Holbrook, R.J. Schmitt, S.Planes, D. Malone, and G. Bernardi. 2012. Larger female fish contribute disproportionately more to selfreplenishment. Proceedings of the Society B 279: 2116-2121.

Briñez, B.R., X.O. Caraballo, and M.V. Salazar. 2011. Genetic diversity of six populations of red hybrid tilapia, using microsatellites genetic markers. Revista MVZ Córdoba 16(2): 2491-2498.

Castro, A.L.S., E. Gonçalve-de-Freitas, G.L. Volpato, and C. Oliveira. 2009. Visual communication stiulates reproduction in Nile tilapia, Oreochromis niloticus (L.) Brazilian Journal of Medical and Biological Research 42(4): 368-374.

Chang, C., C-Y Li, R.L. Earley, and Y. Hsu. 2012. Aggression and related behavioral traits: the impact of winning and losing and the role of hormones. Integrative and Comparitive Biology 52(6): 801-813. 
Chen, K-S., P. Crone, and C-C Hsu. 2006. Reproductive biology of female Pacific bluefin tuna Thunnus orientalis from the south-western North Pacific Ocean. Fisheries Science 72: 985-994.

Clarke, T.A. and L.A. Privitera. 1995. Reproductive biology of two Hawaiian pelagic carangid fishes, the bigeye scad, Selar crumenophthalmus, and the round scad, Decapturus macarellus. Bulletin of Marine Sciences 56(1): $33-47$.

Estoup, A., K. Gharbi, M. SanCristobal, C. Chevalet, P. Haffray, and R. Guyomard. 1998. Parentage assignment using microsatellites in turbot (Scophtalmus maximus) and rainbow trout (Oncorhynchus mykiss) hatchery populations. Canadian Journal of Fisheries and Aquatic Science 55: 715-725.

Fisheries and Agriculture Organization. Updated February 1, 2011. National Aquaculture Sector Overview (NASO). United States of America. National Aquaculture Sector Overview Fact Sheets. Text by Olin, P.G. Rome, Italy.

Gillanders, B.M., D.J. Ferrell, and N.L. Andrew. 1999. Size at maturity and seasonal changes in gonad activity of yellowtail kingfish (Seriola lalandi; Carangidae) in New South Wales, Australia. New Zealand Journal of Marine and Freshwater Research 33(3): 457-468.

Gold, J.R., L. Ma, E. Saillant, P.S. Silva, and R.R. Vega. 2008. Genetic effective size in populations of hatchery-raised red-drum released for stock 
enhancement. Transactions of the American Fisheries Society 137: 13271344.

Gold, J.R., M.A. Renshaw, E. Saillant, and R.R. Vega. 2010. Spawning frequency of brood dams and sires in a marine fish stock-enhancement hatchery. Journal of Fish Biology 77: 1030-1040.

Gonçalves, D.M. and R.F. Oliveira. 2010. Hormones and sexual behavior of teleost fishes. Hormones and Reproduction of Vertebrates, Volume 1 Fishes. Chapter 7. Elsevier Inc.

Gonçalve-de-Freitas, E., A.L. da Silva Castro, T.B. Carvalho, and F.Z. de Mendonça. 2009. Sexual selection and social hierarchy in fishes. Oecologia Brasiliensis 13(1): 80-88.

Gruenthal, K.M. and M.A. Drawbridge. 2012. Toward responsible stock enhancement: broadcast spawning dynamics and adaptive genetic management in white seabass aquaculture. Evolutionary Applications 5(4): 405-417.

Hara, M. and M. Sekino. 2003. Efficient detection of parentage in a cultured Japanese flounder Paralichthys olivaceus using microsatellite DNA marker. Aquaculture 217: 107-114.

Hixon, M.A., D.W. Johnson, and S.M. Sogard. 2013. BOFFFFs: on the importance of conserving old-growth age structure in fishery populations. ICES Journal of Marine Science: 1-15 doi:10.1093/icesjms/fst200. 
Jirsa, D., A. Davis, K. Stuart, and M. Drawbridge. 2011. Development of a practical soy-based diet for California yellowtail, Seriola lalandi. Aquaculture Nutrition 17: e869-e874.

Kalinowski, S.T., M.L. Taper, and T.C. Marshall. 2007. Revising how the computer program CERVUS accommodates genotyping error increases success in paternity assignment. Molecular Ecology 16: 1099-1006. doi: 10.1111/j.1365-294x.2007.03089.x

Liu, P., J.H. Xia, G. Lin, F. Sun, F. Liu, H.S. Lim, H.Y. Pang, and G. H. Yue. 2012. Molecular parentage analysis is essential in breeding Asian seabass. PLoS ONE 7(12): e51142.

Macer, C.T. 1974. The reproductive biology of the horse mackerel Trachurus trachurus (L.) in the North Sea and English Channel. Journal of Fish Biology 6: 415-438.

Martinez-Takeshita, N., C.M Purcell, C.L. Chabot, M.T. Craig, C.N. Paterson, J.R. Hyde, and L.G. Allen. 2015. A tale of three tails: cryptic speciation in a globally distributed marine fish of the genus Seriola. Copeia 103(2): 357-368.

McPherson, G.R. 1991. Reproductive biology of yellowfin tuna in the eastern Australian Fishing Zone, with special reference to the north-western Coral Sea. Australian Journal of Marine and Freshwater Research 42(5): 465477. 
Miller, P.A., A.J. Fitch, M. Gardner, K.S. Hutson, and G. Mair. 2011. Genetic population structure of yellowtail kingfish (Seriola lalandi) in temperate Australasian waters inferred from microsatellite markers and mitochondrial DNA. Aquaculture 319: 328-336.

Moran, D., C.K. Smith, B. Gara, and C.W. Poortenaar. 2007. Reproductive behaviour and early development in yellowtail kingfish (Seriola lalandi Valenciennes 1833). Aquaculture 262: 95-104.

Murua, H. and F. Saborido-Rey. 2003. Female reproductive strategies of marine fish species of the North Atlantic. Journal of Northwest Atlantic Fisheries Science 33: 23-31.

Nugroho E., and N. Taniguchi. 1999. Isolation of greater amberjack microsatellite DNA and their application as genetic marker to species of genus Seriola from Japan. Fisheries Science 65: 353-357.

Nunney, L. 1993. The influence of mating system and overlapping generations on effective population size. Evolution 47(5): 1329-1341.

Ohara, E., T. Nishimura, T. Sakamoto, Y. Nagakura, K. Mushiake, and N. Okamoto. 2003. Isolation and characterization of microsatellite loci from yellowtail Seriola quinqueradiata and cross-species amplification within the genus Seriola. Molecular Ecology Notes 3: 390-391.

Ohara, E., T. Nishimura, Y. Nagakura, T. Sakamoto, K. Mushiake, and N. Okamoto. 2005. Genetic linkage maps of two yellowtails (Seriola quinqueradiata and Seriola lalandi). Aquaculture 244: 41-48. 
Osborne, M.J., T.L. Perez, C.S. Altenbach and T.F. Turner. 2013. Genetic analysis of captive spawning strategies for endangered Rio Grande silvery minnow. Journal of Heredity 104 (3): 437-446.

Poortenaar, C.W., S.H. Hooker, and N. Sharp. 2001. Assessment of yellowtail kingfish (Seriola lalandi lalandi) reproductive physiology, as a basis for aquaculture development. Aquaculture 201: 271-286.

Porta, J.M., P. Novel, G. Martinez-Rodrigues, M.C Alverez, and J. Porta. 2009. Isolation and characterization of microsatellites from Seriola dumerili (Risso 1810). Aquaculture Research 40(2): 249-251.

Purcell, C.M., C.L. Chabot, M.T. Craig, N. Martinez-Takeshita, L.G. Allen, and J.R. Hyde. 2015. Developing a genetic baseline for the yellowtail amberjack species complex, Seriola lalandi senu lato, to assess and preserve variation in wild populations of these globally important aquaculture species. Conservation Genetics DOI 10.1007/s10592-0150755-8.

Renshaw, M.A., J.C. Patton, C.E. Rexroad III, and J.R. Gold. 2006. PCR primers for trinucleotide and tetranucleotide microsatellites in greater amberjack, Seriola dumerili. Molecular Ecology Notes 6(4): 1162-1164.

Renshaw, M.A., J.C. Patton, C.E. Rexroad III, and J.R. Gold. 2007. Isolation and characterization of dinucleotide microsatellites in greater amberjack, Seriola dumerili. Conservation Genetics 8(4): 1009-1011. 
Sala, E., O. Aburto-Oropeza, G. Paredes, and G. Thomson. 2003. Spawning aggregations and reproductive behavior of reef fishes in the Gulf of California. Bulletin of Marine Science 72(2): 103-121.

Smith, B.R., and D.T. Blumstein. 2008. Fitness consequences of personality: a meta-analysis. Behavioral Ecology 19(2): 448-455.

Stuart, K.R. and M.A. Drawbridge. 2013. Captive spawning and larval rearing of California yellowtail (Seriola lalandi). Aquaculture Research 44: 728-737.

Sumida, B.Y., G. Moser, and E.H. Ahlstrom. 1985. Descriptions of the larvae of California yellowtail, Seriola lalandi, and three other Carangids from the eastern tropical Pacific: Chloroscombrus orqueta, Caranx caballus, and Caranx sexfasciatus. CalCOFI Reports 26: 141-159.

Vandeputte, M., and P. Haffray. 2014. Parentage assignment with genomic markers: a major advance for understanding and exploiting genetic variation of quantitative traits in farmed aquatic animals. Frontiers in Genetics 5: 432.

Vandeputte, M., M. Kocour, S. Mauger, M. Dupont-Nivet, D. De Guerry, M. Rodina, D. Gela, D. Vallod, B. Chevassus, and O. Linhart. 2004. Heritability estimates for growth-related traits using microsatellite parentage assignment in juvenile common carp (Cyprinus carpio L.). Aquaculture 235: 223-236.

Whatmore, P., N.H. Nguyen, A. Miller, R. Lamont, D. Powell, T. D’Antignana, E. Bubner, A. Elizur, and W. Knibb. 2013. Genetic parameters for 
economically important traits in yellowtail kingfish Seriola lalandi.

Aquaculture 400-401: 77-84. 


\section{CONCLUSION TO THESIS}

Spawning behavior in fish species is varied and dynamic. Having a thorough understanding of reproduction will aide in management of wild fisheries, or in aquaculture breeding programs. Similar to other pelagic teleosts, CYT broadcast spawn in aggregations. This makes understanding intricacies of spawning nearly impossible without genetic markers, which was done for the first time in the present study on this species. Using microsatellite loci genotyped to a group of brood fish CYT from San Diego, CA, parentage was assigned and analyzed over two spawning seasons.

To gain a better understanding of spawning dynamics, subsampling needed to be adequate for relative brood fish contributions to be meaningfully assigned. By assigning parental contribution to a range of sample sizes of offspring, both in actual practice and via computer simulation, a minimum sampling size was determined to be $\mathrm{n} \geq 30$ offspring per spawning event. In contrast, when a power analysis was applied under theoretical conditions, assuming infinite sample sizes and equal allelic contribution from each potential parent, subsampling was determined to be $n=385$ offspring per spawn. Our results show that an $n \geq 30$ offspring, statistically significant means and $95 \%$ confidence intervals are achieved in comparison to "true" proportional parental contribution. This is similar to other studies which use microsatellite markers for population genetic assessments, but is the first study to directly evaluate microsatellites for parentage studies. 
Using this method justification, $n=47$ offspring were assigned to parental pairs from every spawn occurring during the 2013 and 2014 spawning season of CYT. Using $n=47$ offspring per spawn, allowed us to use a statistically meaningful sample size that also fit into a typical 96-well plate, universally used for genetic lab work. There was no obvious novel correlation between spawning time and environmental factors. For each spawn, there was one primary female in egg production, with males contributing sperm nearly equally. This lottery polygyny system occurred in both 2013 and 2014. However, the additional smaller fish added in 2014 contributed disproportionately fewer offspring than the larger fish available both years tested. Female mass was positively correlated with offspring production, as seen in many other species of fish. Larger females usually spawned weekly or bimonthly, while larger males contributed to offspring production nearly every day.

These patterns could represent hormonal dominance or another form of social hierarchy seen in these fish. Characterization of the individual spawning events showed one female contributing nearly $40 \%$ of all offspring over each year. This could lead to interesting follow up studies to test her levels of testosterone or cortisol, or direct observation of the lesser female behavior if removed from this primary female. If this primary female was removed, and the social hierarchy of females allowed to reestablish, it is possible that the lesser contributing females may increase their egg production. This would directly affect the egg production at the HSWRI facility, at least relative to diversity. This 
information could also help with management of other aquaculture facilities with similar fish.

This study will lead to the advancement of these brood fish in captivity, but can also be used to better understand fish on the global scale. As these fish were wild-caught, and results regarding fecundity and female spawning intervals found from this study are consistent with wild data, it is possible to apply results here to support fisheries management. These data are the first of their kind reported in CYT, and this sample collection justification one of the first for genetic assignment of parentage. The data from this study not only characterized individual spawning events from up to 19 fish, over two years, but also successfully found a statistically significant -and reasonable- sub-sample size to analyze parental pair patterns. 
Appendix 1 -In-house made reagents.

10\% (w/v) Chelex resin:

10g Chelex resin

$100 \mathrm{ml}$ milli-Q water

10X PCR Buffer; pH 8.8:

$670 \mathrm{mM}$ Tris

$166 \mathrm{mM}\left(\mathrm{NH}_{4}\right)_{2} \mathrm{SO}_{4}$

$20 \mathrm{mM} \mathrm{MgCl} 2$

100 mM ß-mercaptoethanol

Bovine Serum Albumin (BSA): $20 \mathrm{mg} / \mathrm{mL}$

$0.22 \mu \mathrm{m}$ filtered and UV sterilized.

dNTP Mix 2 mM each dNTP:

$4 \mu \mathrm{dATP}(100 \mathrm{mM})$

$4 \mu \mathrm{ldCTP}(100 \mathrm{mM})$

$4 \mu \mathrm{dGTP}(100 \mathrm{mM})$

$4 \mu \mathrm{dTTP}(100 \mathrm{mM})$

$184 \mu 1$ milli-Q water 
Appendix 2 -- All PCR mixes

\begin{tabular}{|c|c|c|c|}
\hline Reagent & $\begin{array}{c}\text { Per reaction } \\
(\mu \mathrm{l})\end{array}$ & $\begin{array}{l}\text { Master mix } \\
\quad(\mu \mathrm{l} \mathbf{x 1 0 0})\end{array}$ & $\begin{array}{c}\text { Fluorescent } \\
\text { label }\end{array}$ \\
\hline \multicolumn{4}{|l|}{ PCR 1} \\
\hline Milli-Q water & 7.20 & 720 & \\
\hline 10X PCR buffer & 1.00 & 100 & \\
\hline dNTPs (2 mM) & 1.00 & 100 & \\
\hline BSA & 0.25 & 25 & \\
\hline Sequ $38 \mathrm{~F}(10 \mathrm{mM})$ & 0.25 & 25 & $5 \mathrm{HEX}$ \\
\hline Sequ 38 R (10 mM) & 0.25 & 25 & \\
\hline Taq Polymerase & 0.05 & 5 & \\
\hline DNA & 1.00 & -- & \\
\hline \multicolumn{4}{|l|}{ PCR 2} \\
\hline Milli-Q water & 5.79 & 579 & \\
\hline 10X PCR buffer & 1.00 & 100 & \\
\hline dNTPs (2 mM) & 1.00 & 100 & \\
\hline BSA & 0.25 & 25 & \\
\hline Sequ $77 \mathrm{~F}(10 \mathrm{mM})$ & 0.25 & 25 & $5 \mathrm{HEX}$ \\
\hline Sequ $77 \mathrm{R}$ (10 mM) & 0.25 & 25 & \\
\hline Sdu gA3D F (10 mM) & 0.15 & 15 & 56-FAM \\
\hline Sdu gA3D R (10 mM) & 0.15 & 15 & \\
\hline $\mathrm{Sdu} 46 \mathrm{~F}(10 \mathrm{mM})$ & 0.25 & 25 & 56-TAMN \\
\hline Sdu 46 R (10 mM) & 0.25 & 25 & \\
\hline Sdu 4 F (10 mM) & 0.30 & 30 & 56-FAM \\
\hline $\mathrm{Sdu} 4 \mathrm{R}(10 \mathrm{mM})$ & 0.30 & 30 & \\
\hline Taq Polymerase & 0.06 & 6 & \\
\hline DNA & 1.00 & -- & \\
\hline \multicolumn{4}{|l|}{ PCR 3} \\
\hline Milli-Q water & 5.89 & 589 & \\
\hline 10X PCR buffer & 1.00 & 100 & \\
\hline dNTPs (2 mM) & 1.00 & 100 & \\
\hline BSA & 0.25 & 25 & \\
\hline Sequ $320 \mathrm{~F}(10 \mathrm{mM})$ & 0.20 & 20 & $5 \mathrm{HEX}$ \\
\hline Sequ $320 \mathrm{R}(10 \mathrm{mM})$ & 0.20 & 20 & \\
\hline Sequ $230 \mathrm{~F}(10 \mathrm{mM})$ & 0.15 & 15 & 56-FAM \\
\hline Sequ $230 \mathrm{R}$ (10 mM) & 0.15 & 15 & \\
\hline Sdu $10 \mathrm{~F}(10 \mathrm{mM})$ & 0.25 & 25 & 56-TAMN \\
\hline Sdu 10 R (10 mM) & 0.25 & 25 & \\
\hline Sdn 06 F (10 mM) & 0.30 & 30 & 56-FAM \\
\hline Sdn $06 \mathrm{R}(10 \mathrm{mM})$ & 0.30 & 30 & \\
\hline Taq Polymerase & 0.06 & 6 & \\
\hline DNA & 1.00 & -- & \\
\hline
\end{tabular}


Appendix 3: Mean values and 95\% confidence intervals (CI) of all CYT brood fish from the 2013. Pit tag numbers are listed above each set of values. Date of spawn and simulated sample size ( $\mathrm{S}$ n-value) is listed in first column. Note as simulated sample sizes increase, CI become closer to the mean for each brood fish at each spawn. 
Appendix 3: Mean values and 95\% confidence intervals for CYT brood fish bootstap simulation

\begin{tabular}{|c|c|c|c|c|c|c|c|c|c|}
\hline \multirow{2}{*}{$\begin{array}{l}\text { mmddyy - } \\
\text { S n-value }\end{array}$} & \multicolumn{3}{|c|}{ 048-379-341 } & \multicolumn{3}{|c|}{ 048-519-049 } & \multicolumn{3}{|c|}{ 061-363-804 } \\
\hline & Mean & $\mathrm{Cl} 2.5 \%$ & $\mathrm{Cl} 97.5 \%$ & Mean & $\mathrm{Cl} 2.5 \%$ & $\mathrm{Cl} 97.5 \%$ & Mean & $\mathrm{Cl} 2.5 \%$ & $\mathrm{Cl} 97.5 \%$ \\
\hline $04 / 29 / 13-10$ & 0.0000 & 0.0000 & 0.0000 & 0.6030 & 0.3000 & 0.9000 & 0.0000 & 0.0000 & 0.0000 \\
\hline $04 / 29 / 13-20$ & 0.0000 & 0.0000 & 0.0000 & 0.6023 & 0.4000 & 0.8000 & 0.0000 & 0.0000 & 0.0000 \\
\hline $04 / 29 / 13-30$ & 0.0000 & 0.0000 & 0.0000 & 0.6028 & 0.4333 & 0.7667 & 0.0000 & 0.0000 & 0.0000 \\
\hline $04 / 29 / 13-40$ & 0.0000 & 0.0000 & 0.0000 & 0.6032 & 0.4500 & 0.7500 & 0.0000 & 0.0000 & 0.0000 \\
\hline $04 / 29 / 13-47$ & 0.0000 & 0.0000 & 0.0000 & 0.6041 & 0.4681 & 0.7234 & 0.0000 & 0.0000 & 0.0000 \\
\hline $04 / 29 / 13-60$ & 0.0000 & 0.0000 & 0.0000 & 0.6024 & 0.4833 & 0.7167 & 0.0000 & 0.0000 & 0.0000 \\
\hline $04 / 29 / 13-100$ & 0.0000 & 0.0000 & 0.0000 & 0.6035 & 0.5200 & 0.6800 & 0.0000 & 0.0000 & 0.0000 \\
\hline $04 / 29 / 13-150$ & 0.0000 & 0.0000 & 0.0000 & 0.6030 & 0.5467 & 0.6600 & 0.0000 & 0.0000 & 0.0000 \\
\hline $04 / 29 / 13-200$ & 0.0000 & 0.0000 & 0.0000 & 0.6029 & 0.5600 & 0.6450 & 0.0000 & 0.0000 & 0.0000 \\
\hline $04 / 29 / 13-250$ & 0.0000 & 0.0000 & 0.0000 & 0.6025 & 0.5680 & 0.6360 & 0.0000 & 0.0000 & 0.0000 \\
\hline $04 / 29 / 13-300$ & 0.0000 & 0.0000 & 0.0000 & 0.6025 & 0.5800 & 0.6233 & 0.0000 & 0.0000 & 0.0000 \\
\hline $05 / 17 / 13-10$ & 0.0000 & 0.0000 & 0.0000 & 0.0000 & 0.0000 & 0.0000 & 0.0000 & 0.0000 & 0.0000 \\
\hline $05 / 17 / 13-20$ & 0.0000 & 0.0000 & 0.0000 & 0.0000 & 0.0000 & 0.0000 & 0.0000 & 0.0000 & 0.0000 \\
\hline $05 / 17 / 13-30$ & 0.0000 & 0.0000 & 0.0000 & 0.0000 & 0.0000 & 0.0000 & 0.0000 & .0000 & 0.0000 \\
\hline $05 / 17 / 13-40$ & 0.0000 & 0.0000 & 0.0000 & 0.0000 & 0.0000 & 0.0000 & 0.0000 & 0.0000 & 0.0000 \\
\hline $05 / 17 / 13-47$ & 0.0000 & 0.0000 & 0.0000 & 0.0000 & 0.0000 & 0.0000 & 0.0000 & 0.0000 & 0.0000 \\
\hline $05 / 17 / 13-60$ & 0.0000 & 0.0000 & 0.0000 & 0.0000 & 0.0000 & 0.0000 & 0.0000 & 0.0000 & 0.0000 \\
\hline $05 / 17 / 13-100$ & 0.0000 & 0.0000 & 0.0000 & 0.0000 & 0.0000 & 0.0000 & 0.0000 & 0.0000 & 0.0000 \\
\hline $05 / 17 / 13-150$ & 0.0000 & 0.0000 & 0.0000 & 0.0000 & 0.0000 & 0.0000 & 0.0000 & 0.0000 & 0.0000 \\
\hline $05 / 17 / 13-200$ & 0.0000 & 0.0000 & 0.0000 & 0.0000 & 0.0000 & 0.0000 & 0.0000 & 0.0000 & 0.0000 \\
\hline $05 / 17 / 13-250$ & 0.0000 & 0.0000 & 0.0000 & 0.0000 & 0.0000 & 0.0000 & 0.0000 & 0.0000 & 0.0000 \\
\hline $05 / 17 / 13-300$ & 0.0000 & 0.0000 & 0.0000 & 0.0000 & 0.0000 & 0.0000 & 0.0000 & 0.0000 & 0.0000 \\
\hline $06 / 21 / 13-10$ & 0.0000 & 0.0000 & 0.0000 & 0.0527 & 0.0000 & 0.2000 & 0.9473 & 0.8000 & 1.0000 \\
\hline $06 / 21 / 13-20$ & 0.0000 & 0.0000 & 0.0000 & 0.0523 & 0.0000 & 0.1500 & 0.9477 & 0.8500 & 1.0000 \\
\hline $06 / 21 / 13-30$ & 0.0000 & 0.0000 & 0.0000 & 0.0519 & 0.0000 & 0.1333 & 0.9481 & 0.8667 & 1.0000 \\
\hline $06 / 21 / 13-40$ & 0.0000 & 0.0000 & 0.0000 & 0.0518 & 0.0000 & 0.1250 & 0.9482 & 0.8750 & 1.0000 \\
\hline $06 / 21 / 13-47$ & 0.0000 & 0.0000 & 0.0000 & 0.0523 & 0.0000 & 0.1277 & 0.9477 & 0.8723 & 1.0000 \\
\hline $06 / 21 / 13-60$ & 0.0000 & 0.0000 & 0.0000 & 0.0516 & 0.0000 & 0.1000 & 0.9484 & 0.9000 & 1.0000 \\
\hline $06 / 21 / 13-100$ & 0.0000 & 0.0000 & 0.0000 & 0.0519 & 0.0200 & 0.0900 & 0.9481 & 0.9100 & 0.9800 \\
\hline $06 / 21 / 13-150$ & 0.0000 & 0.0000 & 0.0000 & 0.0521 & 0.0267 & 0.0800 & 0.9479 & 0.9200 & 0.9733 \\
\hline $06 / 21 / 13-200$ & 0.0000 & 0.0000 & 0.0000 & 0.0519 & 0.0300 & 0.0700 & 0.9481 & 0.9300 & 0.9700 \\
\hline $06 / 21 / 13-250$ & 0.0000 & 0.0000 & 0.0000 & 0.0518 & 0.0360 & 0.0680 & 0.9482 & 0.9320 & 0.9640 \\
\hline $06 / 21 / 13-300$ & 0.0000 & 0.0000 & 0.0000 & 0.0519 & 0.0400 & 0.0600 & 0.9481 & 0.9400 & 0.9600 \\
\hline $07 / 26 / 13-10$ & 0.0028 & 0.0000 & 0.1000 & 0.9944 & 0.9000 & 1.0000 & 0.0000 & 0.0000 & 0.0000 \\
\hline $07 / 26 / 13-20$ & 0.0027 & 0.0000 & 0.0500 & 0.9946 & 0.9500 & 1.0000 & 0.0000 & 0.0000 & 0.0000 \\
\hline $07 / 26 / 13-30$ & 0.0026 & 0.0000 & 0.0333 & 0.9948 & 0.9667 & 1.0000 & 0.0000 & 0.0000 & 0.0000 \\
\hline $07 / 26 / 13-40$ & 0.0026 & 0.0000 & 0.0250 & 0.9948 & 0.9750 & 1.0000 & 0.0000 & 0.0000 & 0.0000 \\
\hline $07 / 26 / 13-47$ & 0.0027 & 0.0000 & 0.0213 & 0.9947 & 0.9787 & 1.0000 & 0.0000 & 0.0000 & 0.0000 \\
\hline $07 / 26 / 13-60$ & 0.0026 & 0.0000 & 0.0167 & 0.9948 & 0.9833 & 1.0000 & 0.0000 & 0.0000 & 0.0000 \\
\hline $07 / 26 / 13-100$ & 0.0026 & 0.0000 & 0.0100 & 0.9948 & 0.9800 & 1.0000 & 0.0000 & 0.0000 & 0.0000 \\
\hline $07 / 26 / 13-150$ & 0.0026 & 0.0000 & 0.0067 & 0.9947 & 0.9867 & 1.0000 & 0.0000 & 0.0000 & 0.0000 \\
\hline $07 / 26 / 13-200$ & 0.0027 & 0.0000 & 0.0050 & 0.9947 & 0.9900 & 1.0000 & 0.0000 & 0.0000 & 0.0000 \\
\hline $07 / 26 / 13-250$ & 0.0027 & 0.0000 & 0.0040 & 0.9947 & 0.9920 & 1.0000 & 0.0000 & 0.0000 & 0.0000 \\
\hline $07 / 26 / 13-300$ & 0.0027 & 0.0000 & 0.0033 & 0.9947 & 0.9933 & 1.0000 & 0.0000 & 0.0000 & 0.0000 \\
\hline $08 / 26 / 13-10$ & 0.0000 & 0.0000 & 0.0000 & 0.2336 & 0.0000 & 0.5000 & 0.0000 & 0.0000 & 0.0000 \\
\hline $08 / 26 / 13-20$ & 0.0000 & 0.0000 & 0.0000 & 0.2345 & 0.0500 & 0.4000 & 0.0000 & 0.0000 & 0.0000 \\
\hline $08 / 26 / 13-30$ & 0.0000 & 0.0000 & 0.0000 & 0.2343 & 0.1000 & 0.4000 & 0.0000 & 0.0000 & 0.0000 \\
\hline $08 / 26 / 13-40$ & 0.0000 & 0.0000 & 0.0000 & 0.2331 & 0.1250 & 0.3500 & 0.0000 & 0.0000 & 0.0000 \\
\hline $08 / 26 / 13-47$ & 0.0000 & 0.0000 & 0.0000 & 0.2345 & 0.1277 & 0.3410 & 0.0000 & 0.0000 & 0.0000 \\
\hline $08 / 26 / 13-60$ & 0.0000 & 0.0000 & 0.0000 & 0.2341 & 0.1333 & 0.3333 & 0.0000 & 0.0000 & 0.0000 \\
\hline $08 / 26 / 13-100$ & 0.0000 & 0.0000 & 0.0000 & 0.2341 & 0.1700 & 0.3000 & 0.0000 & 0.0000 & 0.0000 \\
\hline $08 / 26 / 13-150$ & 0.0000 & 0.0000 & 0.0000 & 0.2334 & 0.1867 & 0.2800 & 0.0000 & 0.0000 & 0.0000 \\
\hline $08 / 26 / 13-200$ & 0.0000 & 0.0000 & 0.0000 & 0.2337 & 0.1950 & 0.2700 & 0.0000 & 0.0000 & 0.0000 \\
\hline $08 / 26 / 13-250$ & 0.0000 & 0.0000 & 0.0000 & 0.2342 & 0.2080 & 0.2600 & 0.0000 & 0.0000 & 0.0000 \\
\hline $08 / 26 / 13-300$ & 0.0000 & 0.0000 & 0.0000 & 0.2338 & 0.2200 & 0.2467 & 0.0000 & 0.0000 & 0.0000 \\
\hline
\end{tabular}


Appendix 3: Mean values and 95\% confidence intervals for CYT brood fish bootstap simulation

\begin{tabular}{|c|c|c|c|c|c|c|c|c|c|}
\hline \multirow{2}{*}{$\begin{array}{l}\text { mmddyy - } \\
\text { Sn-value }\end{array}$} & \multicolumn{3}{|c|}{$061-375-363$} & \multicolumn{3}{|c|}{ 061-621-862 } & \multicolumn{3}{|c|}{ 083-026-876 } \\
\hline & Mean & $\mathrm{Cl} 2.5 \%$ & $\mathrm{Cl} 97.5 \%$ & Mean & $\mathrm{Cl} 2.5 \%$ & Cl $97.5 \%$ & Mean & $\mathrm{Cl} 2.5 \%$ & $\mathrm{Cl} 97.5 \%$ \\
\hline $04 / 29 / 13-10$ & 0.0029 & 0.0000 & 0.1000 & 0.0000 & 0.0000 & 0.0000 & 0.0032 & 0.0000 & 0.1000 \\
\hline $04 / 29 / 13-20$ & 0.0027 & 0.0000 & 0.0500 & 0.0000 & 0.0000 & 0.0000 & 0.0028 & 0.0000 & 0.0500 \\
\hline 04/29/13 - 30 & 0.0029 & 0.0000 & 0.0333 & 0.0000 & 0.0000 & 0.0000 & 0.0030 & 0.0000 & 0.0333 \\
\hline $04 / 29 / 13-40$ & 0.0028 & 0.0000 & 0.0250 & 0.0000 & 0.0000 & 0.0000 & 0.0029 & 0.0000 & 0.0250 \\
\hline $04 / 29 / 13-47$ & 0.0027 & 0.0000 & 0.0213 & 0.0000 & 0.0000 & 0.0000 & 0.0028 & 0.0000 & 0.0213 \\
\hline $04 / 29 / 13-60$ & 0.0028 & 0.0000 & 0.0167 & 0.0000 & 0.0000 & 0.0000 & 0.0028 & 0.0000 & 0.0167 \\
\hline 04/29/13 - 100 & 0.0028 & 0.0000 & 0.0100 & 0.0000 & 0.0000 & 0.0000 & 0.0028 & 0.0000 & 0.0100 \\
\hline $04 / 29 / 13-150$ & 0.0028 & 0.0000 & 0.0067 & 0.0000 & 0.0000 & 0.0000 & 0.0028 & 0.0000 & 0.0067 \\
\hline $04 / 29 / 13-200$ & 0.0028 & 0.0000 & 0.0050 & 0.0000 & 0.0000 & 0.0000 & 0.0028 & 0.0000 & 0.0050 \\
\hline $04 / 29 / 13-250$ & 0.0028 & 0.0000 & 0.0040 & 0.0000 & 0.0000 & 0.0000 & 0.0028 & 0.0000 & 0.0040 \\
\hline $04 / 29 / 13-300$ & 0.0028 & 0.0000 & 0.0033 & 0.0000 & 0.0000 & 0.0000 & 0.0028 & 0.0000 & 0.0033 \\
\hline $05 / 17 / 13-10$ & 0.0000 & 0.0000 & 0.0000 & 0.5018 & 0.2000 & 0.8000 & 0.0029 & 0.0000 & 0.1000 \\
\hline $05 / 17 / 13-20$ & 0.0000 & 0. & 0 & 0. & 0 & 0 & 0.0027 & 0 & 00 \\
\hline 05/17/13 - 30 & 0.0000 & 0.0000 & 0.0000 & 0.4982 & 0.3333 & 0.6667 & 0.0028 & 0.0000 & 0.0333 \\
\hline $05 / 17 / 13-40$ & 0.0000 & 0.0000 & 0.0000 & 0.5000 & 0.3500 & 0.6500 & 0.0028 & 0.0000 & 0.0250 \\
\hline $05 / 17 / 13-47$ & 0.0000 & 0.0000 & 0.0000 & 0.4977 & 0.3617 & 0.6383 & 0.0028 & 0.0000 & 0.0213 \\
\hline $05 / 17 / 13-60$ & 0.0000 & 0.0000 & 0.0000 & 0.4987 & 0.3833 & 0.6167 & 0.0029 & 0.0000 & 0.0167 \\
\hline 05/17/13 - 100 & 0.0000 & 0.0000 & 0.0000 & 0.4978 & 0.4200 & 0.5800 & 0.0028 & 0.0000 & 0.0100 \\
\hline 05/17/13 - 150 & 0.0000 & 0.0000 & 0.0000 & 0.4984 & 0.4333 & 0.5600 & 0.0028 & 0.0000 & 0.0067 \\
\hline $05 / 17 / 13-200$ & 0.0000 & 0.0000 & 0.0000 & 0.4984 & 0.4550 & 0.5450 & 0.0028 & 0.0000 & 0.0050 \\
\hline $05 / 17 / 13-250$ & 0.0000 & 0.0000 & 0.0000 & 0.4986 & 0.4640 & 0.5320 & 0.0028 & 0.0000 & 0.0040 \\
\hline $05 / 17 / 13-300$ & 0.0000 & 0.0000 & 0.00 & 0.4986 & 0.4767 & 0 & 0.0028 & 0.0 & 0.0033 \\
\hline $06 / 21 / 13-10$ & 0.0000 & 0.0000 & 0.0000 & 0.0000 & 0.0000 & 0.0000 & 0.0000 & 0.0000 & 0.0000 \\
\hline $06 / 21 / 13-20$ & 0.0000 & 0.0000 & 0.0000 & 0.0000 & 0.0000 & 0.0000 & 0.0000 & 0.0000 & 0.0000 \\
\hline $06 / 21 / 13-30$ & 0.0000 & 0.0000 & 0.0000 & 0.0000 & 0.0000 & 0.0000 & 0.0000 & 0.0000 & 0.0000 \\
\hline $06 / 21 / 13-40$ & 0.0000 & 0.0000 & 0.0000 & 0.0000 & 0.0000 & 0.0000 & 0.0000 & 0.0000 & 0.0000 \\
\hline $06 / 21 / 13-47$ & 0.0000 & 0.0000 & 0.0000 & 0.0000 & 0.0000 & 0.0000 & 0.0000 & 0.0000 & 0.0000 \\
\hline $06 / 21 / 13-60$ & 0.0000 & 0.0000 & 0.0000 & 0.0000 & 0.0000 & 0.0000 & 0.0000 & 0.0000 & 0.0000 \\
\hline $06 / 21 / 13-100$ & 0.0000 & 0.0000 & 0.0000 & 0.0000 & 0.0000 & 0.0000 & 0.0000 & 0.0000 & 0.0000 \\
\hline $06 / 21 / 13-150$ & 0.0000 & 0.0000 & 0.0000 & 0.0000 & 0.0000 & 0.0000 & 0.0000 & 0.0000 & 0.0 \\
\hline $06 / 21 / 13-200$ & 0.0000 & 0.0000 & 0.0000 & 0.0000 & 0.0000 & 0.0000 & 0.0000 & 0.0000 & 0.0000 \\
\hline $06 / 21 / 13-250$ & 0.0000 & 0.0000 & 0.0000 & 0.0000 & 0.0000 & 0.0000 & 0.0000 & 0.0000 & 0.0000 \\
\hline $06 / 21 / 13-300$ & 0.0000 & 0.0000 & 0.0000 & 0.0000 & 0.0000 & 0.0000 & 0.0000 & 0.0000 & 0.0000 \\
\hline $07 / 26 / 13-10$ & 0.0000 & 0.0000 & 0.0000 & 0.0000 & 0.0000 & 0.0000 & 0.0000 & 0.0000 & 0.0000 \\
\hline $07 / 26 / 13-20$ & 0.0000 & 0.0000 & 0.0000 & 0.0000 & 0.0000 & 0.0000 & 0.0000 & 0.0000 & 0.0000 \\
\hline $07 / 26 / 13-30$ & 0.0000 & 0.0000 & 0.0000 & 0.0000 & 0.0000 & 0.0000 & 0.0000 & 0.0000 & 0.0000 \\
\hline $07 / 26 / 13-40$ & 0.0000 & 0.0000 & 0.0000 & 0.0000 & 0.0000 & 0.0000 & 0.0000 & 0.0000 & 0.0000 \\
\hline $07 / 26 / 13-47$ & 0.0000 & 0.0000 & 0.0000 & 0.0000 & 0.0000 & 0.0000 & 0.0000 & 0.0000 & 0.0000 \\
\hline $07 / 26 / 13-60$ & 0.0000 & 0.0000 & 0.0000 & 0.0000 & 0.0000 & 0.0000 & 0.0000 & 0.0000 & 0.0000 \\
\hline $07 / 26 / 13-100$ & 0.0000 & 0.0000 & 0.0000 & 0.0000 & 0.0000 & 0.0000 & 0.0000 & 0.0000 & 0.0000 \\
\hline $07 / 26 / 13-150$ & 0.0000 & 0.0000 & 0.0000 & 0.0000 & 0.0000 & 0.0000 & 0.0000 & 0.0000 & 0.0000 \\
\hline $07 / 26 / 13-200$ & 0.0000 & 0.0000 & 0.0000 & 0.0000 & 0.0000 & 0.0000 & 0.0000 & 0.0000 & 0.0000 \\
\hline $07 / 26 / 13-250$ & 0.0000 & 0.0000 & 0.0000 & 0.0000 & 0.0000 & 0.0000 & 0.0000 & 0.0000 & 0.0000 \\
\hline $07 / 26 / 13-300$ & 0.0000 & 0.0000 & 0.0000 & 0.0000 & 0.0000 & 0.0000 & 0.0000 & 0.0000 & 0.0000 \\
\hline $08 / 26 / 13-10$ & 0.0000 & 0.0000 & 0.0000 & 0.0031 & 0.0000 & 0.1000 & 0.7633 & 0.5000 & 1.0000 \\
\hline $08 / 26 / 13-20$ & 0.0000 & 0.0000 & 0.0000 & 0.0030 & 0.0000 & 0.0500 & 0.7624 & 0.5500 & 0.9500 \\
\hline $08 / 26 / 13-30$ & 0.0000 & 0.0000 & 0.0000 & 0.0031 & 0.0000 & 0.0333 & 0.7626 & 0.6000 & 0.9000 \\
\hline $08 / 26 / 13-40$ & 0.0000 & 0.0000 & 0.0000 & 0.0030 & 0.0000 & 0.0250 & 0.7639 & 0.6500 & 0.8750 \\
\hline $08 / 26 / 13-47$ & 0.0000 & 0.0000 & 0.0000 & 0.0031 & 0.0000 & 0.0213 & 0.7624 & 0.6383 & 0.8723 \\
\hline $08 / 26 / 13-60$ & 0.0000 & 0.0000 & 0.0000 & 0.0031 & 0.0000 & 0.0167 & 0.7628 & 0.6667 & 0.8500 \\
\hline $08 / 26 / 13-100$ & 0.0000 & 0.0000 & 0.0000 & 0.0031 & 0.0000 & 0.0100 & 0.7629 & 0.6900 & 0.8300 \\
\hline $08 / 26 / 13-150$ & 0.0000 & 0.0000 & 0.0000 & 0.0031 & 0.0000 & 0.0067 & 0.7635 & 0.7133 & 0.8133 \\
\hline $08 / 26 / 13-200$ & 0.0000 & 0.0000 & 0.0000 & 0.0030 & 0.0000 & 0.0050 & 0.7633 & 0.7250 & 0.8000 \\
\hline $08 / 26 / 13-250$ & 0.0000 & 0.0000 & 0.0000 & 0.0031 & 0.0000 & 0.0040 & 0.7627 & 0.7400 & 0.7880 \\
\hline $08 / 26 / 13-300$ & 0.0000 & 0.0000 & 0.0000 & 0.0031 & 0.0000 & 0.0033 & 0.7631 & 0.7500 & 0.7767 \\
\hline
\end{tabular}


Appendix 3: Mean values and 95\% confidence intervals for CYT brood fish bootstap simulation

\begin{tabular}{|c|c|c|c|c|c|c|c|c|c|}
\hline \multirow{2}{*}{$\begin{array}{l}\text { mmddyy - } \\
\text { S n-value }\end{array}$} & \multicolumn{3}{|c|}{ 083-027-609 } & \multicolumn{3}{|c|}{ 083-103-352 } & \multicolumn{3}{|c|}{ 048-533-355 } \\
\hline & Mean & $\mathrm{Cl} 2.5 \%$ & Cl $97.5 \%$ & Mean & $\mathrm{Cl} 2.5 \%$ & Cl $97.5 \%$ & Mean & $\mathrm{Cl} 2.5 \%$ & Cl $97.5 \%$ \\
\hline $04 / 29 / 13-10$ & 0.3910 & 0.1000 & 0.7000 & 0.2006 & 0.0000 & 0.5000 & 0.0338 & 0.0000 & 0.2000 \\
\hline $04 / 29 / 13-20$ & 0.3922 & 0.2000 & 0.6000 & 0.2000 & 0.0500 & 0.4000 & 0.0331 & 0.0000 & 0.1000 \\
\hline $04 / 29 / 13-30$ & 0.3914 & 0.2333 & 0.5667 & 0.1991 & 0.0667 & 0.3333 & 0.0344 & 0.0000 & 0.1000 \\
\hline $04 / 29 / 13-40$ & 0.3911 & 0.2500 & 0.5250 & 0.1999 & 0.1000 & 0.3250 & 0.0339 & 0.0000 & 0.1000 \\
\hline $04 / 29 / 13-47$ & 0.3905 & 0.2553 & 0.5319 & 0.1994 & 0.1064 & 0.3191 & 0.0332 & 0.0000 & 0.0851 \\
\hline $04 / 29 / 13-60$ & 0.3920 & 0.2833 & 0.5000 & 0.2011 & 0.1167 & 0.3000 & 0.0337 & 0.0000 & 0.0833 \\
\hline $04 / 29 / 13-100$ & 0.3908 & 0.3100 & 0.4700 & 0.1997 & 0.1300 & 0.2700 & 0.0337 & 0.0100 & 0.0700 \\
\hline 04/29/13 - 150 & 0.3913 & 0.3333 & 0.4533 & 0.2002 & 0.1533 & 0.2467 & 0.0339 & 0.0133 & 0.0533 \\
\hline $04 / 29 / 13-200$ & 0.3915 & 0.3450 & 0.4350 & 0.1998 & 0.1650 & 0.2350 & 0.0338 & 0.0150 & 0.0500 \\
\hline $04 / 29 / 13-250$ & 0.3918 & 0.3600 & 0.4240 & 0.1999 & 0.1720 & 0.2280 & 0.0338 & 0.0200 & 0.0440 \\
\hline $04 / 29 / 13-300$ & 0.3918 & 0.3700 & 0.4133 & 0.1999 & 0.1800 & 0.2167 & 0.0338 & 0.0267 & 0.0400 \\
\hline $05 / 17 / 13-10$ & 0.4953 & 0.2000 & 0.8000 & 0.0454 & 0.0000 & 0.2000 & 0.1009 & 0.0000 & 0.3000 \\
\hline $05 / 17 / 13-20$ & 0.4987 & 0.3000 & 0.7000 & 0.0451 & 0.0000 & 0.1500 & 0.1005 & 0.0000 & 0.2500 \\
\hline 05/17/13 - 30 & 0.4989 & 0.3333 & 0.6667 & 0.0448 & 0.0000 & 0.1333 & 0.1003 & 0.0000 & 0.2000 \\
\hline $05 / 17 / 13-40$ & 0.4972 & 0.3500 & 0.6500 & 0.0449 & 0.0000 & 0.1250 & 0.1014 & 0.0250 & 0.2000 \\
\hline $05 / 17 / 13-47$ & 0.4995 & 0.3617 & 0.6383 & 0.0453 & 0.0000 & 0.1064 & 0.1017 & 0.0213 & 0.1915 \\
\hline $05 / 17 / 13-60$ & 0.4984 & 0.3833 & 0.6167 & 0.0454 & 0.0000 & 0.1000 & 0.1010 & 0.0333 & 0.1667 \\
\hline 05/17/13 - 100 & 0.4995 & 0.4200 & 0.5800 & 0.0449 & 0.0100 & 0.0800 & 0.1012 & 0.0500 & 0.1500 \\
\hline $05 / 17 / 13-150$ & 0.4988 & 0.4400 & 0.5600 & 0.0451 & 0.0200 & 0.0733 & 0.1015 & 0.0667 & 0.1400 \\
\hline $05 / 17 / 13-200$ & 0.4988 & 0.4550 & 0.5450 & 0.0452 & 0.0250 & 0.0650 & 0.1016 & 0.0750 & 0.1300 \\
\hline $05 / 17 / 13-250$ & 0.4986 & 0.4640 & 0.5320 & 0.0450 & 0.0320 & 0.0600 & 0.1015 & 0.0800 & 0.1200 \\
\hline 05/17/13 - 300 & 0.4986 & 0.4767 & 0.5200 & 0.0451 & 0.0367 & 0.0533 & 0.1015 & 0.0867 & 0.1133 \\
\hline $06 / 21 / 13-10$ & 0.0000 & 0.0000 & 0.0000 & 0.0602 & 0.0000 & 0.2000 & 0.0928 & 0.0000 & 0.3000 \\
\hline $06 / 21 / 13-20$ & 0.0000 & 0.0000 & 0.0000 & 0.0597 & 0.0000 & 0.2000 & 0.0923 & 0.0000 & 0.2500 \\
\hline $06 / 21 / 13-30$ & 0.0000 & 0.0000 & 0.0000 & 0.0598 & 0.0000 & 0.1667 & 0.0930 & 0.0000 & 0.2000 \\
\hline $06 / 21 / 13-40$ & 0.0000 & 0.0000 & 0.0000 & 0.0606 & 0.0000 & 0.1250 & 0.0932 & 0.0250 & 0.1750 \\
\hline $06 / 21 / 13-47$ & 0.0000 & 0.0000 & 0.0000 & 0.0602 & 0.0000 & 0.1277 & 0.0932 & 0.0213 & 0.1702 \\
\hline $06 / 21 / 13-60$ & 0.0000 & 0.0000 & 0.0000 & 0.0603 & 0.0167 & 0.1167 & 0.0923 & 0.0333 & 0.1667 \\
\hline $06 / 21 / 13-100$ & 0.0000 & 0.0000 & 0.0000 & 0.0600 & 0.0200 & 0.1000 & 0.0927 & 0.0500 & 0.1400 \\
\hline $06 / 21 / 13-150$ & 0.0000 & 0.0000 & 0.0000 & 0.0601 & 0.0333 & 0.0867 & 0.0928 & 0.0600 & 0.1267 \\
\hline $06 / 21 / 13-200$ & 0.0000 & 0.0000 & 0.0000 & 0.0600 & 0.0400 & 0.0800 & 0.0929 & 0.0650 & 0.1200 \\
\hline $06 / 21 / 13-250$ & 0.0000 & 0.0000 & 0.0000 & 0.0602 & 0.0440 & 0.0760 & 0.0929 & 0.0720 & 0.1120 \\
\hline $06 / 21 / 13-300$ & 0.0000 & 0.0000 & 0.0000 & 0.0600 & 0.0467 & 0.0700 & 0.0930 & 0.0767 & 0.1067 \\
\hline $07 / 26 / 13-10$ & 0.0028 & 0.0000 & 0.1000 & 0.4455 & 0.2000 & 0.7000 & 0.0081 & 0.0000 & 0.1000 \\
\hline $07 / 26 / 13-20$ & 0.0027 & 0.0000 & 0.0500 & 0.4463 & 0.2500 & 0.6500 & 0.0079 & 0.0000 & 0.0500 \\
\hline $07 / 26 / 13-30$ & 0.0026 & 0.0000 & 0.0333 & 0.4454 & 0.2667 & 0.6000 & 0.0079 & 0.0000 & 0.0333 \\
\hline $07 / 26 / 13-40$ & 0.0026 & 0.0000 & 0.0250 & 0.4460 & 0.3000 & 0.6000 & 0.0078 & 0.0000 & 0.0500 \\
\hline $07 / 26 / 13-47$ & 0.0026 & 0.0000 & 0.0213 & 0.4458 & 0.3191 & 0.5745 & 0.0078 & 0.0000 & 0.0426 \\
\hline $07 / 26 / 13-60$ & 0.0026 & 0.0000 & 0.0167 & 0.4455 & 0.3333 & 0.5667 & 0.0081 & 0.0000 & 0.0333 \\
\hline $07 / 26 / 13-100$ & 0.0026 & 0.0000 & 0.0100 & 0.4451 & 0.3600 & 0.5300 & 0.0079 & 0.0000 & 0.0200 \\
\hline $07 / 26 / 13-150$ & 0.0027 & 0.0000 & 0.0067 & 0.4452 & 0.3867 & 0.5067 & 0.0079 & 0.0000 & 0.0200 \\
\hline $07 / 26 / 13-200$ & 0.0027 & 0.0000 & 0.0050 & 0.4453 & 0.3950 & 0.4950 & 0.0080 & 0.0000 & 0.0150 \\
\hline $07 / 26 / 13-250$ & 0.0027 & 0.0000 & 0.0040 & 0.4459 & 0.4120 & 0.4840 & 0.0080 & 0.0000 & 0.0120 \\
\hline $07 / 26 / 13-300$ & 0.0027 & 0.0000 & 0.0033 & 0.4458 & 0.4200 & 0.4700 & 0.0080 & 0.0033 & 0.0100 \\
\hline $08 / 26 / 13-10$ & 0.0000 & 0.0000 & 0.0000 & 0.1728 & 0.0000 & 0.4000 & 0.0831 & 0.0000 & 0.3000 \\
\hline $08 / 26 / 13-20$ & 0.0000 & 0.0000 & 0.0000 & 0.1720 & 0.0500 & 0.3500 & 0.0831 & 0.0000 & 0.2000 \\
\hline $08 / 26 / 13-30$ & 0.0000 & 0.0000 & 0.0000 & 0.1728 & 0.0667 & 0.3000 & 0.0834 & 0.0000 & 0.2000 \\
\hline $08 / 26 / 13-40$ & 0.0000 & 0.0000 & 0.0000 & 0.1722 & 0.0750 & 0.3000 & 0.0832 & 0.0250 & 0.1750 \\
\hline $08 / 26 / 13-47$ & 0.0000 & 0.0000 & 0.0000 & 0.1722 & 0.0851 & 0.2766 & 0.0831 & 0.0213 & 0.1702 \\
\hline $08 / 26 / 13-60$ & 0.0000 & 0.0000 & 0.0000 & 0.1727 & 0.0833 & 0.2504 & 0.0833 & 0.0167 & 0.1500 \\
\hline $08 / 26 / 13-100$ & 0.0000 & 0.0000 & 0.0000 & 0.1718 & 0.1100 & 0.2300 & 0.0832 & 0.0400 & 0.1300 \\
\hline $08 / 26 / 13-150$ & 0.0000 & 0.0000 & 0.0000 & 0.1724 & 0.1267 & 0.2133 & 0.0831 & 0.0533 & 0.1133 \\
\hline $08 / 26 / 13-200$ & 0.0000 & 0.0000 & 0.0000 & 0.1723 & 0.1400 & 0.2050 & 0.0831 & 0.0600 & 0.1050 \\
\hline $08 / 26 / 13-250$ & 0.0000 & 0.0000 & 0.0000 & 0.1722 & 0.1480 & 0.1921 & 0.0831 & 0.0640 & 0.1000 \\
\hline $08 / 26 / 13-300$ & 0.0000 & 0.0000 & 0.0000 & 0.1724 & 0.1600 & 0.1833 & 0.0831 & 0.0733 & 0.0900 \\
\hline
\end{tabular}


Appendix 3: Mean values and 95\% confidence intervals for CYT brood fish bootstap simulation

\begin{tabular}{|c|c|c|c|c|c|c|c|c|c|}
\hline \multirow{2}{*}{$\begin{array}{l}\text { mmddyy- } \\
\text { S n-value }\end{array}$} & \multicolumn{3}{|c|}{ 048-567-798 } & \multicolumn{3}{|c|}{$048-624-825$} & \multicolumn{3}{|c|}{$048-779-622$} \\
\hline & Mean & $\mathrm{Cl} 2.5 \%$ & $\mathrm{Cl} 97.5 \%$ & Mean & Cl $2.5 \%$ & Cl $97.5 \%$ & Mean & $\mathrm{Cl} 2.5 \%$ & Cl $97.5 \%$ \\
\hline $04 / 29 / 13-10$ & 0.2126 & 0.0000 & 0.5000 & 0.0000 & 0.0000 & 0.0000 & 0.0647 & 0.0000 & 0.2000 \\
\hline $04 / 29 / 13-20$ & 0.2126 & 0.0500 & 0.4000 & 0.0000 & 0.0000 & 0.0000 & 0.0647 & 0.0000 & 0.2000 \\
\hline 04/29/13 - 30 & 0.2146 & 0.1000 & 0.3667 & 0.0000 & 0.0000 & 0.0000 & 0.0652 & 0.0000 & 0.1667 \\
\hline $04 / 29 / 13-40$ & 0.2140 & 0.1000 & 0.3250 & 0.0000 & 0.0000 & 0.0000 & 0.0646 & 0.0000 & 0.1500 \\
\hline $04 / 29 / 13-47$ & 0.2148 & 0.1064 & 0.3191 & 0.0000 & 0.0000 & 0.0000 & 0.0650 & 0.0000 & 0.1277 \\
\hline $04 / 29 / 13-60$ & 0.2134 & 0.1167 & 0.3167 & 0.0000 & 0.0000 & 0.0000 & 0.0647 & 0.0167 & 0.1333 \\
\hline 04/29/13 - 100 & 0.2144 & 0.1500 & 0.2800 & 0.0000 & 0.0000 & 0.0000 & 0.0650 & 0.0300 & 0.1100 \\
\hline $04 / 29 / 13-150$ & 0.2140 & 0.1667 & 0.2602 & 0.0000 & 0.0000 & 0.0000 & 0.0647 & 0.0333 & 0.0933 \\
\hline 04/29/13 - 200 & 0.2143 & 0.1750 & 0.2500 & 0.0000 & 0.0000 & 0.0000 & 0.0647 & 0.0400 & .0850 \\
\hline $04 / 29 / 13-250$ & 0.2143 & 0.1840 & 0.2400 & 0.0000 & 0.0000 & 0.0000 & 0.0648 & 0.0480 & 0.0800 \\
\hline $04 / 29 / 13-300$ & 0.2140 & 0.1967 & 0 & 0 & 0. & 00 & 0.0647 & 0.0533 & 0.0733 \\
\hline 05/17/13 - 10 & 0.3698 & 0.1000 & 0.7000 & 0.0091 & 0.0000 & 0.1000 & 0.0085 & 0.0000 & 0.1000 \\
\hline 05/17/13 - 20 & 0.3670 & 0.1500 & 0.6000 & 0.0085 & 0.0000 & 0.0500 & 0.0085 & 0.0000 & 0.0500 \\
\hline 05/17/13 - 30 & 0.3696 & 0.2000 & 0.5333 & 0.0083 & 0.0000 & 0.0333 & 0.0084 & 0.0000 & 0.0333 \\
\hline $05 / 17 / 13-40$ & 0.3682 & 0.2250 & 0.5000 & 0.0083 & 0.0000 & 0.0500 & 0.0086 & 0.0000 & 0.0500 \\
\hline $05 / 17 / 13-47$ & 0.3690 & 0.2340 & 0.4894 & 0.0085 & 0.0000 & 0.0426 & 0.0084 & 0.0000 & 0.0426 \\
\hline 05/17/13 - 60 & 0.3695 & 0.2667 & 0.4833 & 0.0085 & 0.0000 & 0.0333 & 0.0085 & 0.0000 & 0.0333 \\
\hline $05 / 17 / 13-100$ & 0.3688 & 0.2900 & 0.4500 & 0.0085 & 0.0000 & 0200 & 5 & 10 & 0 \\
\hline 05/17/13 - 150 & 0.3692 & 0.3133 & 0.4267 & 0.0084 & 0.0000 & 0.0200 & 0.0085 & 0.0000 & 0.0200 \\
\hline $05 / 17 / 13-200$ & 0.3691 & 0.3250 & 0 & 0.0084 & 0 & 50 & 5 & 0000 & 50 \\
\hline $05 / 17 / 13-250$ & 0.3690 & 0.3360 & 0.4000 & 0.0085 & 0.0000 & 0.0120 & 0.0085 & 0.0040 & 0.0120 \\
\hline 05/17/13 - 300 & 0.3692 & 0.3467 & 0.3900 & 0.0085 & 0.0033 & 0.0100 & 0.0084 & 0.0033 & 0.0100 \\
\hline $06 / 21 / 13-10$ & 0.1750 & 0.0000 & 0.4000 & 0.0115 & 0.0000 & 0.1000 & 0.0225 & 0.0000 & 0.1000 \\
\hline $06 / 21 / 13-20$ & 0.1754 & 0.0500 & 0.3500 & 0.0111 & 0.0000 & 0.0500 & 0.0221 & 0.0000 & 0.1000 \\
\hline 06/21/13 - 30 & 0.1753 & 0.0667 & 0.3000 & 0.0112 & 0.0000 & 0.0667 & 0.0214 & 0.0000 & 0.0667 \\
\hline $06 / 21 / 13$ - 40 & 0.1751 & 0.0750 & 0.3000 & 0.0111 & 0.0000 & 0.0500 & 0.0212 & 0.0000 & 0.0750 \\
\hline $06 / 21 / 13-47$ & 0.1742 & 0.0851 & 0.2766 & 0.0110 & 0.0000 & 0.0426 & 0.0219 & 0.0000 & 0638 \\
\hline $06 / 21 / 13-60$ & 0.1743 & 0.0833 & 0.2667 & 0.0109 & 0.0000 & 0.0333 & 0.0221 & 0.0000 & 0.0667 \\
\hline $06 / 21 / 13-100$ & 0.1748 & 0.1100 & 0.2400 & 0.0111 & 0.0000 & 0.0300 & 0.0219 & 0.0000 & 0.0500 \\
\hline $06 / 21 / 13-150$ & 0.1743 & 0.1267 & 0.2200 & 0.0108 & 0.0000 & 0.0202 & 0.0220 & 0.0067 & 0.0400 \\
\hline $06 / 21 / 13-200$ & 0.1749 & 0.1400 & 0.2100 & 0.0110 & 0.0000 & 0.0200 & 0.0219 & 0.0100 & 0.0350 \\
\hline $06 / 21 / 13-250$ & 0.1748 & 0.1480 & 0.2000 & 0.0109 & 0.0040 & 0.0160 & 0.0218 & 0.0120 & 0.0320 \\
\hline $06 / 21 / 13-300$ & 0.1747 & 0.1567 & 0.1933 & 0.0109 & 0.0067 & 0.0133 & 0.0218 & 0.0133 & 0.0267 \\
\hline $07 / 26 / 13-10$ & 0.0522 & 0.0000 & 0.2000 & 0.0162 & 0.0000 & 0.1000 & 0.0101 & 0.0000 & 0.1000 \\
\hline $07 / 26 / 13-20$ & 0.0530 & 0.0000 & 0.1500 & 0.0159 & 0.0000 & 0.1000 & 0.0111 & 0.0000 & 0.0500 \\
\hline 07/26/13 - 30 & 0.0524 & 0.0000 & 0.1333 & 0.0157 & 0.0000 & 0.0667 & 0.0106 & 0.0000 & 0.0667 \\
\hline $07 / 26 / 13-40$ & 0.0533 & 0.0000 & 0.1250 & 0.0162 & 0.0000 & 500 & 0.0105 & 0.0000 & 500 \\
\hline $07 / 26 / 13-47$ & 0.0536 & 0.0000 & 0.1277 & 0.0160 & 0.0000 & 0.0638 & 0.0108 & 0.0000 & 0.0426 \\
\hline $07 / 26 / 13-60$ & 0.0532 & 0.0000 & 0.1167 & 0.0159 & 0.0000 & 0.0500 & 0.0107 & 0.0000 & 0.0333 \\
\hline $07 / 26 / 13-100$ & 0.0527 & 0.0200 & 0.0900 & 0.0162 & 0.0000 & 0.0400 & 0.0105 & 0.0000 & 0.0300 \\
\hline $07 / 26 / 13-150$ & 0.0531 & 0.0267 & 0.0800 & 0.0159 & 0.0000 & 0.0333 & 0.0107 & 0.0000 & 0.0267 \\
\hline $07 / 26 / 13-200$ & 0.0532 & 0.0300 & 0.0750 & 0.0157 & 0.0050 & 0.0250 & 0.0106 & 0.0000 & 0.0200 \\
\hline $07 / 26 / 13-250$ & 0.0531 & 0.0360 & 0.0680 & 0.0159 & 0.0080 & 0.0240 & 0.0106 & 0.0040 & 0.0160 \\
\hline $07 / 26 / 13-300$ & 0.0530 & 0.0400 & 0.0633 & 0.0159 & 0.0100 & 0.0200 & 0.0106 & 0.0033 & 0.0133 \\
\hline 08/26/13 - 10 & 0.1264 & 0.0000 & 0.3000 & 0.0490 & 0.0000 & 0.2000 & 0.0519 & 0.0000 & 0.2000 \\
\hline 08/26/13 - 20 & 0.1268 & 0.0000 & 0.3000 & 0.0498 & 0.0000 & 0.1500 & 0.0530 & 0.0000 & .1500 \\
\hline 08/26/13 - 30 & 0.1256 & 0.0333 & 0.2333 & 0.0494 & 0.0000 & 0.1333 & 0.0523 & 0.0000 & 0.1333 \\
\hline $08 / 26 / 13$ - 40 & 0.1270 & 0.0500 & 0.2250 & 0.0489 & 0.0000 & 0.1250 & 0.0519 & 0.0000 & 0.1250 \\
\hline 08/26/13 - 47 & 0.1264 & 0.0426 & 0.2128 & 0.0491 & 0.0000 & 0.1064 & 0.0518 & 0.0000 & 0.1064 \\
\hline $08 / 26 / 13-60$ & 0.1253 & 0.0500 & 0.2000 & 0.0490 & 0.0000 & 0.1000 & 0.0522 & 0.0000 & 0.1000 \\
\hline $08 / 26 / 13-100$ & 0.1257 & 0.0700 & 0.1800 & 0.0490 & 0.0200 & 0.0900 & 0.0525 & 0.0200 & 0.0900 \\
\hline $08 / 26 / 13-150$ & 0.1260 & 0.0867 & 0.1667 & 0.0493 & 0.0267 & 0.0733 & 0.0523 & 0.0267 & 0.0800 \\
\hline $08 / 26 / 13-200$ & 0.1262 & 0.0950 & 0.1550 & 0.0492 & 0.0300 & 0.0650 & 0.0525 & 0.0350 & 0.0700 \\
\hline $08 / 26 / 13-250$ & 0.1262 & 0.1040 & 0.1440 & 0.0492 & 0.0360 & 0.0600 & 0.0524 & 0.0400 & 0.0640 \\
\hline $08 / 26 / 13-300$ & 0.1261 & 0.1133 & 0.1367 & 0.0492 & 0.0400 & 0.0533 & 0.0523 & 0.0433 & 0.0567 \\
\hline
\end{tabular}


Appendix 3: Mean values and 95\% confidence intervals for CYT brood fish bootstap simulation

\begin{tabular}{|c|c|c|c|c|c|c|c|c|c|}
\hline \multirow{2}{*}{$\begin{array}{l}\text { mmddyy - } \\
\text { S n-value }\end{array}$} & \multicolumn{3}{|c|}{ 061-381-264 } & \multicolumn{3}{|c|}{ 061-536-613 } & \multicolumn{3}{|c|}{ 083-024-797 } \\
\hline & Mean & $\mathrm{Cl} 2.5 \%$ & $\mathrm{Cl} 97.5 \%$ & Mean & $\mathrm{Cl} 2.5 \%$ & Cl $97.5 \%$ & Mean & $\mathrm{Cl} 2.5 \%$ & $\mathrm{Cl} 97.5 \%$ \\
\hline $04 / 29 / 13-10$ & 0.0641 & 0.0000 & 0.2000 & 0.1728 & 0.0000 & 0.4000 & 0.0114 & 0.0000 & 0.1000 \\
\hline $04 / 29 / 13-20$ & 0.0661 & 0.0000 & 0.2000 & 0.1723 & 0.0500 & 0.3500 & 0.0112 & 0.0000 & 0.0500 \\
\hline $04 / 29 / 13-30$ & 0.0650 & 0.0000 & 0.1667 & 0.1717 & 0.0667 & 0.3000 & 0.0111 & 0.0000 & 0.0667 \\
\hline $04 / 29 / 13-40$ & 0.0652 & 0.0000 & 0.1500 & 0.1716 & 0.0750 & 0.2750 & 0.0114 & 0.0000 & 0.0500 \\
\hline $04 / 29 / 13-47$ & 0.0649 & 0.0000 & 0.1277 & 0.1718 & 0.0851 & 0.2766 & 0.0114 & 0.0000 & 0.0426 \\
\hline $04 / 29 / 13-60$ & 0.0653 & 0.0167 & 0.1333 & 0.1715 & 0.0833 & 0.2667 & 0.0113 & 0.0000 & 0.0333 \\
\hline 04/29/13 - 100 & 0.0645 & 0.0300 & 0.1100 & 0.1718 & 0.1100 & 0.2400 & 0.0112 & 0.0000 & 0.0300 \\
\hline 04/29/13 - 150 & 0.0647 & 0.0333 & 0.0933 & 0.1720 & 0.1267 & 0.2200 & 0.0113 & 0.0000 & 0.0267 \\
\hline $04 / 29 / 13-200$ & 0.0650 & 0.0400 & 0.0900 & 0.1716 & 0.1350 & 2050 & 0.0112 & .0000 & 0.0200 \\
\hline $04 / 29 / 13-250$ & 0.0647 & 0.0480 & 0.0800 & 0.1717 & 0.1440 & 0.1960 & 0.0113 & 0.0040 & 0.0160 \\
\hline 04/29/13 - 300 & 0.0648 & 33 & 733 & 19 & 33 & 77 & 12 & 57 & 33 \\
\hline $05 / 17 / 13-10$ & 0.1487 & 0.0000 & 0.4000 & 0.1096 & 0.0000 & 0.3000 & 0.1094 & 0.0000 & 0.3000 \\
\hline $05 / 17 / 13-20$ & 0.1502 & 0.0000 & 3000 & 0.1115 & 0.0000 & 2500 & 1104 & .0000 & 2500 \\
\hline $05 / 17 / 13-30$ & 0.1505 & 0.0333 & 0.2667 & 0.1099 & 0.0000 & 0.2333 & 0.1097 & 0.0000 & 0.2333 \\
\hline $05 / 17 / 13-40$ & 0.1497 & 0.0500 & 0.2500 & 0.1099 & 0.0250 & 0.2000 & 1095 & 0.0250 & 0.2000 \\
\hline $05 / 17 / 13-47$ & 0.1488 & 0.0638 & 0.2553 & 0.1100 & 0.0426 & 0.1915 & 0.1096 & 0.0426 & 0.1915 \\
\hline $05 / 17 / 13-60$ & 0.1482 & 0.0667 & 0.2333 & 0.1102 & 0.0500 & 0.1833 & 0.1099 & 0.0500 & 0.1833 \\
\hline $05 / 17 / 13-100$ & 0.1496 & 0.0900 & 0.2100 & 0.1099 & 0.0600 & 0.1600 & 0.1096 & 0.0600 & 0.1600 \\
\hline 05/17/13 - 150 & 0.1488 & 0.1067 & 0.1933 & 0.1099 & 0.0733 & 0.1467 & 0.1096 & 0.0733 & 0.1467 \\
\hline $05 / 17 / 13-200$ & 0.1492 & 0.1150 & 0.1800 & 0.1098 & 0.0800 & 1400 & 1096 & .0800 & 00 \\
\hline $05 / 17 / 13-250$ & 0.1492 & 0.1240 & 0.1720 & 0.1098 & 0.0880 & 0.1320 & 0.1099 & 0.0880 & 0.1280 \\
\hline $05 / 17 / 13-300$ & 0.1492 & 33 & 1633 & 98 & 3 & 3 & 7 & 33 & 33 \\
\hline $06 / 21 / 13-10$ & 0.2407 & 0.0000 & 0.5000 & 0.0559 & 0.0000 & 0.2000 & 0.0936 & 0.0000 & 0.3000 \\
\hline $06 / 21 / 13-20$ & 0.2459 & 0.1000 & 0.4500 & 0.0577 & 0.0000 & 1500 & 0.0927 & 0.0000 & 0.2500 \\
\hline $06 / 21 / 13-30$ & 0.2439 & 0.1000 & 0.4000 & 0.0570 & 0.0000 & 0.1333 & 0.0927 & 0.0000 & 0.2000 \\
\hline $06 / 21 / 13-40$ & 0.2436 & 0.1250 & 0.3750 & 0.0576 & 0.0000 & 1250 & 0.0929 & 0.0250 & 0.1750 \\
\hline $06 / 21 / 13-47$ & 0.2438 & 0.1277 & 0.3617 & 0.0571 & 0.0000 & 0.1277 & 0.0926 & 0.0213 & 0.1702 \\
\hline $06 / 21 / 13-60$ & 0.2435 & 0.1500 & 0.3500 & 0.0574 & 0.0167 & 1167 & .0925 & .0333 & 0.1667 \\
\hline $06 / 21 / 13-100$ & 0.2434 & 0.1700 & 0.3200 & 0.0575 & 0.0200 & 0.1000 & 0.0929 & 0.0500 & 0.1400 \\
\hline $06 / 21 / 13-150$ & 0.2435 & 0.1933 & 0.2933 & 0.0574 & 0.0267 & 0.0867 & 0.0932 & 0.0600 & 0.1267 \\
\hline $06 / 21 / 13-200$ & 0.2428 & 0.2050 & 0.2800 & 0.0575 & 0.0350 & 0.0800 & 0.0930 & 0.0650 & 0.1200 \\
\hline $06 / 21 / 13-250$ & 0.2432 & 0.2120 & 0.2720 & 0.0573 & 0.0400 & 0720 & .0929 & .0720 & 0.1120 \\
\hline 06/21/13 - 300 & 0.2433 & 0.2233 & 0.2633 & 0.0574 & 0.0467 & 0667 & .0929 & .0800 & 0.1067 \\
\hline $07 / 26 / 13-10$ & 0.0571 & 00 & 2000 & 1521 & 000 & & 1975 & & 00 \\
\hline $07 / 26 / 13-20$ & 0.0566 & 0.0000 & 0.1500 & 0.1527 & 0.0000 & 3000 & .1954 & .0500 & 0.3500 \\
\hline $07 / 26 / 13-30$ & 0.0563 & 0.0000 & 0.1333 & 0.1534 & 0.0333 & $26 / 5$ & 1971 & .0667 & 3333 \\
\hline $07 / 26 / 13-40$ & 0.0555 & 0.0000 & 0.1250 & 0.1535 & 0.0500 & 0.2750 & 0.1961 & 0.0750 & 0.3250 \\
\hline $07 / 26 / 13-47$ & 0.0555 & 0.0000 & 0.1277 & 0.1535 & 0.0638 & 3 & 0.1961 & 0.0851 & 0.2979 \\
\hline $07 / 26 / 13-60$ & 0.0557 & 0.0167 & 0.1167 & 0.1537 & 0.0667 & 0.2500 & 0.1966 & 0.1167 & 0.3000 \\
\hline $07 / 26 / 13-100$ & 0.0554 & 0.0200 & 0.1000 & 0.1545 & 0.1000 & 0.2200 & 0.1968 & 0.1300 & 0.2602 \\
\hline $07 / 26 / 13-150$ & 0.0559 & 0.0267 & 0.0867 & 0.1540 & 0.1067 & 0.2000 & 0.1963 & 0.1467 & 0.2467 \\
\hline $07 / 26 / 13-200$ & 0.0557 & 0.0350 & 0.0750 & 0.1540 & 0.1200 & 0.1850 & 0.1965 & 0.1600 & 0.2350 \\
\hline $07 / 26 / 13-250$ & 0.0556 & 0.0400 & 0.0720 & 0.1536 & 0.1280 & 0.1800 & 0.1963 & 0.1680 & 0.2240 \\
\hline $07 / 26 / 13-300$ & 0.0557 & 0.0433 & 0.0667 & 0.1537 & 0.1333 & 0.1700 & .1963 & .1767 & 0.2167 \\
\hline $08 / 26 / 13-10$ & 0.1166 & 0.0000 & 3000 & 0.1780 & 0.0000 & 4000 & 0.0739 & 0.0000 & 0.3000 \\
\hline $08 / 26 / 13-20$ & 0.1167 & 0.0000 & 0.2500 & 0.1777 & 0.0500 & 0.3500 & .0734 & 0.0000 & 0.2000 \\
\hline $08 / 26 / 13-30$ & 0.1171 & 0.0333 & 2333 & 0.1777 & 0.0667 & 0.3333 & 0.0745 & 0.0000 & 0.1667 \\
\hline $08 / 26 / 13-40$ & 0.1161 & 0.0250 & 0.2250 & 0.1786 & 0.0750 & 0.3000 & 0.0739 & 0.0000 & 0.1500 \\
\hline $08 / 26 / 13-47$ & 0.1162 & 0.0426 & 0.2128 & 0.1797 & 0.0851 & 2766 & 0.0739 & 0.0213 & 0.1489 \\
\hline $08 / 26 / 13-60$ & 0.1165 & 0.0500 & 0.2000 & 0.1787 & 0.1000 & 0.2667 & 0.0742 & 0.0167 & 0.1333 \\
\hline $08 / 26 / 13-100$ & 0.1171 & 0.0700 & 0.1700 & 0.1790 & 0.1200 & 0.2400 & 0.0738 & 0.0300 & 0.1200 \\
\hline $08 / 26 / 13-150$ & 0.1171 & 0.0800 & 0.1533 & 0.1783 & 0.1333 & 0.2267 & 0.0736 & 0.0467 & 0.1067 \\
\hline $08 / 26 / 13-200$ & 0.1167 & 0.0900 & 0.1450 & 0.1788 & 0.1450 & 0.2100 & 0.0737 & 0.0500 & 0.0950 \\
\hline $08 / 26 / 13-250$ & 0.1167 & 0.0960 & 60 & 0.1787 & 0.1560 & 0.2000 & 0.0738 & 0.0560 & 0.0880 \\
\hline $08 / 26 / 13-300$ & 0.1170 & 0.1067 & 0.1267 & 0.1783 & 0.1667 & 0.1900 & 0.0739 & 0.0667 & 0.0800 \\
\hline
\end{tabular}


Appendix 3: Mean values and 95\% confidence intervals for CYT brood fish bootstap simulation

\begin{tabular}{|c|c|c|c|c|c|c|c|c|c|c|c|c|}
\hline \multirow{2}{*}{$\begin{array}{l}\text { mmddyy - } \\
\text { S n-value }\end{array}$} & \multicolumn{3}{|c|}{$083-042-784$} & \multicolumn{3}{|c|}{$083-070-054$} & \multicolumn{3}{|c|}{$083-101-080$} & \multicolumn{3}{|c|}{ 083-103-352 } \\
\hline & Mean & Cl $2.5 \%$ & $\mathrm{Cl} 97.5 \%$ & Mean & Cl $2.5 \%$ & Cl $97.5 \%$ & Mean & Cl $2.5 \%$ & Cl $97.5 \%$ & Mean & Cl $2.5 \%$ & Cl $97.5 \%$ \\
\hline $04 / 29 / 13-10$ & 0.0747 & 0.0000 & 0.3000 & 0.0026 & 0.0000 & 0.1000 & 0.1627 & 0.0000 & 0.4000 & 0.1627 & 0.1627 & 0.2373 \\
\hline $04 / 29 / 13-20$ & 0.0732 & 0.0000 & 0.2000 & 0.0028 & 0.0000 & 0.0500 & 0.1640 & 0.0500 & 0.3500 & 0.1640 & 0.1140 & 0.1861 \\
\hline $04 / 29 / 13-30$ & 0.0732 & 0.0000 & 0.1667 & 0.0028 & 0.0000 & 0.0333 & 0.1628 & 0.0333 & .3000 & .1628 & .1295 & 1372 \\
\hline $04 / 29 / 13-40$ & 0.0739 & 0.0000 & 0.1500 & 0.0028 & 0.0000 & 0.0250 & 0.1628 & 0.0500 & 0.2750 & 0.1628 & 0.1128 & 0.1122 \\
\hline $04 / 29 / 13-47$ & 0.0729 & 0.0213 & 0.1489 & 0.0029 & 0.0000 & 0.0213 & 0.1637 & 0.0638 & 0.2553 & 0.1637 & 0.0999 & 0.0916 \\
\hline $04 / 29 / 13-60$ & 0.0732 & 0.0167 & 0.1333 & 0.0027 & 0.0000 & 0.0167 & 0.1630 & 0.0833 & 0.2500 & 0.1630 & 0.0797 & 0.0870 \\
\hline $04 / 29 / 13-100$ & 0.0734 & 0.0300 & 0.1200 & 0.0028 & 0.0000 & 0.0100 & 0.1636 & 0.1000 & 0.2300 & 0.1636 & 0.0636 & 0.0664 \\
\hline $04 / 29 / 13-150$ & 0.0732 & 0.0400 & 0.1067 & 0.0028 & 0.0000 & 0.0067 & 0.1633 & 0.1200 & 0.2067 & 0.1633 & 0.0433 & 0.0434 \\
\hline $04 / 29 / 13-200$ & 0.0733 & 0.0500 & 0.0950 & 0.0028 & 0.0000 & 0.0050 & 0.1634 & 0.1300 & 0.1950 & 0.1634 & 0.0334 & 0.0316 \\
\hline $04 / 29 / 13-250$ & 0.0733 & 0.0560 & 0.0920 & 0.0028 & 0.0000 & 0.0040 & 0.1634 & 0.1400 & 1880 & .1634 & 0.0234 & 0246 \\
\hline $04 / 29 / 13-300$ & 0.0733 & 0.0600 & 0.0833 & 0.0028 & 0.0000 & 0.0033 & 0.1634 & 0.1467 & 0.1800 & 0.1634 & 0.0167 & 0.0166 \\
\hline $05 / 17 / 13-10$ & 0.0594 & 0.0000 & 0.2000 & 0.0000 & 0.0000 & 0.0000 & 0.0395 & 0.0000 & 0.2000 & 0.0395 & 0.0395 & 0.1606 \\
\hline $05 / 17 / 13-20$ & 0.0589 & 0.0000 & 0.1500 & 0.0000 & 0.0000 & 0.0000 & 0.0393 & 0.0000 & 0.1500 & 0.0393 & 0.0393 & 0.1107 \\
\hline $05 / 17 / 13-30$ & 0.0595 & 0.0000 & 0.1667 & 0.0000 & 0.0000 & 0.0000 & 0.0390 & 0.0000 & 0.1000 & 0.0390 & 0.0390 & 0.0610 \\
\hline $05 / 17 / 13-40$ & 0.0594 & 0.0000 & 0.1250 & 0.0000 & 0.0000 & 0000 & 0.0400 & 0.0000 & 1000 & .0400 & .0400 & .0600 \\
\hline $05 / 17 / 13-47$ & 0.0591 & 0.0000 & 0.1277 & 0.0000 & 0.0000 & 0.0000 & 0.0398 & 0.0000 & 0.1064 & 0.0398 & 0.0398 & 0.0666 \\
\hline $05 / 17 / 13-60$ & 0.0591 & 0.0167 & 0 & 0.0000 & 0.0000 & 00 & 0.03 & 0000 & 0833 & 8 & 8 & 36 \\
\hline $05 / 17 / 13-100$ & 0.0594 & 0.0200 & 0.1000 & 0.0000 & 0.0000 & 0.0000 & 0.0394 & 0.0100 & 0.0700 & 0.0394 & 0.0294 & 0.0306 \\
\hline $05 / 17 / 13-150$ & 0.0593 & 0.0333 & 0.0867 & 0.0000 & 0.0000 & 0.0000 & 0.0396 & 0.0133 & 0.0667 & 0.0396 & 0.0262 & 0.0271 \\
\hline $05 / 17 / 13-200$ & 0.0592 & 0.0400 & 0.0800 & 0.0000 & 0.0000 & 0.0000 & 0.0394 & 0.0200 & 0.0550 & 0.0394 & 0.0194 & 0.0156 \\
\hline $05 / 17 / 13-250$ & 0.0593 & 0.0440 & 0.0760 & 0.0000 & 0.0000 & 0.0000 & 0.0394 & 0.0240 & 0.0520 & 0.0394 & 0.0154 & 0.0126 \\
\hline $05 / 17 / 13-300$ & 0.0592 & 0.0467 & 0.0700 & 0.0000 & 0.0000 & 0.0000 & 0.0394 & 0.0300 & 0.0467 & .0394 & .0094 & 0.0073 \\
\hline $06 / 21 / 13-10$ & 0.1399 & 0.0000 & 0.4000 & 0.0000 & 0.0000 & 0.0000 & 0.1079 & 0.0000 & 0.3000 & 0.1079 & 0.1079 & 0.1921 \\
\hline $06 / 21 / 13-20$ & 0.1380 & 0.0000 & 0.3000 & 0.0000 & 0.0000 & 0.0000 & 0.1052 & 0.0000 & .2500 & 0.1052 & 0.1052 & 0.1448 \\
\hline $06 / 21 / 13-30$ & 0.1397 & 0.0333 & 0.2667 & 0.0000 & 0.0000 & 0.0000 & 0.1061 & 0.0000 & 0.2333 & 0.1061 & 0.1061 & 0.1273 \\
\hline $06 / 21 / 13-40$ & 0.1384 & 0.0500 & 0.2500 & 0.0000 & 0.0000 & 0.0000 & 0.1065 & 0.0250 & 0.2000 & 0.1065 & 0.0815 & 0.0935 \\
\hline $06 / 21 / 13-47$ & 0.1399 & 0.0426 & 0.2340 & 0.0000 & 0.0000 & 0.0000 & 0.1061 & 0.0213 & 0.1915 & 0.1061 & .0848 & .0854 \\
\hline $06 / 21 / 13-60$ & 0.1393 & 0.0667 & 0.2167 & 0.0000 & 0.0000 & 0.0000 & 0.1074 & 0.0333 & 0.1833 & 0.1074 & 0.0741 & 0.0759 \\
\hline $06 / 21 / 13-100$ & 0.1394 & 0.0800 & 0.2000 & 0.0000 & 0.0000 & 0.0000 & 0.1062 & 0.0600 & 1600 & 1062 & .0462 & .0538 \\
\hline $06 / 21 / 13-150$ & 0.1394 & 0.1000 & 0.1800 & 0.0000 & 0.0000 & 0.0000 & 0.1066 & 0.0667 & 0.1 & 0.1066 & 0.0399 & 0.0401 \\
\hline $06 / 21 / 13-200$ & 0.1396 & 0.1050 & 0.1700 & 0.0000 & 0.0000 & 0.0000 & 0.1066 & 0.0800 & .1350 & 0.1066 & 0.0266 & 0.0284 \\
\hline $06 / 21 / 13-250$ & 0.1394 & 0.1160 & 0.1640 & 0.0000 & 0.0000 & 0.0000 & 0.1065 & 0.0840 & 0.1280 & 0.1065 & 0.0225 & 0.0215 \\
\hline $06 / 21 / 13-300$ & 0.1394 & 0.1233 & 0.1567 & 0.0000 & 0.0000 & 0.0000 & 0.1066 & 0.0900 & 0.1200 & 0.1066 & 0.0166 & 0.0134 \\
\hline $07 / 26 / 13-10$ & 0.0454 & 0.0000 & 0.2000 & 0.0000 & 0.0000 & 0.0000 & 0.0158 & 0.0000 & 0.1000 & 0.0158 & 0.0158 & 0.0842 \\
\hline $07 / 26 / 13-20$ & 0.0454 & 0.0000 & 0.1500 & 0.0000 & 0.0000 & 0.0000 & 0.0158 & 0.0000 & 0.1000 & 0.0158 & .0158 & .0842 \\
\hline $07 / 26 / 13-30$ & 0.0450 & 0.0000 & 0.1333 & 0.0000 & 0.0000 & 0.0000 & 0.0163 & 0.0000 & 0.0667 & 0.0163 & .0163 & 0.0504 \\
\hline $07 / 26 / 13-40$ & 0.0453 & 0.0000 & 0.1250 & 0.0000 & 0.0000 & 0.0000 & 0.0159 & 0.0000 & 0.0500 & 0.0159 & 0.0159 & .0341 \\
\hline $07 / 26 / 13-47$ & 0.0448 & 0.0000 & 0.1064 & 0.0000 & 0.0000 & 0.0000 & 0.0162 & 0.0000 & 0.0638 & 0.0162 & 0.0162 & 0.0477 \\
\hline $07 / 26 / 13-60$ & 0.0448 & 0.0000 & 0.1000 & 0.0000 & 0.0000 & 0.0000 & 0.0159 & 0.0000 & 0.0500 & 0.0159 & 0.0159 & 0.0341 \\
\hline $07 / 26 / 13-100$ & 0.0448 & 0.0100 & 0.0800 & 0.0000 & 0.0000 & 0.0000 & 0.0160 & 0.0000 & 0.0400 & 0.0160 & 0.0160 & 0.0240 \\
\hline $07 / 26 / 13-150$ & 0.0450 & 0.0200 & 0.0733 & 0.0000 & 0.0000 & 0.0000 & 0.0160 & 0.0000 & 0.0333 & 0.0160 & 0.0160 & 0.0174 \\
\hline $07 / 26 / 13-200$ & 0.0451 & 0.0250 & 0.0650 & 0.0000 & 0.0000 & 0.0000 & 0.0159 & 0.0050 & 0.0250 & 0.0159 & 0.0109 & 0.0091 \\
\hline $07 / 26 / 13-250$ & 0.0451 & 0.0280 & 0.0600 & 0.0000 & 0.0000 & 0.0000 & 0.0159 & 0.0080 & 0.0240 & 0.0159 & 0.0079 & 0.0081 \\
\hline $07 / 26 / 13-300$ & 0.0451 & 0.0333 & 0.0533 & 0.0000 & 0.0000 & 0.0000 & 0.0159 & 0.0100 & 0.0200 & 0.0159 & 0.0059 & 0.0041 \\
\hline $08 / 26 / 13-10$ & 0.0991 & 0.0000 & 0.3000 & 0.0000 & 0.0000 & 0.0000 & 0.0492 & 0.0000 & 0.2000 & 0.0492 & 0.0492 & 0.1508 \\
\hline $08 / 26 / 13-20$ & 0.0979 & 0.0000 & 0.2500 & 0.0000 & 0.0000 & 0.0000 & 0.0495 & 0.0000 & 0.1500 & 0.0495 & 0.0495 & 0.1005 \\
\hline $08 / 26 / 13-30$ & 0.0986 & 0.0000 & 0.2000 & 0.0000 & 0.0000 & 0.0000 & 0.0487 & 0.0000 & 0.1333 & 0.0487 & 0.0487 & 0.0847 \\
\hline $08 / 26 / 13-40$ & 0.0987 & 0.0250 & 0.2000 & 0.0000 & 0.0000 & 0.0000 & 0.0494 & 0.0000 & .1250 & 0.0494 & 0.0494 & 0.0756 \\
\hline $08 / 26 / 13-47$ & 0.0985 & 0.0213 & 0.1702 & 0.0000 & 0.0000 & 0.0000 & 0.0492 & 0.0000 & 0.1064 & 0.0492 & 0.0492 & 0.0572 \\
\hline $08 / 26 / 13-60$ & 0.0988 & 0.0333 & 0.1667 & 0.0000 & 0.0000 & 0.0000 & 0.0493 & 0.0000 & 0.1000 & 0.0493 & 0.0493 & 0.0507 \\
\hline $08 / 26 / 13-100$ & 0.0983 & 0.0500 & 0.1500 & 0.0000 & 0.0000 & 0.0000 & 0.0496 & 0.0200 & 0.0900 & 0.0496 & 0.0296 & 0.0404 \\
\hline $08 / 26 / 13-150$ & 0.0987 & 0.0667 & 0.1333 & 0.0000 & 0.0000 & 0.0000 & 0.0492 & 0.0267 & 0.0733 & 0.0492 & 0.0225 & 0.0241 \\
\hline $08 / 26 / 13-200$ & 0.0984 & 0.0750 & 0.1250 & 0.0000 & 0.0000 & 0.0000 & 0.0493 & 0.0300 & 0.0650 & 0.0493 & 0.0193 & 0.0157 \\
\hline $08 / 26 / 13-250$ & 0.0984 & 0.0800 & 0.1160 & 0.0000 & 0.0000 & 0.0000 & 0.0492 & 0.0360 & 0.0600 & 0.0492 & 0.0132 & 0.0108 \\
\hline $08 / 26 / 13-300$ & 0.0984 & 0.0867 & 0.1067 & 0.0000 & 0.0000 & 0.0000 & 0.0493 & 0.0400 & 0.0533 & 0.0493 & 0.0093 & 0.0041 \\
\hline
\end{tabular}

